UNIVERSIDADE DE SÃO PAULO

ESCOLA DE ENFERMAGEM

KELLY CRISTINA STRAZZIERI PULIDO

INCIDÊNCIA DE ÚLCERA POR PRESSÃO

EM UNIDADE DE TERAPIA INTENSIVA

São Paulo

2015 


\section{INCIDÊNCIA DE ÚLCERA POR PRESSÃO EM UNIDADE DE TERAPIA INTENSIVA}

Tese apresentada ao Programa de Pós-Graduação em Enfermagem na Saúde do Adulto da Escola de Enfermagem da Universidade de São Paulo para obtenção do título de Doutora em Ciências

Área de concentração: Enfermagem na Saúde do Adulto

Orientadora: Profa Dra Vera Lúcia Conceição de Gouveia Santos

Versão Corrigida

Original disponível na unidade do programa

\section{São Paulo}




\begin{abstract}
AUTORIZO A REPRODUÇÃO E DIVULGAÇÃO TOTAL OU PARCIAL DESTE TRABALHO, POR QUALQUER MEIO CONVENCIONAL OU ELETRÔNICO, PARA FINS DE ESTUDO E PESQUISA, DESDE QUE CITADA A FONTE.
\end{abstract}

Assinatura: Data:

Catalogação na Publicação (CIP) Biblioteca "Wanda de Aguiar Horta" Escola de Enfermagem da Universidade de São Paulo

Strazzieri-Pulido, Kelly Cristina

Incidência de úlcera por pressão em Unidade De Terapia Intensiva. / Kelly Cristina Strazzieri Pulido. São Paulo, 2015. 100p.

Tese (Doutorado) - Escola de Enfermagem da Universidade de São Paulo.

Orientadora: Prof ${ }^{\mathrm{a}} \mathrm{Dr}^{\mathrm{a}}$ Vera Lúcia Conceição de Gouveia Santos Área de concentração: Enfermagem na Saúde do Adulto

1. Úlcera por pressão. 2. Unidades de terapia intensiva. 3.

Epidemiologia. 4. Enfermagem. 5.Incidência. 6. Carga de trabalho. I. Título. 
Nome: Kelly Cristina Strazzieri Pulido

Título: Incidência de úlcera por pressão em unidade de terapia intensiva

Tese apresentada ao Programa de Pós-Graduação em Enfermagem na Saúde do Adulto da Escola de Enfermagem da Universidade de São Paulo para obtenção do título de Doutora em Ciências

Aprovado em:

\section{Banca Examinadora}

Prof. Dr.

Julgamento:

Prof. Dr.

Julgamento:

Prof. Dr.

Julgamento:

Prof. Dr.

Julgamento:

Prof. Dr.

Julgamento:
Instituição:

Assinatura:

Instituição:

Assinatura:

Instituição:

Assinatura:

Instituição:

Assinatura:

Instituição:

Assinatura: 
DEDICATÓRIA

Pela minha filha Larissa

Para o meu marido Ricardo 
À Profa Dra Vera Lúcia Conceição de Gouveia Santos, pelo incentivo, apoio, amizade e compreensão nos bons e maus momentos.

À Profa Dra Kátia Grillo Padilha, pela oportunidade de participar do Projeto Universal e pelas valiosas contribuições.

À Profa Dra Silvia Regina Secoli, por todo apoio e compreensão.

Ao Prof Dr Moacyr Roberto Cuce Nobre e Profa Dra Diba Maria Sebba Tosta de Souza, pelos brilhantes apontamentos durante o exame de qualificação.

Ao Dr Ricardo Luis Barbosa por toda a atenção, colaboração e empenho para a viabilização deste trabalho.

Ao Bernardo, pela paciência em refazer as análises estatísticas e por todos os ensinamentos.

À Coordenação de Aperfeiçoamento de Pessoal de Nível Superior (CAPES), Fundação de Amparo à Pesquisa de São Paulo (FAPESP), Conselho Nacional de Desenvolvimento Científico e Tecnológico (CNPq), do Brasil, e Fundación Mapfre, da Espanha pelo apoio financeiro.

À minha família, pelo apoio e pelo amor.

Aos amigos, pela compreensão, apoio e torcida.

Aos pacientes e enfermeiros, que participaram de cada fase deste estudo. 


\section{EPÍGRAFE}

"O coração do homem planeja seu caminho, mas o Senhor lhe dirige os passos."

(Provérbios 16,9) 
Strazzieri-Pulido KC. Incidência de úlcera por pressão em unidade de terapia intensiva. [tese]. São Paulo: Escola de Enfermagem, Universidade de São Paulo; 2015.

\section{RESUMO}

Objetivo: determinar e analisar a incidência de úlcera por pressão e os fatores de risco para o seu desenvolvimento, assim como sua relação com a carga de trabalho de enfermagem, em pacientes internados em unidade de terapia intensiva. Métodos: como parte do projeto de pesquisa intitulado "Segurança do paciente em unidades de terapia intensiva: influência dos recursos humanos de enfermagem na ocorrência de eventos adversos”, o presente estudo constituiu uma coorte retrospectiva, realizado em nove unidades de terapia intensiva e uma semi-intensiva, de dois hospitais-escola da cidade de São Paulo. A amostra foi composta por 766 pacientes, sem úlcera por pressão 24 horas após a admissão nas unidades do estudo. As variáveis de interesse foram extraídas do banco de dados do estudo original e dos prontuários digitalizados dos pacientes que participaram do estudo. Para as análises estatísticas foram utilizados incidência cumulativa, Qui-quadrado de Pearson, Mann-Whitney e Regressão logística (Stepwise Forward). Resultados: a incidência de úlcera por pressão foi de 18,7\%. Pacientes em ventilação mecânica apresentaram 3,5 vezes maior chance de úlcera por pressão (OR 3,479; IC 95\% 2,190-5,528; $\mathrm{p}<0,001$ ); estar em cuidados paliativos aumentou a chance de úlcera por pressão em 7,8 vezes (OR 7,829; IC 95\% 1,927-31,817; p = 0,004); cada dia a mais de internação aumentou em 10,1\% a chance de úlcera por pressão (OR 1,101; IC 95\% 1,071-1,132; p < 0,001); cada ponto do Nursing Activities Score aumentou a chance de úlcera por pressão em 1,5\% (OR 1,015; IC 95\% 1,003-1,027; p = 0,016); entre 60 e 84 anos a chance foi 2,3 vezes maior de úlcera por pressão do que aqueles com menos de 45 anos (OR 2,331; IC 95\% 1,283-4,236; $\mathrm{p}=0,005$ ) e a partir dos 85 anos, a chance foi 2,7 vezes maior de úlcera por pressão do que aqueles com menos de 45 anos (OR 2,695; IC 95\% 0,945-7,683; p < 0,064). Conclusão: admitindo-se que a UP é um evento adverso e que sua ocorrência está relacionada a baixa qualidade da assistência, a incidência de 18,7\% aqui encontrada pode ser considerada alta. Muito ainda precisa ser feito no âmbito da prevenção, no intuito de alcançar índices mais aceitáveis.

PALAVRAS-CHAVE: Úlcera por pressão; Unidades de terapia intensiva; Epidemiologia; Incidência; Enfermagem; Carga de trabalho. 
Strazzieri-Pulido KC. Pressure ulcer incidence in intensive care unit [thesis]. Sao Paulo: School of Nursing, University of Sao Paulo; 2015.

\begin{abstract}
Objective: To determine and to analyze pressure ulcers incidence and risk factors, and their relationships with nursing work-load in critical care patients. Methods: As a part of the research project named "Patient safety in intensive care units: the influence of nursing personnel in adverse events occurrence", a retrospective cohort study was taken in nine intensive care units and one semi-intensive care unit in two university hospitals in Sao Paulo. A total of 766 pacients without pressure ulcer 24 hours after their admission in the units were studied. The variables of interest for this study were collected in digitalized records. The statistical analysis were done using cumulative incidence, Pearson's Chi-Square, MannWhitney's and Logisitic regression (Stepwise Forward) tests. Results: the incidence of pressure ulcers was $18.7 \%$. Patients under mechanical ventilation had a chance 3.5 times higher for developing of pressure ulcer (OR 3.479; IC 95\% 2.190-5.528; p < 0.001); being under paliative care augmented 7.8 times the chance for developing pressure ulcer (OR 7.829; IC 95\% 1.927-31.817; $\mathrm{p}=0.004)$; for each day more of stay in ICU, the chance of developing pressure ulcers were 10.1\% higher (OR 1.101; IC 95\% 1.071-1.132; $\mathrm{p}<0.001$ ); each point of Nursing Activities Score rose the chance of developing pressure ulcer in 1.5\% (OR 1.015; IC 95\% 1.003-1.027; $\mathrm{p}=0.016$ ); patients between 60 and 84 years-old had a 2.3 higher chance of developing pressure ulcers than patients younger than 45 years-old (OR 2.331; IC 95\% 1.2834.236; $\mathrm{p}=0.005$ ) and, after the age of 85 , the chance for developing pressure ulcers were 2.7 times higher than in patients younger than 45 years-old (OR 2.695; IC 95\% 0.945-7.683; p < 0.064). Conclusion: admitting that pressure ulcers are an adverse effect and that their occurrence is related with poor assistance quality, we can consider the incidence of 18,7\% found in this cohort as high. Prevention actions must be enforced to guarantee a decrease in these figures.
\end{abstract}

KEY WORDS: Pressure ulcers; Intensive care units; Epidemiology; Incidence; Nursing; Workload. 


\section{LISTA DE QUADROS}

Quadro 1 - Estudos epidemiológicos nacionais sobre incidência e fatores de risco para UP, segundo autor e ano de publicação, estado em que foi realizado, métodos e resultados, no período de janeiro de 2006 a maio de 2015.

Quadro 2 - Estudos epidemiológicos internacionais sobre incidência e fatores de risco para UP, segundo autor e ano de publicação, estado em que foi realizado, métodos e resultados, no período de janeiro de 2006 a maio de 2015.

Quadro 3 - Variáveis do estudo.

Quadro 4 - Índice de Comorbidade de Charlson.

Quadro 5 - Relação entre os escores de Braden e o risco para úlcera por pressão. 


\section{LISTA DE FIGURAS}

Figura 1 - Esquema conceitual sobre a etiologia das úlceras por pressão 23

Figura 2 - Suspeita de lesão tissular profunda $\quad 25$

Figura 3 - Categoria I $\quad 25$

Figura 4 - Categoria II $\quad 26$

Figura 5 - Categoria III $\quad 26$

Figura 6 - Categoria IV $\quad 27$

Figura 7 - Úlceras que não podem ser classificadas $\quad 27$ 


\section{LISTA DE TABELAS}

Tabela 1 - Distribuição dos pacientes segundo as características demográficas e clínicas. São Paulo, 2012.

Tabela 2 - Distribuição das úlceras por pressão segundo classificação e localização anatômica. São Paulo, 2012.

Tabela 3 - $\quad$ Associações entre as variáveis demográficas sexo e idade e úlcera por

55 pressão. São Paulo, 2012.

Tabela 4 - $\quad$ Associações entre as variáveis clínicas e úlcera por pressão. São Paulo, 56 2012.

Tabela 5 - $\quad$ Regressão logística das variáveis de interesse para a incidência de úlcera 59 por pressão (n=760). São Paulo, 2012. 


\section{SUMÁRIO}

1 INTRODUÇÃO

1.1 TEMA DE PESQUISA E JUSTIFICATIVA DO ESTUDO 16

1.2 ÚLCERA POR PRESSÃO 18

$\begin{array}{ll}\text { 1.2.1 Conceito } & 18\end{array}$

$\begin{array}{ll}\text { 1.2.2 Etiologia } & 18\end{array}$

$\begin{array}{ll}\text { 1.2.3 Avaliação de risco } & 23\end{array}$

1.2.4 Classificação 24

1.2.5 Epidemiologia 28

1.2.5.1 Incidência de úlcera por pressão em unidade de terapia intensiva 28

1.2.6 Úlcera por pressão e carga de trabalho de enfermagem 33

2 OBJETIVOS 36

2.1 OBJETIVO GERAL 36

2.2 OBJETIVOS ESPECÍFICOS 36

3 MÉTODOS 38

3.1 TIPO DE ESTUDO 38

3.2 PROCEDIMENTOS ÉTICOS 38

$\begin{array}{ll}3.3 \text { LOCAL DO ESTUDO } & 39\end{array}$

3.4 POPULAÇÃO/ AMOSTRA DO ESTUDO 40

3.5 VARIÁVEIS DO ESTUDO 40

3.6 COLETA DE DADOS 41

3.6.1 Procedimentos para a coleta de dados $\quad 41$

3.6.2 Operacionalização da coleta de dados $\quad 42$

3.6.3 Instrumentos para a coleta de dados $\quad 43$

3.6.3.1 Instrumento para a coleta dos dados demográficos e clínicos 43

3.6.3.2 Índice de Comorbidade de Charlson (ICC) 43

3.6.3.3 Simplyfied Acute Physiologic II (SAPS II) 44

3.6.3.4 Logistic Organ Dysfunction System (LODS)

3.6.3.5 Nursing Activities Score (NAS)

3.6.3.6 Escala de Braden $\quad 46$

$\begin{array}{ll}\text { 3.6.3.7 Gravidade do dano } & 47\end{array}$

3.7 ANÁLISE DOS DADOS

3.7.1 Cálculo da incidência $\quad 49$

4 RESULTADOS 52

4.1 CARACTERIZAÇÃO DA AMOSTRA

4.2 INCIDÊNCIA E CARACTERIZAÇÃO DAS ÚLCERAS POR

PRESSÃO
4.3 FATORES DE RISCO PARA O DESENVOLVIMENTO DE ÚLCERAS

POR PRESSÃO

5 DISCUSSÃO

5.1 INCIDÊNCIA DE ÚLCERA POR PRESSÃO 61

5.2 FATORES DE RISCO PARA O DESENVOLVIMENTO DE ÚLCERA POR 62 PRESSÃO 
5.3 CARGA DE TRABALHO DE ENFERMAGEM E ÚLCERA POR PRESSÃO 66

6 CONCLUSÃO 69

7 CONSIDERAÇÕES FINAIS

REFERÊNCIAS

APENNICE $\quad 83$

APÊNDICE A - Instrumento para a coleta de dados 83

ANEXOS

ANEXO 1 - Aprovação do Comitê de Ética em Pesquisa do Instituto 85

Central do Hospital das Clínicas da Faculdade de Medicina da

Universidade de São Paulo (CAPPesq ICHC-FMUSP)

ANEXO 2 - Aprovação do Comitê de Ética em Pesquisa do Hospital 86

Universitário da Universidade de São Paulo (CEP HU-USP)

ANEXO 3 - Classificação dos Eventos Adversos/ Incidentes 87

ANEXO 4 - Manual para análise de eventos adversos e incidentes 89

ANEXO 5 - Instrumento para levantamento de eventos adversos/ incidentes 92

ANEXO 6 - Nursing Activities Score 94

ANEXO 7 - Manual do Nursing Activities Score 96 


\section{INTRODUÇÃO}




\section{INTRODUÇÃO}

\subsection{TEMA DE PESQUISA E JUSTIFICATIVA DO ESTUDO}

Até há pouco tempo atrás, as Úlceras por Pressão (UP) eram tidas como uma falha nos cuidados de enfermagem. Florence Nightingale (1820-1910) já acreditava que uma boa enfermagem poderia preveni-las, enquanto seu contemporâneo, Jean-Martin Charcot (18251893), influente médico francês, alegava que a medicina nada podia fazer a esse respeito. Ousey, 2009

Felizmente, o desenvolvimento científico e o estudo aprofundado acerca desse tipo de ferida vêm contribuindo para uma mudança de atitude dos profissionais de saúde. Nas últimas décadas, há maior percepção de que toda a equipe de saúde precisa estar engajada para o sucesso de sua prevenção. ${ }^{\text {DoH, } 1993}$

Como grande parte das UP pode ser evitada, seu desenvolvimento reflete negativamente sobre a qualidade dos serviços de saúde prestados, sendo considerado um evento adverso. Black et al., 2011 Com base nisso, a Joint Commission for the Accreditation of Health Care Organization, órgão do governo americano para avaliação e credenciamento dos serviços de saúde, estabeleceu a UP como um dos indicadores de qualidade da assistência. Mainz, ${ }^{2003}$ A partir de então, diferentes iniciativas ao redor do mundo foram tomadas para prevenir o seu desenvolvimento e garantir a segurança dos pacientes. ${ }^{\text {Allegranzi et al., } 2007}$

No Brasil, o recente Programa Nacional de Segurança do Paciente, Brasil, 2013 com o intuito de prevenir e reduzir a incidência de eventos adversos em todos os estabelecimentos de saúde do território nacional, instituiu a obrigatoriedade da notificação compulsória mensal dos eventos adversos associados à assistência à saúde, além de publicar diversos protocolos para sua prevenção, incluindo a UP.

Pacientes internados em Unidades de Terapia Intensiva (UTI) são altamente vulneráveis à ocorrência de eventos adversos, uma vez que as constantes alterações hemodinâmicas e o iminente risco de morte exigem atenção ininterrupta, tomadas de decisões imediatas e um grande número de procedimentos complexos. ${ }^{\text {Bucknall, } 2010}$

A UP constitui um dos eventos adversos mais prevalentes em pacientes de UTI. Aranaz et al., 2011; Paiva et al., 2010; Silva, 2003 Longos períodos confinados ao leito impostos pela proposta 
terapêutica, uso de drogas potentes com efeito sedativo, analgésico e relaxante, além das restrições imputadas pela própria doença de base, Bucknall, 2010; Paiva et al., 2010; Silva, 2003 podem limitar ou até mesmo impedir uma reação eficiente à dor e ao desconforto provocados pela pressão prolongada nos tecidos. Adicione-se a isso, instabilidade hemodinâmica, diminuição da perfusão e algum grau de comprometimento do estado nutricional, seja devido a um trauma maior, sepse, cirurgia, jejum prolongado ou inapetência, Bucknall, 2010; Paiva et al., 2010; Silva, 2003 que levam à diminuição da tolerância tecidual e, consequentemente, ao aumento do risco para UP.

No contexto da UTI, há controvérsias quanto à influência da carga de trabalho para a ocorrência de eventos adversos. Alguns autores afirmam Blegen et al., 1998; Carayon e Gurses, 2005; Inoue e Matsuda, 2010; Laschinger e Leiter, 2006; Robert et al., 2000 que o excesso dessa carga pode interferir negativamente na qualidade da assistência prestada, contribuindo assim para a ocorrência de eventos adversos como a UP; outros Cremasco et al., 2009; McGahan et al., 2012; Numata et al., 2006; West et al., 2009 não corroboram essas afirmações.

O tempo de assistência de enfermagem apresentou-se inversamente proporcional às taxas de UP, no estudo de Blegen e colaboradores, ${ }^{1998}$ tornando evidente que quanto mais horas de enfermagem eram dispensadas aos cuidados com os pacientes, menos UP os acometiam. Stone e colaboradores ${ }^{2007}$ também encontraram associação significativa entre maior número de horas de assistência de enfermagem, por paciente-dia, e baixa incidência de UP. Al-Kandari e Thomas, ${ }^{2009}$ investigando a percepção dos enfermeiros acerca da ocorrência de eventos adversos relacionados à carga de trabalho de enfermagem, mostraram a correlação entre o aumento da carga de trabalho e o desenvolvimento de UP.

Na contramão desses achados, três revisões sistemáticas McGahan et al., 2012; Numata et al., 2006; West et al., 2009 propuseram-se a examinar a relação entre a carga de trabalho de enfermagem e a incidência de eventos adversos em UTI e não encontraram associação significativa.

A dificuldade em estabelecer uma relação pode estar no fato de que a maioria dos estudos analisados era do tipo transversal, desenho este inadequado para inferir relações causais. Além disso, o pequeno tamanho das amostras e inadequações metodológicas podem ter limitado a capacidade dos estudos em lidar com vieses e fatores de confusão, impossibilitando o conhecimento da real associação entre as variáveis estudadas. McGahan et al., 2012; Numata et al., 2006; West et al., 2009

Diante dessa realidade, este estudo buscou contribuir para a construção desse conhecimento, realizando uma investigação epidemiológica sobre a incidência de UP e os fatores de risco para o seu desenvolvimento em UTI, assim como sua relação com a carga de trabalho de enfermagem. 


\section{2 ÚLCERA POR PRESSÃO}

\subsubsection{Conceito}

UP é uma lesão localizada na pele e/ ou no tecido ou estrutura subjacente, geralmente sobre uma proeminência óssea, resultante de pressão isolada ou de pressão combinada com cisalhamento. Inúmeros fatores contribuintes ou fatores de confusão podem também estar associados às UP; o significado desses fatores, no entanto, ainda deve ser elucidado. NPUAP et al., 2014; Santos e Caliri, 2007

\subsubsection{Etiologia}

Complexa e multifatorial, a etiologia das UP está ligada tanto a fatores extrínsecos como intrínsecos ao indivíduo. A pressão é o fator etiológico extrínseco primordial envolvido no desenvolvimento das UP, enquanto que a tolerância tecidual à pressão/ carga mecânica figura como o principal elemento intrínseco. Bergstrom et al., 1987

Para os físicos, pressão (p) é uma grandeza representada pela relação de uma força (F) aplicada perpendicularmente sobre uma área (A) ou, $\mathrm{p}=\mathrm{F} / \mathrm{A}$, medida em Pascal (Pa). Lembrando que força é o único agente capaz de deformar um corpo e que o peso é um tipo de força (a força que a gravidade exerce sobre os corpos), tem-se que a pressão é o resultado da relação do peso do corpo do indivíduo sobre a superfície à qual ele está apoiado. Coleman et al., 2013; NPUAP, 2007; Strazzieri-Pulido e Santos, 2010 Por essa equação, depreende-se que a pressão se relaciona inversamente com a área, ou seja, a pressão será tanto maior quanto menor for a área em que a força for aplicada perpendicularmente. Logo, uma simples elevação da cabeceira do leito redireciona a carga mecânica, ou seja, a distribuição das forças que agem sobre a superfície, concentrando a pressão no sacro e ísquios. Coleman et al., 2013; Hanson et al., 2010; NPUAP, 2007; Strazzieri-Pulido e Santos, 2010

A intensidade dessa pressão depende das características mecânicas e físicas das superfícies. É fácil depreender que superfícies duras, como um banco de madeira, 
proporcionam pressões mais intensas do que as macias, como uma poltrona acolchoada. ${ }^{\text {Coleman }}$ et al., 2013; NPUAP, 2007; Strazzieri-Pulido e Santos, 2010

Além da intensidade, deve-se considerar também a duração da pressão. Intensidade e duração são componentes da pressão que mantêm uma relação inversamente proporcional, ou seja, uma baixa intensidade de pressão durante um tempo prolongado pode ser tão danoso quanto uma alta intensidade de pressão por um curto período de tempo. Bergstrom et al., 1987; Coleman et al., 2013; Hanson et al., 2010; NPUAP, 2007; Strazzieri-Pulido e Santos, 2010

A pressão acarreta dano quando o limiar de tolerância tecidual é ultrapassado. Bergstrom et al., 1987 Ao nível dos capilares sanguíneos de indivíduos jovens e sadios, a pressão média necessária para o fechamento das arteríolas gira em torno de $32 \mathrm{mmHg}$ e das vênulas de

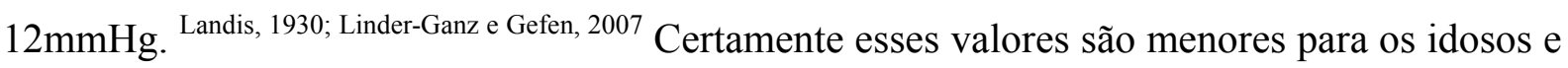
indivíduos que se encontram em circunstâncias de diminuição da pressão sanguínea, como durante alguns procedimentos cirúrgicos ou afecções clínicas.

Pressões externas capazes de ocluir os capilares sanguíneos levam à isquemia tecidual localizada. A dor e o desconforto provocados impelem o indivíduo a mudar de posição para que o fluxo sanguíneo possa ser restabelecido. Linder-Ganz e Gefen, 2007 Caso isso aconteça, localmente o organismo se recupera dessa situação promovendo uma congestão sanguínea passageira denominada hiperemia reativa, com o intuito de remover dejetos tóxicos, que se acumularam durante a oclusão dos capilares, e fornecer oxigênio e nutrientes. Bergstrom et al., 1987; Braden e Bergstrom, 1987; Coleman et al., 2013; Defloor, 1999

Contudo, se a pressão externa persistir por tempo suficiente, ela pode danificar de forma permanente os capilares Linder-Ganz e Gefen, 2007 e acarretar uma drástica diminuição do aporte de nutrientes e oxigênio, além do acúmulo de proteínas e catabólitos no espaço intersticial. Nessa situação, a permeabilidade capilar aumenta ocasionando extravasamento de fluidos responsáveis pela formação de edema, deteriorando ainda mais as condições circulatórias locais e aumentando a pressão intersticial. Eventualmente, a pressão aumentada no interstício provoca hemorragia local visualizada como uma hiperemia que não esbranquece. A persistência desse quadro pode suplantar a tolerância tecidual e ser fatal aos tecidos, culminando na formação da UP. Bergstrom et al., 1987; Braden e Bergstrom, 1987; Coleman et al., 2013; Defloor, 1999

Combinadas à pressão, podem ainda estar presentes as forças mecânicas de fricção e cisalhamento, também como fatores etiológicos extrínsecos na gênese das UP. Bergstrom et al., 1987; Braden e Bergstrom, 1987; Coleman et al., 2013; 2014; Defloor, 1999 
Entendendo fricção como uma força que resulta do contato entre o corpo do indivíduo e a superfície à qual ele está apoiado, e cisalhamento como uma força de deformação, temos que fricção é a força tangencial que se opõe à força de cisalhamento (deformação), de intensidade e direção iguais, mas com sentido oposto, segundo a Lei de Ação e Reação de Newton. Coleman et al., 2013; 2014; Hanson et al., 2010; Strazzieri-Pulido e Santos, 2010

A partir disso, depreende-se que o coeficiente de fricção resultante do contato entre a pele corporal e a superfície de apoio é forte o suficiente para mantê-las intimamente unidas. Contudo, por ação da força da gravidade o corpo tende ao solo e, como a pele permanece irremediavelmente aderida à superfície de apoio pelas forças de fricção, ocorre o cisalhamento das estruturas subjacentes. A deformação provocada será, então, definitiva caso os tecidos não tolerem essa força, podendo até mesmo resultar em completo descolamento. Coleman et al., 2013; 2014; Hanson et al., 2010; Strazzieri-Pulido e Santos, 2010

Como principal fator etiológico intrínseco, a tolerância tecidual determina o efeito deletério das forças de pressão, fricção e cisalhamento. Bergstrom et al., 1987; Braden e Bergstrom, 1987; Coleman et al., 2013; Defloor, 1999 Indivíduos jovens e hígidos apresentam maior tolerância tecidual do que idosos e debilitados. Além disso, a tolerância à pressão e à isquemia varia conforme as forças e os tipos de tecidos envolvidos, sofrendo influência direta da habilidade das estruturas de suporte como vasos sanguíneos, colágeno e fluido intersticial, em redistribuir a pressão às áreas adjacentes. Vale a pena ressaltar que, na vigência de fricção e cisalhamento, a tolerância

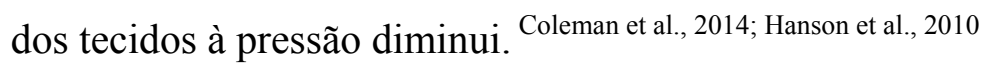

Idade avançada, desnutrição e hipotensão são fatores etiológicos intrínsecos que afetam negativamente a tolerância tecidual. Benoit e Mion, 2012; Bergstrom et al., 1987; Braden e Bergstrom, 1987; Coleman et al., 2013

Com a idade, aumenta a queratinização prematura da epiderme e observam-se o alargamento e aplainamento dos sulcos intrapapilares, juntamente com a perda do pregueamento da lâmina basal. Consequentemente, o sistema de ancoragem entre as camadas de epiderme e derme passa a não resistir tão bem às forças de fricção e cisalhamento. $\mathrm{Na}$ derme, por sua vez, os fibroblastos produzem menos colágeno tipo I e mais tipo III. As fibras do colágeno tornam-se rarefeitas, fragmentadas e separadas por grandes áreas ocupadas por substância fundamental amorfa, o que deixa a microcirculação desprotegida e suscetível ao cisalhamento. Os mucopolissacarídeos perdem sua função estrutural e apresentam-se como um sedimento amorfo. A pele perde força tênsil, resistência, elasticidade e extensibilidade. Sua espessura diminui progressivamente, chegando a uma perda de $20 \%$. A produção das glândulas sudoríparas e sebáceas também reduz com a idade, tornando a pele desidratada, 
ressecada e sem elasticidade. Tela subcutânea, assim como a musculatura, tornam-se mais delgadas e, portanto, menos eficientes na absorção de impacto. Diridollou et al., 2001; Hussain et al., 2013; Souza e Santos, 2006 Somando-se às alterações fisiológicas esperadas, com o passar dos anos aumenta a probabilidade de doenças crônicas, predispondo os idosos ainda mais às UP.

Como último fator extrínseco envolvido na gênese da UP, a umidade também contribui para diminuir a tolerância da pele à fricção. Além de macerá-la, a umidade pode

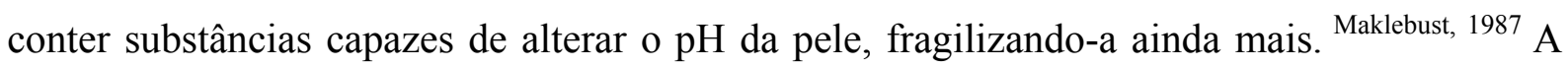
umidade está associada às incontinências urinária e fecal, drenagem de feridas, transpiração e

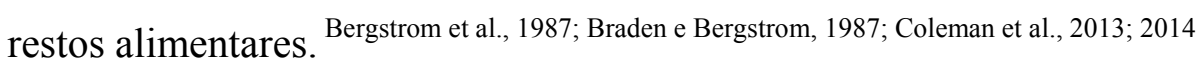

A desnutrição, também muito comum entre os idosos, é outro fator de risco intrínseco para UP, porque diminui o limiar de tolerância dos tecidos à pressão. Braden e Bergstrom, 1987 Apesar da necessidade calórica diária reduzir de 10 a 25\% com o passar dos anos, a necessidade protéica continua a mesma. Para os idosos, a desnutrição está relacionada à persistente falta de apetite e às restrições alimentares impostas pelo tratamento de doenças crônicas Harris e Fraser, 2004 como o diabetes mellitus e a hipertensão arterial sistêmica. Além das alterações fisiológicas, todo idoso está propenso a desnutrição e desidratação crônicas por razões sociais e psicológicas. A dependência de ajuda para comer, a dificuldade de mastigação, deglutição, tabus alimentares, o comprometimento cognitivo e da comunicação, o uso de medicações que interferem no apetite e aumentam a perda de nutrientes e os fatores psicossociais, como isolamento, depressão e falta de estímulo para manter uma alimentação adequada colaboram para a desnutrição. Harris e Fraser, 2004 A deficiência de proteínas, vitaminas e sais minerais compromete a qualidade e integridade dos componentes dos tecidos, particularmente do colágeno, cuja síntese já se encontra diminuída nos idosos. Braden e Bergstrom, 1987

Além dos idosos, qualquer indivíduo que apresenta desnutrição protéica causada por deficiência nutricional, por falta de ingestão ou deficiência na absorção de proteínas, é mais suscetível ao desenvolvimento de UP devido à diminuição da tolerância tecidual. Benoit e Mion, 2012; Braden e Bergstrom, 1987; Coleman et al., 2013; 2014

A hipoalbuminemia, preditora da ocorrência de UP, Serpa e Santos, 2014 e a anemia estão intimamente relacionadas à fragilização dos tecidos. Com a anemia, diminui a quantidade de oxigênio para os fibroblastos e, com isso, reduz a formação de colágeno, tornando os tecidos mais suscetíveis a pressão e cisalhamento. ${ }^{\text {Russell, } 2000}$ A deficiência de vitaminas prejudica a formação, manutenção e organização do colágeno. Baixos níveis de vitamina $\mathrm{C}$ levam à inibição da hidroxilação da prolina e lisina, aminoácidos da molécula de protocolágeno; ${ }^{\text {Braden e }}$ 
Bergstrom, 1987 o déficit de vitamina A está diretamente ligado ao retardo da síntese de colágeno e a falta de tiamina e riboflavina prejudica a organização dessas fibras. Outros nutrientes como ferro, cobre, zinco e cálcio também são importantes para o transporte de oxigênio, síntese e modelagem de colágeno e síntese de proteínas. Russell, 2000

Segundo Braden e Bergstrom, ${ }^{1987}$ a hipotensão (pressão diastólica $<60 \mathrm{mmHg}$ ) afeta a tolerância tecidual e predispõe à UP. A hipoperfusão ocasionada na pele aumenta sua suscetibilidade às forças de pressão, fricção e cisalhamento devido à desnutrição dos tecidos. Ela está associada a doenças cardíacas, insuficiência vascular periférica e diabetes mellitus, além das drogas que levam à vasoconstrição periférica. Benoit e Mion, 2012

A diminuição da mobilidade/ atividade constitui um fator de risco intrínseco pois afeta a capacidade do indivíduo de se defender eficazmente das forças de pressão, friç̧ão e cisalhamento. Benoit e Mion, 2012; Bergstrom et al., 1987; Braden e Bergstrom, 1987; Coleman et al., 2013 ; 2014

Hipnóticos, ansiolíticos, antidepressivos, analgésicos e anti-histamínicos são drogas associadas à diminuição da mobilidade/ atividade, principalmente durante o sono. Indivíduos submetidos a procedimentos cirúrgicos também tem sua mobilidade/ atividade reduzida, seja propriamente durante o procedimento, ou no pós-operatório imediato, pelos efeitos da

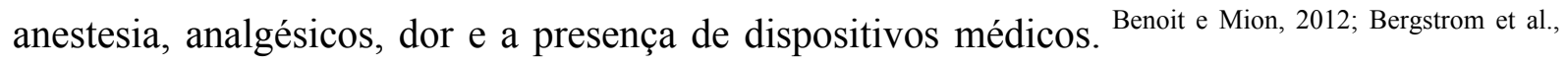
1987; Braden e Bergstrom, 1987

A alteração da percepção sensorial é fator de risco intrínseco para UP uma vez que interfere na capacidade dos indivíduos para perceber a pressão e, consequentemente reagir a ela, mesmo sendo fisicamente capazes de fazê-lo. Pode estar relacionada a doenças mentais, diabetes mellitus, traumas neurológicos, distúrbios metabólicos ou certos medicamentos. Benoit e Mion, 2012; Bergstrom et al., 1987; Coleman et al., 2013; 2014 No idoso, as funções de percepção apresentam-se comprometidas pelas alterações das fibras e órgãos terminais inerentes ao envelhecimento. Hussain et al., 2013

O clássico algoritmo de Braden e Bergstrom ${ }^{1987}$ (Figura 1) resume as relações entre pressão, tolerância tissular e os fatores de risco envolvidos na formação das UP. 
Figura 1 - Esquema conceitual sobre a etiologia das úlceras por pressão.

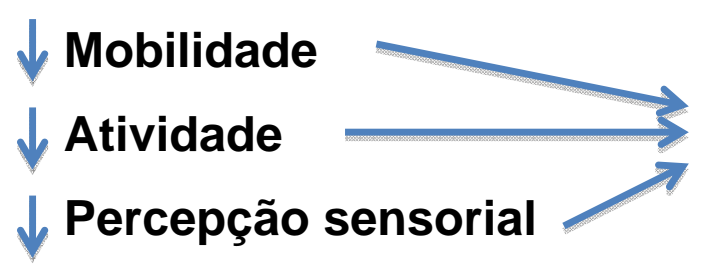

PRESSÃO

Fatores extrínsecos

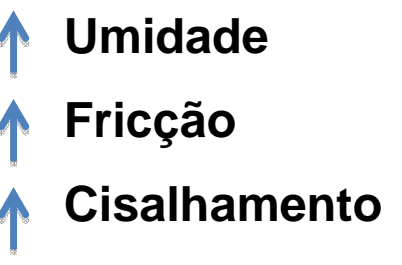

Fatores intrínsecos

$\downarrow$ Nutrição

个 Idade

$\downarrow$ Pressão arterial

Fonte: Braden BJ, Bergstrom N. A conceptual schema for study of etiology of pressure sores. Rehabil Nurs 1987; 12(1):8-12.

\subsubsection{Avaliação de risco}

Em 1962, Norton e colaboradores idealizaram o primeiro instrumento para avaliação do risco de desenvolvimento de UP. Segundo Schoonhoven ${ }^{2008}$ já existem mais de 40 escalas desse tipo em todo o mundo.

No Brasil, apenas duas escalas para aplicação em adultos encontram-se disponíveis. A escala de Braden, adaptada e validada por Paranhos e Santos, ${ }^{1999}$ é a mais utilizada em nosso meio; e a escala de Waterlow, por Rocha e Barros. ${ }^{2003}$

Especificamente desenhada para pacientes críticos, a escala de Cubbin Jackson ${ }^{1999}$ considerou parâmetros relevantes para essa população, como estado hemodinâmico e respiração. Derivada da escala de Norton e colaboradores, ${ }^{1962}$ inclui idade, peso, história médica anterior, condições da pele, estado mental, mobilidade, estado hemodinâmico, 
respiração, necessidade de oxigênio, nutrição, incontinência e higiene, administração de hemoderivados, cirurgia ou transporte nas últimas 24 horas e hipotermia. Quando comparada às escalas de Braden e Douglas, na aplicação ao paciente crítico, a escala de Cubbin Jackson apresentou melhor valor preditivo positivo, sensibilidade e especificidade. ${ }^{\text {Seongsook, }{ }^{2004} \text { No }}$ entanto, existem poucos estudos a esse respeito. A revisão de Pancorbo-Hidalgo e colaboradores, ${ }^{2006}$ encontrou apenas duas publicações relacionadas a validação dessa escala. Recentemente a escala de Cubbin Jackson foi validada para Portugal, Sousa, 2013 infelizmente ela não se encontra adaptada e validada para o Brasil.

\subsubsection{Classificação}

Segundo o National Pressure Ulcer Advisory Panel, European Pressure Ulcer Advisory Panel e Pan Pacific Pressure Injury Alliance, ${ }^{2014 ;}$ Santos e Caliri, 2007 as UP são classificadas segundo o comprometimento tecidual em categorias. A saber:

- Suspeita de lesão tissular profunda: área localizada de pele intacta, de coloração púrpura ou castanha ou bolha sanguinolenta, devido a dano no tecido mole, decorrente de pressão e/ ou cisalhamento. A área pode ser precedida por um tecido que se apresenta dolorido, endurecido, amolecido, esponjoso e mais quente ou frio comparativamente ao tecido adjacente. ${ }^{\text {NPUAP et }}$ al., 2014; Santos e Caliri, 2007

A lesão tissular profunda pode ser de difícil detecção em indivíduos com pele de tonalidades mais escuras. A sua evolução pode incluir uma pequena bolha sobre o leito escurecido da ferida. A lesão pode evoluir e ficar coberta por uma fina escara. A evolução pode ser rápida com exposição de camadas tissulares adicionais, mesmo com tratamento adequado. NPUAP et al., 2014; Santos e Caliri, 2007 
Figura 2 - Suspeita de lesão tissular profunda

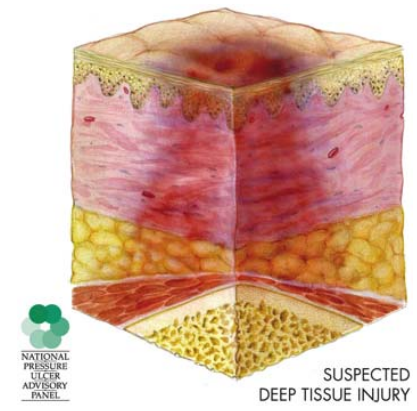

Fonte: www.npuap.org

- Categoria I: pele intacta com hiperemia de uma área localizada que não esbranquece, geralmente sobre proeminência óssea. A pele de cor escura pode não apresentar esbranquecimento visível: sua cor pode diferir da pele ao redor. NPUAP et al., 2014; Santos e Caliri, 2007

A área hiperemiada pode apresentar-se dolorosa, endurecida, amolecida, mais quente ou mais fria comparativamente ao tecido adjacente. Feridas de categoria I podem ser difíceis de detectar em pessoas de pele com tonalidades escuras. Pode indicar pessoas "em risco" (um sinal precursor de risco). NPUAP et al., 2014; Santos e Caliri, 2007

Figura 3 - Categoria I

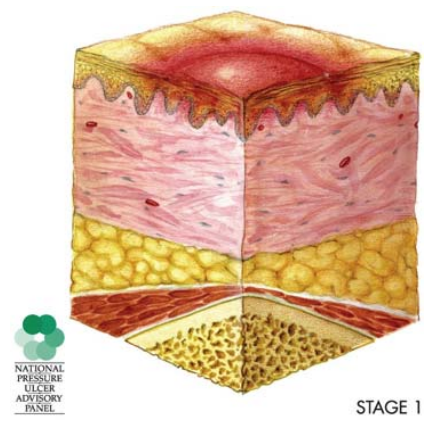

Fonte: www.npuap.org

- Categoria II: perda parcial da espessura dérmica. Apresenta-se como úlcera superficial com o leito de coloração vermelho pálida, sem esfacelo. Pode apresentar-se ainda como uma bolha (preenchida com exsudato seroso), intacta ou aberta/ rompida. NPUAP et al., 2014; Santos e Caliri, 2007

Apresenta-se como uma úlcera superficial brilhante ou seca sem esfacelo ou arroxeamento (aspecto de equimose)*. Esta categoria não deve ser usada para descrever lesões por fricção, dermatite associada a incontinência, maceração ou escoriação. * indica 
suspeita de lesão tissular profunda. NPUAP et al., 2014; Santos e Caliri, 2007

Figura 4 - Categoria II

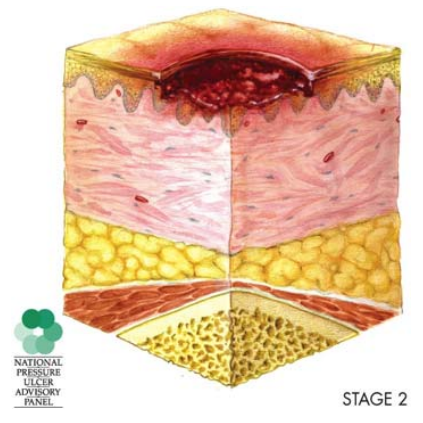

Fonte: www.npuap.org

- Categoria III: perda de tecido em sua espessura total. A gordura subcutânea pode estar visível, sem exposição de osso, tendão ou músculo. Esfacelo pode estar presente sem prejudicar a identificação da profundidade da perda tissular. Pode incluir descolamento e túneis. NPUAP et al., 2014; Santos e Caliri, 2007

A profundidade da UP categoria III varia conforme a localização anatômica. A asa do nariz, orelha, as regiões occipital e maleolar não possuem tecido subcutâneo e, portanto, as úlceras podem ser rasas nesta categoria. Em contraste, áreas com adiposidade significativa podem desenvolver UP categoria III bastante profundas. Ossos e tendões não são visíveis nem diretamente palpáveis. NPUAP et al., 2014; Santos e Caliri, 2007

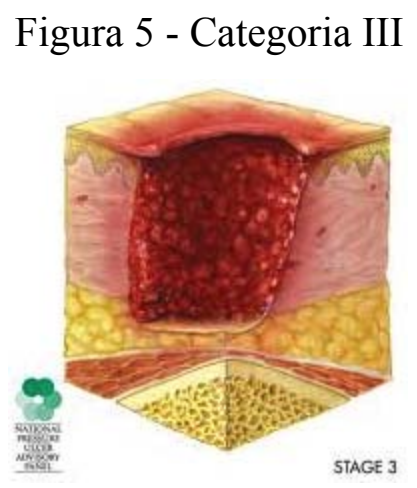

Fonte: www.npuap.org

- Categoria IV: perda total de tecido com exposição óssea, de músculo ou tendão. Pode haver presença de esfacelo ou escara em algumas partes do leito da ferida. Freqüentemente, inclui descolamento e túneis. NPUAP et al., 2014; Santos e Caliri, 2007 
A profundidade da UP categoria IV varia conforme a localização anatômica. A asa do nariz, orelha, as regiões occipital e maleolar não possuem tecido subcutâneo e, portanto, as úlceras podem ser rasas nesta categoria. As úlceras categoria IV podem estender-se aos músculos e/ ou estruturas de suporte (como fáscia, tendão ou cápsula articular), possibilitando a ocorrência de osteomielite. A exposição de osso/ tendão é visível ou diretamente palpável. NPUAP et al., 2014; Santos e Caliri, 2007

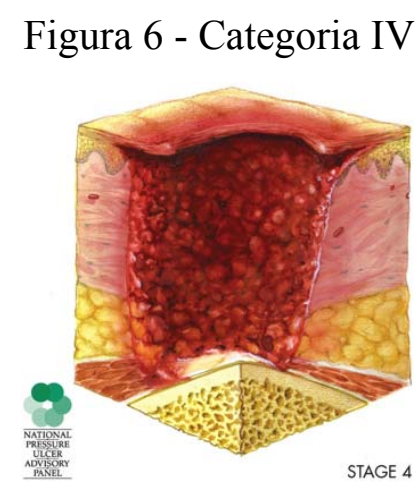

Fonte: www.npuap.org

- Úlceras que não podem ser classificadas: lesão com perda total de tecido, na qual a base da úlcera está coberta por esfacelo (amarelo, marrom, cinza, esverdeado ou castanho) e/ ou há escara (marrom, castanha ou negra) no leito da lesão. ${ }^{\text {NPUAP et al., 2014; Santos e Caliri, } 2007}$

A verdadeira profundidade $\mathrm{e}$, portanto, a categoria da úlcera não pode ser determinada até que suficiente esfacelo e/ ou escara sejam removidos para expor a base da úlcera. Escara estável (seca, aderente, intacta, sem eritema ou flutuação) nos calcâneos serve como “cobertura natural (biológica) corporal” e não deve ser removida. NPUAP et al., 2014; Santos e Caliri, 2007

Figura 7 - Úlceras que não podem ser classificadas

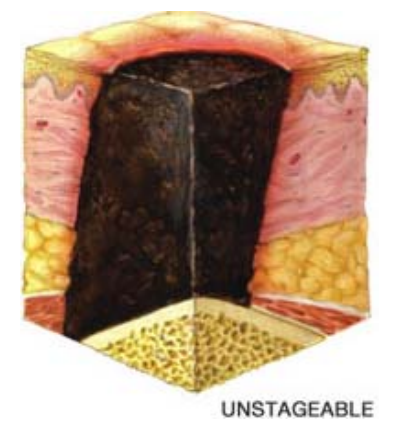

Fonte: www.npuap.org 


\subsubsection{Epidemiologia}

A epidemiologia das UP varia de acordo com o país, o tipo de paciente, a instituição e a metodologia empregada para rastreá-la. Baharestani e col., 2009

Para a realização desta tese foi realizada uma revisão sistemática da literatura acerca da incidência e fatores associados à UP em UTI nos últimos 10 anos. Foram consultadas as bases de dados eletrônicas MEDLINE, CINAHL, LILACS, EMBASE e The Cochrane Library e selecionados artigos publicados na íntegra em inglês, espanhol ou português.

Não foram encontrados muitos estudos, pois a maioria dos países desenvolvidos, já passaram da fase de investigação epidemiológica e estão, no momento, publicando resultados referentes a seus programas de prevenção.

\subsubsection{Incidência de úlcera por pressão em unidades de terapia intensiva}

O Quadro 1 apresenta as publicações nacionais acerca da incidência e fatores de risco para o desenvolvimento de UP em UTI, nos últimos 10 anos.

Quadro 1 - Estudos epidemiológicos nacionais sobre incidência e fatores de risco para UP, segundo autor e ano de publicação, estado em que foi realizado, métodos e resultados, no período de janeiro de 2006 a maio de 2015.

\begin{tabular}{|c|c|c|c|}
\hline $\begin{array}{c}\text { Autor/ } \\
\text { Ano } \\
\text { Estado } \\
\end{array}$ & Métodos & Incidência de UP & Fatores associados às UP \\
\hline $\begin{array}{l}\text { Fernandes } \\
\text { e Torres, } \\
2008 \\
\text { Natal - RN }\end{array}$ & $\begin{array}{l}2 \text { UTI privadas } \\
\text { Geral e cardiológica } \\
50 \text { dias de seguimento } \\
40 \text { pacientes } \\
\text { UP categoria I } \\
\text { Exame físico diário } \\
\text { Não cita classificação } \\
\text { Não cita avaliação de risco } \\
\text { Não cita protocolo de prevenção } \\
\text { Análise descritiva e inferencial } \\
\text { Razão de chance } \\
\text { Qui-quadrado }\end{array}$ & $\begin{array}{c}50,0 \% \\
64,3 \% \text { geral } \\
42,3 \% \text { cardio } \\
40 \% \text { sacro } \\
36 \% \text { calcâneo } \\
8 \% \text { orelha } \\
4 \% \text { cotovelo } \\
4 \% \text { occipício } \\
4 \% \text { nariz } \\
4 \% \text { maléolo }\end{array}$ & $\begin{array}{c}\text { Sexo masculino } \\
\text { RC 5,0 p 0,0267 } \\
\text { Tempo de permanência } \\
\text { RC } 26 \text { p } 0,0358 \\
\text { Cisalhamento } \\
\text { RC } 3,3 \text { p } 0,0393 \\
\text { Pressão } \\
\text { RC } 4,1 \text { p 0,0006 } \\
\text { Agitação psicomotora } \\
\text { RC 5,8 p 0,0375 } \\
\text { Leucocitose } \\
\text { RC 5,0 p 0,0285 } \\
\text { Sedação } \\
\text { RC 9,3 p 0,0015 } \\
\text { Condições predisponentes } \\
\text { RC } 2,3 \text { p } 0,0099 \\
\text { Fatores extrínsecos } \\
\text { RC } 4,5 \text { p } 0,000\end{array}$ \\
\hline
\end{tabular}




\begin{tabular}{|c|c|c|c|}
\hline & & & $\begin{array}{l}\text { Colchão inadequado e cisalhamento/ } \\
\text { fricção e pressão } \\
\text { RC } 11,2 \text { p } 0,0190 \\
\text { Condições predisponentes }+ \text { fatores } \\
\text { intrínsecos }+ \text { fatores extrínsecos } \\
\text { RC } 4,6 \text { p } 0,0384\end{array}$ \\
\hline $\begin{array}{l}\text { Matos, } \\
\text { Duarte e } \\
\text { Minetto, } \\
2010 \\
\text { Distrito } \\
\text { Federal - } \\
\quad \text { GO }\end{array}$ & $\begin{array}{l}1 \text { UTI pública } \\
\text { Coronariana, trauma e geral } 60 \text { dias } \\
\text { de seguimento } \\
27 \text { pacientes } \\
\text { Exame físico diário, exceto finais de } \\
\text { semana } \\
\text { Classificação NPUAP } \\
\text { Escala de Braden } \\
\text { Não cita protocolo de prevenção } \\
\text { Análise descritiva } \\
\text { Equação de incidência cumulativa }\end{array}$ & $\begin{array}{c}37,0 \% \\
41,7 \% \text { trauma } \\
33,3 \% \text { geral } \\
\\
60,0 \% \text { sacro } \\
20,0 \% \text { glúteo }\end{array}$ & ------ \\
\hline $\begin{array}{l}\text { Serpa, } \\
\text { Santos, } \\
\text { Oliveira, } \\
\text { Caetano e } \\
\text { Donadon, } \\
2011 \\
\text { São Paulo } \\
\quad \text { - SP }\end{array}$ & $\begin{array}{l}4 \text { UTI privadas } \\
180 \text { dias de seguimento } \\
72 \text { pacientes } \\
\text { Exame físico admissional e em dias } \\
\text { alternados } \\
\text { Não cita classificação UP } \\
\text { Escala de Braden } \\
\text { Não possui protocolo de prevenção } \\
\text { Análise descritiva }\end{array}$ & $\begin{array}{c}11,1 \% \\
42,9 \% \text { UP I } \\
57,1 \% \text { UP II } \\
\\
37,0 \% \text { sacro } \\
24,0 \% \text { calcâneo } \\
13,0 \% \text { trocânter } \\
13,0 \% \text { maléolo } \\
13,0 \% \text { orelha }\end{array}$ & ------ \\
\hline $\begin{array}{l}\text { Pereira, } \\
\text { Luz, } \\
\text { Santana, } \\
\text { Bezerra e } \\
\text { Figueiredo, } \\
2013 \\
\\
\text { Teresina - } \\
\quad \text { PI } \\
\end{array}$ & $\begin{array}{l}1 \text { UTI universitária } \\
90 \text { dias de seguimento } \\
62 \text { pacientes } \\
\text { Exame físico em dias alternados } \\
\text { Classificação NPUAP } \\
\text { Escala de Braden } \\
\text { Não cita protocolo de prevenção } \\
\text { Análise descritiva } \\
\text { Teste de Mann-Whitney }\end{array}$ & $\begin{array}{c}29,0 \% \\
70,8 \% \text { UP I } \\
29,2 \% \text { UP II } \\
\\
58,3 \% \text { sacro } \\
16,7 \% \text { trocânter } \\
16,7 \% \text { calcâneo }\end{array}$ & ------ \\
\hline $\begin{array}{l}\text { Silva, } \\
\text { Caminha, } \\
\text { Oliveira, } \\
\text { Diniz, } \\
\text { Oliveira e } \\
\text { Neves, } \\
2013 \\
\quad \text { João } \\
\text { Pessoa - } \\
\quad \text { PB } \\
\end{array}$ & $\begin{array}{l}1 \text { UTI pública } \\
90 \text { dias de seguimento } \\
36 \text { pacientes } \\
\text { Exame físico } \\
\text { Classificação NPUAP } \\
\text { Não cita avaliação de risco } \\
\text { Não cita protocolo de prevenção } \\
\text { Análise descritiva }\end{array}$ & $\begin{array}{c}22,2 \% \\
63,6 \% \text { UP II } \\
18,2 \% \text { UP I } \\
18,2 \% \text { SLTP } \\
\\
27,3 \% \text { sacro } \\
18,2 \% \text { dorso } \\
54,6 \% \text { outros }\end{array}$ & $\begin{array}{l}----- \\
\end{array}$ \\
\hline $\begin{array}{l}\text { Ventura, } \\
\text { Moura, } \\
\text { Carvalho, } \\
2014 \\
\text { Petrolina - } \\
\quad \text { PE }\end{array}$ & $\begin{array}{l}1 \text { UTI pública } \\
90 \text { dias de seguimento } \\
64 \text { pacientes } \\
\text { Exame físico a cada } 3 \text { dias até alta ou } \\
\text { UP } \\
\text { Classificação NPUAP } \\
\text { Escala de Braden } \\
\text { Não cita protocolo de prevenção } \\
\text { Análise descritiva }\end{array}$ & $\begin{array}{c}18,8 \% \\
\text { 73,3\% UP I } \\
20,0 \% \text { UP II } \\
6,6 \% \text { UP III } \\
\text { 46,6\% sacro } \\
40,0 \% \text { calcâneos } \\
\text { 13,3\% outros } \\
\end{array}$ & ------ \\
\hline $\begin{array}{l}\text { Campanili, } \\
\text { Santos, } \\
\text { Thomaz, } \\
\text { Nogueira, } \\
\text { Strazzieri- } \\
\text { Pulido, } \\
2015 \\
\text { São Paulo } \\
\text { - SP }\end{array}$ & $\begin{array}{l}\text { 1 UTI universitária } \\
\text { cardiopneumológica } \\
90 \text { dias de seguimento } \\
370 \text { pacientes } \\
\text { Exame físico diário } \\
\text { Classificação NPUAP } \\
\text { Escala de Braden } \\
\text { Não possui protocolo de prevenção } \\
\text { Análise descritiva } \\
\text { Teste exato de Fisher, teste t-Student } \\
\text { e teste de Wilcoxon-Mann-Whitney }\end{array}$ & $\begin{array}{c}10,8 \% \\
40,0 \% \text { UP I } \\
40,0 \% \text { UP II } \\
8,0 \% \text { SLTP } \\
\\
30 \text { sacro } \\
6 \text { calcâneos } \\
4 \text { outros }\end{array}$ & $\begin{array}{c}\text { Tempo de permanência na UTI } \\
\text { maior ou igual a 9,5 dias } \\
\text { Idade igual ou superior a } 42,5 \text { anos } \\
\text { Raça branca }\end{array}$ \\
\hline
\end{tabular}




\begin{tabular}{|l|l|l|l|}
\hline & $\begin{array}{l}\text { Classification and Regression Tree } \\
\text { Incidência cumulativa }\end{array}$ & & \\
\hline
\end{tabular}

Os sete estudos são, em sua maioria, provenientes da região Nordeste (4) Fernandes e Torres, 2008; Pereira et al., 2013; Silva et al., 2013; Ventura et al., 2014 e realizados predominantemente em UTI públicas (5). Campanili et al., 2015; Matos et al., 2010; Pereira et al., 2013; Silva et al., 2013; Ventura et al., 2014 O tempo de seguimento foi inferior a 90 dias em apenas dois deles. Fernandes e Torres, 2008; Matos et al., $2010 \mathrm{O}$ exame físico foi a principal estratégia para a coleta de dados, sendo realizado em todos os estudos. Campanili et al., 2015; Fernandes e Torres, 2008; Matos et al., 2010; Pereira et al., 2013; Serpa et al., 2011; Silva et al., 2013; Ventura et al., 2014 Em cinco estudos Campanili et al., 2015; Matos et al., 2010; Pereira et al., 2013; Silva et al., 2013; Ventura et al., 2014 os autores utilizaram a classificação do NPUAP e nos demais Fernandes e Torres, 2008; Serpa et al., ${ }^{2011}$ não se encontrou referência a algum tipo de sistema de classificação. A escala de Braden foi utilizada em cinco estudos Campanili et al., 2015; Matos et al., 2010; Pereira et al., 2013; Serpa et al., 2011; Ventura et al., 2014 e tampouco se encontrou descrição sobre avaliação de risco nos outros dois. Fernandes e Torres, 2008; Silva et al., 2013 Dois estudos Campanili et al., 2015; Serpa et al., 2011 afirmam que as instituições pesquisadas não possuíam protocolo de prevenção de UP, informação ausente em todos os demais. Fernandes e Torres, 2008; Matos et al., 2010; Pereira et al., 2013; Silva et al., 2013; Ventura et al., 2014

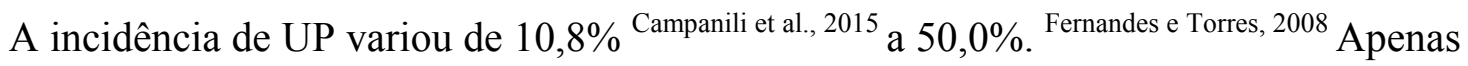
dois estudos Campanili et al., 2015; Fernandes e Torres, 2008 analisaram e descreveram os fatores de risco associados ao desenvolvimento de UP e apenas tempo de permanência na UTI foi comum em ambas as publicações.

O Quadro 2 apresenta as publicações internacionais acerca da incidência e fatores de risco para o desenvolvimento de UP em UTI, nos últimos 10 anos.

Quadro 2 - Estudos epidemiológicos internacionais sobre incidência e fatores de risco para UP, segundo autor e ano de publicação, estado em que foi realizado, métodos e resultados, no período de janeiro de 2006 a maio de 2015.

\begin{tabular}{|c|c|c|c|}
\hline $\begin{array}{c}\text { Autor/Ano } \\
\text { País }\end{array}$ & Métodos & $\begin{array}{c}\text { Incidência de } \\
\text { UP }\end{array}$ & Fatores associados às UP \\
\hline $\begin{array}{l}\text { Frankel, } \\
\text { Sperry, } \\
\text { Kaplan, } 2007 \\
\\
\text { Estados } \\
\text { Unidos da } \\
\text { América }\end{array}$ & $\begin{array}{l}1 \text { UTI cirúrgica universitária } \\
365 \text { dias de seguimento } \\
820 \text { pacientes } \\
\text { Leitura de prontuário } \\
\text { UP II ou maior } \\
\text { Não cita classificação } \\
\text { Não cita avaliação de risco } \\
\text { Protocolo de prevenção } \\
\mathrm{X}^{2} \text { t-teste e análise de regressão logística } \\
\text { Significância estatística } 5 \%\end{array}$ & $3,0 \%$ & $\begin{array}{c}\text { Diabetes } \\
\text { OR 2,7 IC 95\% 1,1-6,4 } \\
\text { Lesão medular } \\
\text { OR 16,8 IC 95\% 1,5-183 } \\
\text { Idade > } 60 \text { anos } \\
\text { OR 2,9 IC 95\% 1,2-7,1 } \\
\text { Creatinina }>3 \mathrm{mg} / \mathrm{dL} \\
\text { OR 3,7 IC 95\% 1,2-9,3 }\end{array}$ \\
\hline $\begin{array}{l}\text { Suriadi, } \\
\text { Sugama, } \\
\text { Kitagawa, } \\
\text { Thigpen, }\end{array}$ & $\begin{array}{l}1 \text { UTI pública } \\
150 \text { dias de seguimento } \\
105 \text { pacientes } \\
\text { Exame físico diário }\end{array}$ & $\begin{array}{c}33,3 \% \\
73,7 \% \text { sacro } \\
13,2 \% \text { calcâneo }\end{array}$ & $\begin{array}{c}\text { Interface de pressão tecidual OR } 17,6 ; \\
\text { IC } 95 \% 4,1-74,3 \\
\text { Umidade } \\
\text { OR } 8,2 ; \text { IC } 95 \% 2,2-30,9\end{array}$ \\
\hline
\end{tabular}




\begin{tabular}{|c|c|c|c|}
\hline $\begin{array}{l}\text { Kinosita e } \\
\text { Murayama, } \\
2007 \\
\text { Indonésia }\end{array}$ & $\begin{array}{l}\text { Classificação NPUAP } \\
\text { Risco UP: ser acamado ou não poder } \\
\text { deambular } \\
\text { Não cita protocolo de prevenção } \\
\text { Análises descritiva, univariada e de } \\
\text { regressão logística multivariada binária } \\
\text { Razão de chances } \\
\text { Intervalo de confiança } 95 \% \\
\text { Significância estatística 5\% }\end{array}$ & $\begin{array}{l}5,3 \% \text { cotovelo } \\
2,6 \% \text { trocânter } \\
2,6 \% \text { vértebra } \\
2,6 \% \text { escápula }\end{array}$ & $\begin{array}{c}\text { Tabagismo } \\
\text { OR 12,7; IC 95\% 2,8-56,7 } \\
\text { Temperatura corporal } \\
\text { OR 102,0; IC 95\% 7,7-98,8 }\end{array}$ \\
\hline $\begin{array}{l}\text { Sayar, } \\
\text { Turgut, } \\
\text { Dogan, Ekici, } \\
\text { Yurtsever, } \\
\text { Demirkan, } \\
\text { Doruk e } \\
\text { Tasdelen, } \\
2008 \\
\quad \text { Turquia }\end{array}$ & $\begin{array}{l}3 \text { UTI universitárias } \\
\text { Médica, cirúrgica e reanimação } \\
46 \text { dias de seguimento } \\
140 \text { pacientes } \\
\text { Exame físico diário } \\
\text { Classificação EPUAP } \\
\text { Escala de Waterlow } \\
\text { Protocolo de prevenção } \\
\text { Teste t-student } \\
\text { Qui-quadrado } \\
\text { Teste de Kaplan-Meier } \\
\text { Regressão logística multivariada } \\
\text { Intervalo de confiança } 95 \% \\
\text { Significância estatística 5\% }\end{array}$ & $\begin{array}{c}14,3 \% \\
10 \text { Reanimação } \\
6 \text { Cirúrgica } \\
4 \text { Médica } \\
7 \text { ombro } \\
6 \text { sacro } \\
2 \text { ombro/sacro } \\
2 \text { sacro/calcâneo } \\
2 \\
\text { ombro/calcâneo } \\
2 \text { cotovelo/ } \\
\text { calcâneo } \\
2 \text { sacro/cotovelo } \\
2 \text { cotovelo/ } \\
\text { maléolo } \\
2 \\
\text { ísquio/maléolo }\end{array}$ & $\begin{array}{c}\text { Nível de consciência } \\
\mathrm{p}<0,05 \\
\text { Nível de atividade } \\
\text { OR } 0,34 \text { IC } 95 \% 0,16-0,73 \\
\mathrm{p} 0,005 \\
\text { Cooperação } \\
\mathrm{p}<0,05 \\
\text { Tempo de permanência } \\
\text { OR } 1,20 \text { IC } 95 \% 1,11-1,30 \\
\mathrm{p} 0,000 \\
\text { Escore Waterlow alto } \\
\mathrm{p}<0,05 \\
\text { Nível de proteína C reativa } \\
\mathrm{p}<0,05\end{array}$ \\
\hline $\begin{array}{l}\text { Nijs, Toppets, } \\
\text { Defloor, } \\
\text { Bernaerts, } \\
\text { Milisen e Van } \\
\text { Den Berghe, } \\
2009 \\
\quad \text { Bélgica }\end{array}$ & $\begin{array}{l}\text { 1 UTI universitária } \\
\text { Cirúrgica de longa permanência } \\
108 \text { dias de seguimento } \\
520 \text { pacientes } \\
\text { UP categorias } 2-4 \\
\text { Exame físico diário } \\
\text { Classificação EPUAP } \\
\text { Escala de Norton } \\
\text { Protocolo de prevenção } \\
\text { Regressão logística multivariada }\end{array}$ & $20,1 \%$ & $\begin{array}{c}\text { História de doença vascular } \\
\text { OR 4,51 IC 95\% 1,99-10,24 } \\
\text { Tratamento com Dopamina ou } \\
\text { Dobutamina } \\
\text { OR 6,05 IC 95\% 1,88-19,54 } \\
\text { Hemodiálise intermitente/ } \\
\text { hemofiltração venovenosa contínua } \\
\text { OR 3,77 IC 95\% 1,03-13,86 } \\
\text { Ventilação mecânica } \\
\text { OR 4,82 IC 95\% 1,74-13,36 }\end{array}$ \\
\hline $\begin{array}{l}\text { Shahin, } \\
\text { Dassen e } \\
\text { Halfens, } 2009 \\
\text { Alemanha }\end{array}$ & $\begin{array}{l}\text { UTI hospital geral } \\
\text { Cardiológica e cirúrgica } \\
\text { UTI universitária } \\
\text { Nefrológica } \\
180 \text { dias de seguimento } \\
121 \text { pacientes } \\
\text { Exame físico admissão e alta ou após } \\
\text { duas semanas } \\
\text { Classificação EPUAP } \\
\text { Escala de Braden/ Apache II } \\
\text { Protocolo de prevenção } \\
\text { Análise descritiva }\end{array}$ & $\begin{array}{c}3,3 \% \\
4,5 \% \text { nefro } \\
2,9 \% \text { cirúrgica }\end{array}$ & ----- \\
\hline $\begin{array}{l}\text { Terekeci, } \\
\text { Kucukardali, } \\
\text { Top, Onem, } \\
\text { Celik, } \\
\text { Öktenli, } 2009 \\
\quad \\
\quad \text { Turquia }\end{array}$ & $\begin{array}{l}\text { 1 UTI } \\
60 \text { dias de seguimento } \\
142 \text { pacientes } \\
\text { Não refere método de avaliação dos } \\
\text { pacientes } \\
\text { Classificação NPUAP } \\
\text { Escala de Norton } \\
\text { Protocolo de prevenção } \\
\text { Apache II; Nutritional risk screening } \\
2002 \\
\text { Teste Exato de Fisher } \\
\text { Significância estatística 5\% }\end{array}$ & $7,8 \%$ & $\begin{array}{c}\text { Nutritional Risk Screening-2002 } \mathrm{p}<0.05 \\
\text { Norton } \mathrm{p}<0.05 \\
\text { albumina } \mathrm{p}<0.05 \\
\text { PAM } \mathrm{p}<0.05 \\
\text { APACHE-II } \mathrm{p}<0.05 \\
\text { Período de hospitalização } \mathrm{p}<0.05\end{array}$ \\
\hline $\begin{array}{l}\text { Kaitani, } \\
\text { Tokunaga, } \\
\text { Matsui e } \\
\text { Sanada, } 2010\end{array}$ & $\begin{array}{l}1 \text { UTI e } 1 \text { SEMI } \\
\text { Hospital terciário } \\
90 \text { dias de seguimento } \\
98 \text { pacientes } \\
\text { Exame físico diário }\end{array}$ & $\begin{array}{c}11,2 \% \\
\\
35,7 \% \text { UP I } \\
57,1 \% \text { UP II } \\
7,1 \% \text { UP III }\end{array}$ & $\begin{array}{c}\text { Admissão de emergência } \\
\text { OR 0,041 IC 95\% } 0,004-0,470 \mathrm{p}<0,01 \\
\text { Menor frequência de mudança de } \\
\text { decúbito } \\
\text { OR } 0,452 \text { IC } 95 \% 0,212-0,966 \mathrm{p}<0,05\end{array}$ \\
\hline
\end{tabular}




\begin{tabular}{|c|c|c|c|}
\hline Japão & $\begin{array}{l}\text { Classificação NPUAP } \\
\text { Escala de risco própria/ Apache II } \\
\text { Protocolo de prevenção } \\
\text { Teste t-Student } \\
\text { Qui-quadrado } \\
\text { Teste Exato de Fisher } \\
\text { Qui-quadrado de Pearson's } \\
\text { Regressão logística multivariada } \\
\text { Razão de chances } \\
\text { Intervalo de confiança 95\% } \\
\text { Significância estatística 5\% }\end{array}$ & $\begin{array}{l}64,3 \% \text { tronco } \\
35,7 \% \text { membros } \\
\text { inferiores }\end{array}$ & \\
\hline $\begin{array}{l}\text { Efteli e } \\
\text { Günes, } 2013 \\
\text { Turquia }\end{array}$ & $\begin{array}{l}1 \text { UTI universitária } \\
\text { Recuperação anestésica } \\
180 \text { dias de seguimento } \\
70 \text { pacientes } \\
\text { Exame físico diário } \\
\text { Classificação NPUAP } \\
\text { Escala de Braden/ Apache II } \\
\text { Protocolo de prevenção } \\
\text { Teste t-Student } \\
\text { Qui-quadrado } \\
\text { Teste Exato de Fisher } \\
\text { Regressão logística multivariada } \\
\text { Razão de chances } \\
\text { Intervalo de confiança } 95 \% \\
\text { Significância estatística 5\% }\end{array}$ & $\begin{array}{c}28,6 \% \\
52,1 \% \text { UP I } \\
34,8 \% \text { UP II } \\
13,1 \% \text { UP III } \\
\text { 39,8\% cóccix } \\
32,7 \% \text { sacro }\end{array}$ & $\begin{array}{c}\text { Sexo feminino } \\
\text { OR 0,15 IC 95\% 0,03-0,71 } \\
\mathrm{p}<0,05 \\
\text { Albumina sérica baixa } \\
\text { OR 11,6 IC } 95 \% 1,92-70,4 \\
\mathrm{p}<0,01\end{array}$ \\
\hline
\end{tabular}

Dentre oito publicações, a maioria (5) Efteli e Günes, 2013; Nijs et al., 2009; Sayar et al., 2008; Shahin et al., 2009; Terekeci et al., 2009 foi desenvolvida por europeus e realizada predominantemente em instituições universitárias (5). Efteli e Günes, 2013; Frankel et al., 2007; Nijs et al., 2009; Sayar et al., 2008; Shahin et al., ${ }^{2009}$ Apenas um estudo Sayar et al., 2008 teve tempo de seguimento inferior a 90 dias. O exame físico foi a principal estratégia para a coleta de dados em quatro estudos. Efteli e Günes, 2013; Nijs et al., 2009; Sayar et al., 2008; Shahin et al., 2009; A classificação do NPUAP foi utilizada em quatro estudos Efteli e Günes, 2013; Kaitani et al., 2010; Suriadi et al., 2007; Terekeci et al., 2009; a do EPUAP em três, Nijs et al., 2009; Sayar et al., 2008; Shahin et al., 2009 e somente em um Frankel et al., 2007 não houve referência quanto à classificação das UP. Em dois estudos Kaitani et al., 2010; Suriadi et al., 2007 os autores utilizaram escala de avaliação de risco própria, dois Efteli e Günes, 2013; Shahin et al., 2009 utilizaram a escala de Braden, dois Nijs et al., 2009; Terekeci et al., 2009 a de Norton, um a de Waterlow Sayar et al., 2008 e apenas em um estudo Frankel et al., 2007 não se detectou menção a esse tipo de avaliação. Somente os autores de um dos estudos Suriadi et al., 2007 não referem se a instituição pesquisada possuía protocolo de prevenção de UP.

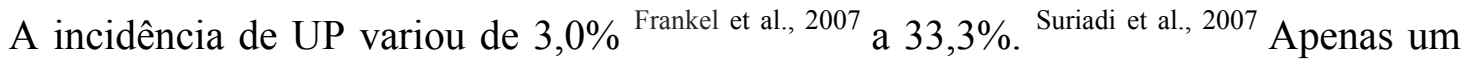
estudo Shahin et al., ${ }^{2009}$ não relacionou fatores de risco associados com a ocorrência de UP. Tempo de permanência Sayar et al., 2008 e período de hospitalização, Terekeci et al., 2009 assim como albumina $^{\text {Terekeci et al., } 2009}$ e albumina sérica baixa ${ }^{\text {Efteli e Günes, } 2013}$ foram os únicos fatores de risco que apareceram em mais de um estudo; todos os demais não se repetiram. 


\subsection{6 Úlcera por pressão e carga de trabalho de enfermagem}

Carga de trabalho de enfermagem refere-se ao tempo dispendido nas atividades concernentes à prática profissional, sejam elas relacionadas ou não aos cuidados com os pacientes. Conishi e Gaidzinski, 2007; Gonçalves e Padilha, 2007

Vários pesquisadores Al-Kandari e Thomas, 2009; Blegen et al., 1998; Burnes et al., 2007; Cremasco et al., 2009; Inoue e Matsuda, 2010; Laschinger e Leiter, 2006; Oliveira, 2012; Robert et al., 2000; Shuldham et al., 2009; Stone et al., 2007; Unrah, 2003; Weissman et al., 2007; Whitman et al., 2002; Yang, 2003 têm estudado o impacto do excesso da carga de trabalho de enfermagem nos resultados da assistência prestada.

Revisão de literatura, Carayon e Gurses, 2005 que englobou estudos a partir da década de 70 até 2005, concluiu que o excesso de carga de trabalho de enfermagem pode colocar a segurança do paciente em risco, evidenciando-a como preditora de eventos adversos. Desse modo, a elevada carga de trabalho levaria não só à exaustão física mas também emocional da equipe, abrindo margem aos erros. Carayon e Gurses, ${ }^{2005}$ Carga de trabalho e média de horas de cuidados de enfermagem são poderosos preditores de quedas, UP, infecções respiratórias e urinárias e queixas dos pacientes e familiares. Yang, 2003

Pesquisa realizada pela Kaiser Family Foundation, ${ }^{2004}$ dos Estados Unidos, apontou que carga de trabalho, estresse ou fadiga dos profissionais de saúde, inadequação do número de enfermeiros e do tempo gasto com os pacientes incidem diretamente nos índices de eventos adversos. Em consonância com essa pesquisa, no estudo conduzido por Unrah, ${ }^{2003}$ aumentar o quadro de pessoal de enfermagem em $10 \%$ levou à diminuição dos índices de UP em $2 \%$. Stone e colaboradores ${ }^{2007}$ também referiram que pacientes admitidos em uma UTI com maior número de horas de assistência de enfermagem por paciente-dia, apresentaram significativamente menor incidência de UP (OR 0,69; IC 95\% 0,49-0,98; p $\leq 0.01$ para o terceiro quartil, quando comparado ao primeiro). Por outro lado, para Weissman e colaboradores, ${ }^{2007}$ aumentar a razão paciente/ enfermeiro em $0,1 \%$ aumentou a taxa de eventos adversos em $28 \%$.

Estudo transversal realizado nas clínicas médicas e cirúrgicas de cinco hospitais gerais

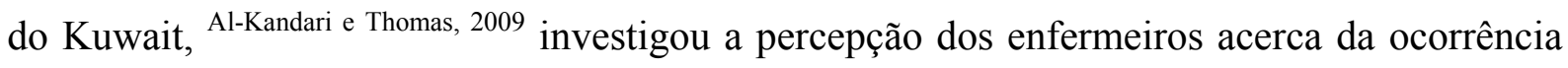
de eventos adversos relacionados à carga de trabalho de enfermagem. Reclamações de pacientes e familiares $(2 \%)$, erros de medicação $(1,8 \%)$, UP $(1,5 \%)$, infecção de ferida $(1,2 \%)$ e infecção de sítio de cateter venoso $(1,2 \%)$ foram os eventos adversos mais apontados pelos 
enfermeiros durante seu último plantão. Correlação positiva foi encontrada entre a razão paciente/ enfermeiro e a ocorrência de quedas $(\mathrm{r}=0,1 ; \mathrm{p}=0,01)$ e UP $(\mathrm{r}=0,08 ; \mathrm{p}=0,04)$.

No Brasil, estudo realizado por Oliveira ${ }^{2012}$ considerou que o aumento da carga de trabalho da enfermagem implicou em maior risco para a ocorrência de UP. Por outro lado, Cremasco e colaboradores ${ }^{2009}$ não constataram associação entre carga de trabalho de enfermagem e risco para o desenvolvimento de UP. Similarmente, Whitman e colaboradores 2002 também não encontraram associação significativa entre o quantitativo do pessoal de enfermagem e a ocorrência de UP; apesar disso, afirmam que a relação entre essas variáveis é inversamente proporcional, ou seja, quadro reduzido de pessoal de enfermagem resulta em aumento da ocorrência de UP.

Visando a aumentar a segurança do paciente, em 2004, o Estado da Califórnia, nos Estados Unidos, regulamentou uma razão mínima paciente/ enfermeiro para a atenção hospitalar. Contudo, estudo realizado Burnes et al., 2007 dois anos após a regulamentação da lei concluiu que, apesar do aumento do número de enfermeiros, não houve diminuição significativa dos casos de quedas e UP adquiridas nos hospitais. Shuldham e colaboradores, 2009 também não encontraram associação significativa entre alto número de profissionais de enfermagem e diminuição da incidência de UP (taxa de incidência 0,986; IC 95\% 0,9411,034; $\mathrm{p}=0,564)$. Ao contrário, relataram alguma evidência sobre a associação entre aumento do quadro de enfermeiros e aumento da taxa de UP na UTI. Segundo Cho e colaboradores, 2003 uma das razões para tanto seria que a maior quantidade de enfermeiros implicaria no aumento do número de avaliações completas dos pacientes, assim como em registros mais precisos. Outra hipótese seria que o aumento no número de enfermeiros levaria a falhas na comunicação sobre a execução ou não das medidas preventivas. Reconhece-se que a relação entre quantitativo de enfermagem e UP pode ter sido distorcida pela falta de acurácia na documentação sobre as UP preexistentes à admissão na UTI.

Como se vê, muitos estudos vêm sendo realizados com o objetivo de caracterizar a relação entre UP e carga de trabalho de enfermagem, contudo, ainda são bastante controversos e escassos, principalmente em âmbito nacional. 
OBJETIVOS 


\section{OBJETIVOS}

\subsection{OBJETIVO GERAL}

Estimar e analisar a incidência de UP e os fatores de risco para o seu desenvolvimento, em pacientes internados em UTI.

\subsection{OBJETIVOS ESPECÍFICOS}

- Identificar as características demográficas e clínicas dos pacientes internados em UTI;

- Caracterizar as UP quanto a classificação, localização, tempo para o aparecimento e gravidade do dano;

- Verificar as associações estatísticas existentes entre a presença de UP e as características demográficas e clínicas dos pacientes internados em UTI;

- Verificar as associações estatísticas existentes entre a presença de UP e a carga de trabalho de enfermagem. 
MÉTODOS 


\section{MÉTODOS}

O presente estudo constitui parte do projeto de pesquisa intitulado "Segurança do paciente em unidades de terapia intensiva: influência dos recursos humanos de enfermagem na ocorrência de eventos adversos", financiado pela Fundação de Amparo à Pesquisa do Estado de São Paulo (FAPESP), sob o protocolo 11/51874-5, e pelo Conselho Nacional de Desenvolvimento Científico e Tecnológico (CNPq) - Projeto Universal (477860/2010-9). O presente estudo teve como foco a análise da incidência de um dos eventos adversos nele incluídos, qual seja a UP.

\subsection{TIPO DE ESTUDO}

Trata-se de um estudo de coorte retrospectivo.

\subsection{PROCEDIMENTOS ÉTICOS}

O projeto foi aprovado pelo Comitê de Ética em Pesquisa do Instituto Central do Hospital das Clínicas da Faculdade de Medicina da Universidade de São Paulo (CAPPesq ICHC-FMUSP), processo número 0196/2011 (ANEXO 1), e pelo Comitê de Ética em Pesquisa do Hospital Universitário da Universidade de São Paulo (CEP HU-USP), processo número 1086/10 (ANEXO 2).

Para a coleta de dados dos prontuários, o Termo de Consentimento Livre e Esclarecido dos pacientes foi substituído pelo Termo de Compromisso de Sigilo dos Dados assinado pelo coordenador do projeto. 


\subsection{LOCAL DO ESTUDO}

O estudo foi realizado no Hospital das Clínicas da Faculdade de Medicina da Universidade de São Paulo (HC-FMUSP) e no Hospital Universitário da Universidade de São Paulo (HU-USP), ambos situados na cidade de São Paulo.

O HC-FMUSP é uma autarquia estadual integrante do Sistema Único de Saúde (SUS) e vinculado à Secretaria de Estado da Saúde para fins administrativos e à Faculdade de Medicina da Universidade de São Paulo para fins de ensino, pesquisa e prestação de ações e serviços de saúde de alta complexidade destinados à comunidade. Seu complexo hospitalar é composto de sete institutos, dentre eles o Instituto Central do Hospital das Clínicas da Faculdade de Medicina da Universidade de São Paulo (ICHC-FMUSP), com 843 leitos em 2012 (à época da coleta de dados). Desse total, as UTI contavam com 74 leitos ativos e distribuídos a saber: 16 leitos na UTI do Pronto Socorro Cirúrgico, 12 leitos na UTI do Pronto-Socorro de Emergência Clínica, 11 leitos na UTI de Cirurgia Geral, 11 leitos na UTI de Neurologia, 7 leitos na UTI de Moléstias Infecciosas, 5 leitos na UTI de Nefrologia, 4 leitos na UTI de Clínica Médica, 4 leitos na UTI de Pneumologia e 4 leitos na UTI de Queimados. Apesar de haver assistência de enfermagem sistematizada e documentada por meio de Histórico, Prescrição, Evolução e Diagnósticos de Enfermagem, as UTI do ICHCFMUSP não contavam com protocolo específico para prevenção de UP à época da coleta de dados. Nesse sentido, apenas a escala de Braden encontrava-se instituída para detecção dos pacientes em risco.

O HU-USP é um hospital geral de atenção secundária, integrante do SUS e da Universidade de São Paulo (USP), voltado ao ensino, pesquisa e extensão de serviços à comunidade. À época da coleta de dados, o hospital dispunha de 247 leitos, dos quais 12 eram destinados à UTI e 8 à Unidade Semi Intensiva (USI). A sistematização da assistência de enfermagem encontrava-se plenamente implantada, incluindo Histórico, Prescrição, Evolução e Diagnósticos de Enfermagem. Desde 2005, o serviço conta com protocolo de prevenção de UP para nortear as ações de enfermagem junto aos pacientes com escore Braden menor ou igual a 16. 


\subsection{POPULAÇÃO/ AMOSTRA DO ESTUDO}

A população do estudo foi constituída de todos os pacientes internados na UTI e USI do HU-USP no período de 3 de maio a 31 de julho de 2012, e nas UTI do Pronto Socorro Cirúrgico, do Pronto-Socorro de Emergência Clínica, de Cirurgia Geral, de Neurologia, de Moléstias Infecciosas, de Nefrologia, de Clínica Médica e de Pneumologia do ICHC-FMUSP, de 3 de setembro a 1 de dezembro de 2012.

Do total de 1196 pacientes que compuseram a amostra total no período de coleta de dados, a seleção dos pacientes baseou-se nos seguintes critérios de inclusão no presente estudo:

- Apresentar tempo de internação superior a 24 horas; e

- Não possuir UP.

A presença de UP no momento da internação implicou na não inclusão do paciente do estudo. Por outro lado, tendo em vista o caráter retrospectivo do estudo, com coleta documental de dados, optou-se por excluir também aqueles pacientes com lesões de pele disseminadas pelo corpo, seja por queimaduras ou dermatoses, que poderiam dificultar o diagnóstico das UP.

\subsection{VARIÁVEIS DO ESTUDO}

As variáveis do estudo apresentam-se listadas no Quadro 3.

Quadro 3 - Variáveis do estudo.

\begin{tabular}{|l|c|c|}
\hline \multicolumn{3}{|c|}{ VARIÁVEL DEPENDENTE } \\
\hline UP & Variável Nominal & Ausente/ Presente \\
\hline \multicolumn{3}{|c|}{ VARIÁ } \\
\hline \multicolumn{3}{|c|}{ DEIS INDEPENDENTES } \\
\hline Sexo & Variável Nominal & Masculino/ Feminino \\
\hline Idade & Variável Contínua & Em anos \\
\hline Idade (Faixas etárias) & Variável Ordinal & $<45 / 45-59 / 60-84 / 85+$ \\
\hline \multicolumn{3}{|c|}{ CLÍNICAS } \\
\hline Tipo de Internação & Variável Nominal & Clínica/ Cirúrgica Eletiva/ Cirúrgica \\
\hline Tempo de Internação & Eariável Contínua & Emergência dias \\
\hline
\end{tabular}




\begin{tabular}{|l|c|c|}
\hline Condição de Alta da UTI & Variável Nominal & Não Sobrevivente/ Sobrevivente \\
\hline Comorbidades (ICC) & Variável Discreta & 0 a 32 \\
\hline Gravidade do Paciente (SAPS II) & Variável Contínua & quanto > a pontuação, > risco de morte \\
\hline Gravidade do Paciente (LODS) & Variável Discreta & 1 a 22 \\
\hline Carga de Trabalho de Enfermagem (NAS) & Varíavel Contínua & até 176,8\% \\
\hline Diagnóstico de Admissão & Variável Nominal & Agrupados por sistemas orgânicos \\
\hline Cirurgias & Variável Nominal & Não / Sim \\
\hline Número de Cirurgias & Variável Discreta & ---- \\
\hline Drogas Vasoativas & Variável Nominal & Não / Sim \\
\hline $\begin{array}{c}\text { Número de Dias com Drogas } \\
\text { Vasoativas }\end{array}$ & Variável Discreta & Em dias \\
\hline Ventilação Mecânica & Variável Nominal & Não / Sim \\
\hline $\begin{array}{c}\text { Número de Dias em Ventilação } \\
\text { Mecânica }\end{array}$ & Variável Discreta & Em dias \\
\hline Tipo de Colchão & Variável Nominal & Piramidal/ Pneumático/ Convencional \\
\hline Cuidados Paliativos & Variável Nominal & Não / Sim \\
\hline Classificação da UP (NPUAP-EPUAP) & Variável Ordinal & 1/ 2/ 3/ 4/ SLTP/ UPNC \\
\hline Localização da UP & Variável Nominal & Localização Anatômica \\
\hline Gravidade do Dano (OMS) & Variável Ordinal & Ausente/ Fraco/ Moderado/ Grave/ Morte \\
\hline Tempo Para o Aparecimento da UP & Variável Contínua & Em dias \\
\hline
\end{tabular}

\subsection{COLETA DE DADOS}

\subsubsection{Procedimentos para a coleta de dados}

Antecedendo à coleta de dados, realizada no período de abril de 2011 a abril de 2012, desenvolveram-se atividades fundamentais voltadas à infraestrutura para a consecução do projeto, que incluíram os seguintes processos:

1) capacitação dos enfermeiros e desenvolvimento e implantação do sistema computacional NAS;

2) desenvolvimento do sistema banco de dados da pesquisa;

3) digitalização dos dados dos prontuários;

4) capacitação dos analistas/ colaboradores para a análise dos eventos adversos/ incidentes (ANEXOS 3 e 4);

5) extração e carga dos dados de identificação dos pacientes e exames laboratoriais do banco de dados dos sistemas utilizados nos hospitais para o banco de dados da pesquisa; e

6) capacitação de monitores para a observação das passagens de plantão. 


\subsubsection{Operacionalização da coleta de dados}

A coleta de dados dos pacientes foi realizada no período de 90 dias consecutivos, de 3 de maio a 31 de julho de 2012, no HU-USP, e de 3 de setembro a 1 de dezembro de 2012, no ICHC-FMUSP. A diferença no período de coleta de dados entre as duas instituições ocorreu devido à necessidade de adequação da infraestrutura física e administrativa para a realização do projeto, diferente em ambas.

Foram coletados dados demográficos e clínicos (ANEXO 5). O estudo das

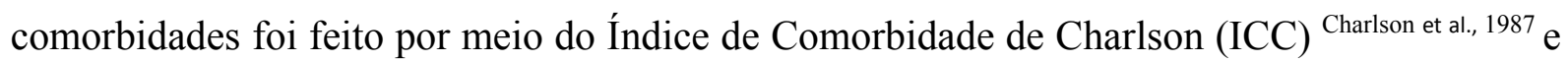
da gravidade pelos índices Simplyfied Acute Physiologic II (SAPS II) ${ }^{\text {Le Gall et al., } 1993}$ e Logistic

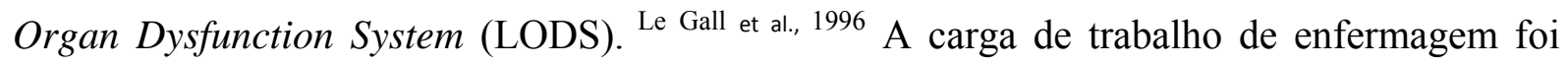
coletada pelo Nursing Activities Score (NAS). Miranda et al., 2003; Queijo et al., 2002 O ANEXO 6 traz o instrumento na íntegra e o ANEXO 7 o manual para sua aplicação.

Para o armazenamento e organização dos dados, foi desenvolvido e implementado um sistema em C\# (C-Sharp) com um banco de dados SQL (Structured Query Language ou Linguagem de Consulta Estruturada), por um especialista em Tecnologia da Informação, que permaneceu alocado em um servidor de banco de dados da Escola de Enfermagem da Universidade de São Paulo. Denominado Banco de Dados Universal, o sistema é um programa de organização, armazenamento e análise de dados, elaborado a partir do formulário impresso utilizado no estudo e que incluiu informações sobre a Identificação do paciente; Dados da internação na UTI; Parâmetros de Gravidade; Intervenções terapêuticas; EA/I, acrescido da prescrição medicamentosa e exames laboratoriais.

No presente estudo, as variáveis de interesse identificação do paciente, número do registro na instituição, número de registro no projeto, idade, sexo, tipo de internação, duração

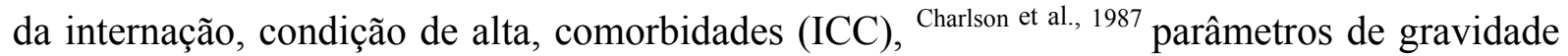
(SAPS II ${ }^{\text {Le Gall et al., } 1993}$ e LODS), ${ }^{\text {Le Gall et al., } 1996}$ diagnóstico de admissão, cirurgias, número de cirurgias, drogas vasoativas, número de dias em uso de drogas vasoativas, ventilação mecânica, número de dias em ventilação mecânica, cuidados paliativos (ANEXO 5) e carga de trabalho de enfermagem (NAS) Queijo et al., 2002; Miranda et al., 2003 (ANEXO 6), foram extraídas diretamente do Banco de Dados Universal. Adicionalmente, entre os meses de abril e maio de 2015, informações referentes ao tipo de colchão/ superfície de suporte, escores mínimo e máximo de Braden e ocorrência e caracterização das UP - classificação, NPUAP et al., 2014 
localização anatômica, tempo de aparecimento e sua gravidade - (APÊNDICE A) foram coletadas diretamente dos prontuários digitalizados, uma vez que tais informações não constavam do Banco de Dados Universal.

\subsubsection{Instrumentos para a coleta de dados}

Os instrumentos empregados para a coleta de dados são descritos a seguir.

\subsubsection{Instrumento para a coleta dos dados demográficos e clínicos}

No Instrumento para a coleta dos dados demográficos e clínicos (ANEXO 5), constam os dados extraídos do Banco de Dados Universal referentes a identificação do paciente, número do registro na instituição, número de registro no projeto, idade, sexo, tipo de internação, duração da internação, condição de alta, comorbidades (ICC), Charlson et al., 1987 parâmetros de gravidade (SAPS II ${ }^{\text {Le Gall et al., } 1993}$ e LODS), ${ }^{\text {Le Gall et al., } 1996}$ carga de trabalho de enfermagem (NAS), Miranda et al., 2003; Queijo et al., 2002 diagnóstico de admissão, cirurgias, número de cirurgias, drogas vasoativas, número de dias em uso de drogas vasoativas, ventilação mecânica, número de dias em ventilação mecânica e cuidados paliativos.

As variáveis coletadas diretamente dos prontuários digitalizados complementam as informações e constam do Apêndice A: tipo de colchão/ superfície de suporte, escores mínimo e máximo de Braden, presença de UP, tempo para seu aparecimento, classificação da UP NPUAP et al., 2014 localização anatômica da UP e gravidade do dano (OMS). 2009

\subsubsection{2 Índice de Comorbidade de Charlson (ICC)}

O ICC é um método que emprega condições clínicas selecionadas na admissão do paciente, registradas como diagnóstico secundário - comorbidades - no cálculo do risco de óbito. 
O índice calcula a carga de morbidade do paciente, independentemente do diagnóstico principal. Dezenove condições clínicas predefinidas compõem o ICC. Cada uma delas recebe uma pontuação com base no risco relativo, com pesos variando de 0 a 6 . $\mathrm{O}$ escore de gravidade do paciente resulta da soma dos pesos de todas as comorbidades componentes do índice que foram registradas no campo dos diagnósticos secundários. Charlson et al., 1987 Quanto maior o escore, maior o risco de óbito. O Quadro 4 apresenta o ICC.

Quadro 4 - Índice de Comorbidade de Charlson.

\begin{tabular}{|c|c|}
\hline \multirow{2}{*}{ Índice de Comorbidade de Charlson } & Ausentes 0 \\
\hline & Presentes 1 a 32 \\
\hline CATEGORIA DIAGNÓSTICA & PESO \\
\hline Infarto do Miocárdio & 1() \\
\hline Insuficiência Cardíaca Congestiva & 1() \\
\hline Doença Vascular Periférica & 1() \\
\hline Doença Cerebrovascular & 1() \\
\hline Demência & 1() \\
\hline Doença Pulmonar Crônica & 1() \\
\hline Doença do Tecido Conectivo & 1() \\
\hline Doença Péptica & 1() \\
\hline Doença Hepática Leve & 1() \\
\hline Diabetes & 1() \\
\hline Hemiplegia & 2() \\
\hline Doença Renal Moderada ou Grave & 2() \\
\hline Diabetes com Lesão de Órgão Alvo & 2() \\
\hline Tumor & 2() \\
\hline Leucemia & 2() \\
\hline Linfoma & 2() \\
\hline Doença Hepática Moderada ou Grave & 3() \\
\hline Tumor Sólido Metastático & 6() \\
\hline AIDS & 6() \\
\hline
\end{tabular}

Fonte: Charlson ME, Pompei P, Ales KL, Mackenzie CR. A new method of classifying prognostic comorbidity in longitudinal studies: development and validation. J Chronic Dis. 1987; 40(5):373-83.

\subsubsection{Simplyfied Acute Physiologic II (SAPS II)}

O SAPS II é um índice de gravidade que permite calcular a probabilidade de mortalidade resultante de um quadro patológico. Composto por 17 variáveis, 12 são fisiológicas (frequência cardíaca, pressão arterial sistólica, temperatura corporal, relação entre a pressão parcial de oxigênio e a fração inspirada de oxigênio para pacientes intubados, débito urinário em $\mathrm{ml} / 24 \mathrm{~h}$, uréia sérica, número de leucócitos, potássio, bicarbonato e sódio sérico, 
bilirrubinas totais e Escala de Coma de Glasgow), uma é demográfica (idade), uma de internação (eletiva, urgência ou clínica) e três são relacionadas às doenças preexistentes (AIDS com complicação, doenças hematológicas e câncer metastático). Cada variável recebe uma pontuação que varia, no mínimo, de 0 a 3 para a temperatura corporal e, no máximo, de 0 a 26 para a Escala de Coma de Glasgow. O escore total resulta da soma desses valores. Quanto mais elevado o escore obtido, maior a gravidade. Devem ser considerados o pior valor das variáveis fisiológicas das últimas 24h na UTI. Para pacientes sedados, a Escala de Coma de Glasgow deve ser pontuada antes da sedação. Na falta de informações, devem ser registrados os valores de normalidade das variáveis envolvidas. Os autores não estabeleceram ponto de corte, divisão em categorias ou valores mínimos e máximos para o índice. O cálculo da probabilidade de mortalidade hospitalar é realizada por meio de uma equação de regressão logística múltilpla. Le Gall et al., 1993 O índice foi calculado na admissão dos pacientes nas UTI envolvidas.

\subsubsection{Logistic Organ Dysfunction System (LODS)}

O LODS é um índice de gravidade baseado na falência de órgãos. Doze variáveis distribuídas em seis sistemas descrevem o nível de disfunção orgânica dos pacientes: neurológico (Escala de Coma de Glasgow), cardiovascular (frequência cardíaca, pressão arterial sistólica), renal (uréia, creatinina e débito urinário), pulmonar (relação entre a pressão parcial de oxigênio e a fração inspirada de oxigênio), hematológico (plaquetas e leucócitos) e hepático (bilirrubina e tempo de protrombina). O índice pode variar de 1 a 22 pontos. Quanto mais elevado o escore obtido, maior a disfunção orgânica. Por meio de uma equação de regressão logística o escore obtido é traduzido na probabilidade de morte. ${ }^{\text {Le Gall et }}$ al., 1996 O índice foi calculado quando da admissão dos pacientes nas UTI envolvidas e durante todo o período de internação.

\subsubsection{Nursing Activities Score (NAS)}

O NAS (ANEXOS 6 e 7) foi desenvolvido por Miranda e colaboradores, ${ }^{2003}$ e 
traduzido e validado para o Brasil por Queijo e Padilha. ${ }^{2009}$ Desenvolvido para melhor representar as atividades de enfermagem realizadas na UTI, Miranda et al., 2003 ele contabiliza o tempo dispensado na assistência direta e indireta de enfermagem, considerando, inclusive, as atividades administrativas e de suporte aos familiares e pacientes.

O instrumento é composto por 23 itens, a saber: 1. Monitorização e controles; 2. Investigações laboratoriais; 3. Medicação, exceto drogas vasoativas; 4. Procedimentos de higiene; 5. Cuidados com drenos; 6. Mobilização e posicionamento; 7. Suporte e cuidados aos pacientes e familiares; 8. Tarefas administrativas e gerenciais; 9. Suporte respiratório; 10. Cuidado com vias aéreas artificiais; 11. Tratamento para melhora da função pulmonar; 12. Medicação vasoativa; 13. Reposição de grandes perdas de fluidos; 14. Monitorização do átrio esquerdo; 15. Reanimação cardiorrespiratória; 16. Técnicas de hemofiltração/ dialíticas; 17. Medida quantitativa do débito urinário; 18. Medida da pressão intracraniana; 19. Tratamento da acidose/ alcalose metabólica; 20. Nutrição parenteral total; 21. Alimentação enteral; 22. Intervenções específicas na UTI; 23. Intervenções específicas fora da UTI. Miranda et al., 2003; Queijo et al., 2002 Os itens contam ainda com subitens, alguns mutuamente excludentes, que podem receber pontos que variam de 1,2 a 32. Para o cômputo final, considera-se o subitem assinalado que tenha apresentado a maior pontuação nas $24 \mathrm{~h}$ de assistência.

A pontuação obtida estima a proporção de tempo gasto pela equipe de enfermagem na assistência, sendo seu valor máximo $176,8 \%$. Cada ponto do NAS equivale a 14,4 minutos; Miranda et al., 2003; Queijo e Padilha, 2009 dessa forma, um paciente que tenha 68,5 pontos de NAS consome 986,4 minutos, ou 16,44 horas de trabalho.

O NAS foi calculado diariamente para cada paciente durante todo o período de estudo, sendo, ao final, computada sua média para o período acompanhado no Banco de Dados Universal. Neste estudo, o NAS foi utilizado para calcular a carga de trabalho de enfermagem que, por sua vez, foi entendida como o tempo de assistência de enfermagem, em horas, dispendido pelo profissional, para realizar cuidados de enfermagem, incluindo aqueles relacionados à prevenção e tratamento de UP.

\subsubsection{Escala de Braden}

Para a identificação dos pacientes em risco de desenvolvimento de UP, Bergstrom e colaboradores 1987 desenvolveram uma escala composta de seis subescalas: percepção 
sensorial, atividade, mobilidade, umidade, nutrição, fricção e cisalhamento. A Escala de Braden tem-se mostrado como instrumento eficaz no auxílio ao enfermeiro quando em processo de decisão sobre as medidas preventivas a serem adotadas, de acordo com o risco de cada paciente.

Essa escala foi adaptada e validada para o português por Paranhos e Santos. ${ }^{\text {Paranhos e }}$ Santos, 1999 A pontuação da escala varia de 1 a 4, exceto para fricção e cisalhamento, que varia de 1 a 3 pontos, sendo a soma dos escores de 6 a 23. Em estudo posterior, Ayello e Braden 2002 sugeriram o escore de corte 18 para os pacientes com idade maior que 65 anos, febre, baixa ingestão de proteína, pressão diastólica menor que $60 \mathrm{mmHg}$ e/ ou instabilidade hemodinâmica. Neste estudo, adotou-se o escore 18 como nota de corte para o risco de desenvolvimento de UP.

O Quadro 5 apresenta a relação entre os escores da Escala de Braden e a classificação, segundo o risco de UP, utilizados neste estudo.

Quadro 5 - Relação entre os escores de Braden e o risco para úlcera por pressão.

\begin{tabular}{|c|l|}
\hline $\begin{array}{c}\text { Escores de } \\
\text { Braden }\end{array}$ & Risco para Úlcera por Pressão \\
\hline$\geq \mathbf{1 9}$ & fora de risco \\
\hline $\mathbf{1 5 - 1 8}$ & baixo risco \\
\hline $\mathbf{1 3}-\mathbf{1 4}$ & médio risco \\
\hline $\mathbf{1 0}-\mathbf{1 2}$ & alto risco \\
\hline$\leq \mathbf{9}$ & risco muito alto \\
\hline
\end{tabular}

Segundo o Wound Ostomy and Continence Nursing Society, WOCN, 2010 no paciente crítico, a escala de Braden deve ser aplicada na admissão ou até 24 horas após a admissão e, pelo menos, a cada 48 horas, ou antes disso, quando ocorrer alteração em suas condições de saúde, já que esses pacientes apresentam inúmeros fatores de risco.

Escores mínimo e máximo de Braden foram coletados diretamente dos prontuários digitalizados. 


\subsubsection{Gravidade do dano}

Evento adverso é um incidente que resulta em dano desnecessário ao paciente. Por dano se entende comprometimento de estrutura ou função do corpo e/ou quaisquer efeitos deletérios decorrentes deste comprometimento, incluindo doença, lesão, sofrimento, incapacidade e morte. No contexto da saúde, o dano surge ou está associado a planejamentos ou ações tomados durante a realização de assistência ao paciente, e não está relacionado com a evolução natural da doença de base do indivíduo. OMS, 2009 Segundo a Classificação

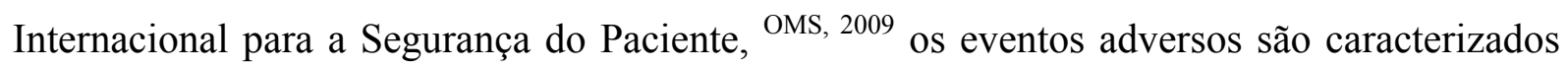
conforme o tipo de incidente e a gravidade do dano.

A UP é considerada um incidente tipo processo clínico/ procedimento, pela Classificação Internacional para a Segurança do Paciente. OMS, 2009

A gravidade do dano inclui a gravidade e a duração do dano, bem como as implicações terapêuticas. ${ }^{\text {OMS, }}{ }^{2009}$ Consideraram-se as seguintes gravidades de danos no Projeto Universal e, por conseguinte, para esta tese:

- Nenhuma - a consequência no doente é assintomática ou sem sintomas detectados e não necessita tratamento.

- Fraca - a consequência no doente é sintomática, com sintomas ligeiros, perda de funções ou danos mínimos ou intermédios de curta duração, sem intervenção ou com uma intervenção mínima requerida (por exemplo: observação extra, inquérito, análise ou pequeno tratamento).

- Moderada - a consequência no doente é sintomática, requerendo intervenção (por exemplo: procedimento suplementar, terapêutica adicional) um aumento na estadia, ou causou danos permanentes ou a longo prazo, ou perda de funções.

- Severa/ Grave - a consequência no doente é sintomática, requerendo intervenção para salvar a vida ou grande intervenção médico/ cirúrgica, encurta a esperança de vida ou causa grandes danos permanentes ou a longo prazo, ou perda de funções.

- Morte - no balanço das probabilidades, a morte foi causada ou antecipada a curto prazo, pelo incidente. 
Segundo a gravidade do dano, no Projeto Universal, as UP categoria I foram classificadas como dano de gravidade fraca; as UP categoria II, fraca ou moderada; as UP categoria III, moderada (inlcuindo aquelas que necessitaram de pequenas intervenções cirúrgicas) ou grave (incluindo as que necessitaram de grandes desbridamentos ou estavam infectadas); e as UP categoria IV, como grave.

O Projeto Universal não incluiu as categorias SLTP e UNPC. Para esta tese, ambas foram consideradas como danos graves.

As UP foram inseridas no Banco de Dados Universal como incidente tipo processo clínico/ procedimento, juntamente com outros eventos desta mesma natureza. Sua classificação foi utilizada apenas para determinar a gravidade do dano, não sendo, portanto, registrada. Por esta razão, todas as UP foram identificadas e classificadas pela pesquisadora, segundo os registros dos prontuários digitalizados.

\subsection{ANÁLISE DOS DADOS}

Estatísticas descritivas foram realizadas para todas as variáveis do estudo com o intuito de caracterizar a amostra.

Variáveis qualitativas (categóricas) nominais e ordinais foram descritas por meio de frequências absolutas (n) e relativas (percentuais). Foi utilizado o teste Qui-quadrado de Pearson para avaliar se as proporções em cada grupo são semelhantes ou não.

Para as variáveis quantitativas contínuas e discretas foram calculados: média, desvio padrão, mediana e sua variação. Para avaliar a associação entre a presença de UP e as variáveis quantitativas foi utilizado o teste de Mann-Whitney.

A identificação dos fatores associados à UP foi realizada por meio da regressão logística, método Stepwise Forward, tendo a UP como variável dependente e as demais variáveis como independentes (Quadro 3).

Apesar da relevância dos escores de Braden na avaliação do risco para o desenvolvimento de UP, optou-se por descartar a variável independente escore de Braden das análises uma vez que quase a metade dos pacientes (40,2\%/ 308) não possuía a classificação de risco registrada em seus prontuários. 
Para todo o estudo foram considerados significativos os testes que obtiveram um nível descritivo menor que 5\% $(\mathrm{p}<0,05)$. Odds ratio e Intervalos de 95\% de Confiança foram determinados para as variáveis independentes.

\subsubsection{Cálculo da incidência}

Este estudo segue as recomendações do consenso internacional Baharestani et al., 2009; NPUAP et al., 2014 para a medida da incidência que considera incidência cumulativa, estimativa da incidência ou simplesmente incidência como a expressão do número de casos novos de determinada condição ou doença (UP) na população, durante um determinado período de tempo. A incidência reflete a dinâmica com que os casos aparecem no grupo e a força da morbidade. Para estabelecer a incidência, é necessário especificar a duração do tempo de observação de surgimento dos casos novos. Baharestani et al., 2009; NPUAP et al., 2014

Para o cálculo da incidência cumulativa, foi utilizada a seguinte fórmula:

$$
\mathrm{n}^{\circ} \text { de "casos novos" em determinado período }
$$

Incidência cumulativa $=$ 100

$\mathrm{n}^{\circ}$ de pessoas expostas ao risco no mesmo período 
RESULTADOS 


\section{RESULTADOS}

Os resultados são apresentados na seguinte sequência:

- caracterização da amostra;

- incidência e caracterização das UP: localização, classificação, gravidade e tempo para o aparecimento; e

- fatores de risco para o desenvolvimento de UP.

\subsection{CARACTERIZAÇÃO DA AMOSTRA}

A amostra do estudo foi constituída de 1196 pacientes, dos quais 890 internados nas UTI do ICHC-FMUSP, e os demais 306, na UTI e USI do HU-USP.

No presente estudo 430 pacientes não atenderam aos critérios de inclusão, 316 do ICHC-FMUSP e 114 do HU-USP: 295 pacientes (215 do ICHC-FMUSP e 80 do HU-USP) apresentaram tempo de internação inferior a 24 horas; 109 pacientes (82 do ICHC-FMUSP e 27 do HU-USP) possuíam UP prévia; 19 pacientes (13 do ICHC-FMUSP e seis do HU-USP) apresentaram dermatoses disseminadas pelo corpo e sete pacientes (seis do ICHC-FMUSP e um do HU-USP), com queimaduras extensas. A amostra do estudo foi composta, então, de 766 pacientes (574 do ICHC-FMUSP e 192 do HU-USP), que atenderam aos critérios de inclusão estabelecidos.

A Tabela 1 apresenta as características demográficas e clínicas dos pacientes. 
Tabela 1 - Distribuição dos pacientes críticos segundo as características demográficas e clínicas. São Paulo, 2012.

\begin{tabular}{|c|c|c|}
\hline $\begin{array}{c}\text { Características Demográficas } \\
\text { e Clínicas }\end{array}$ & $\mathbf{N}$ & $\%$ \\
\hline \multicolumn{3}{|l|}{ Sexo } \\
\hline Masculino & 446 & 58,2 \\
\hline Feminino & 320 & 41,8 \\
\hline TOTAL & 766 & 100,0 \\
\hline \multicolumn{3}{|l|}{ Idade (faixa etária) } \\
\hline$<45$ & 182 & 23,7 \\
\hline $45 \mid-60$ & 232 & 30,3 \\
\hline $60 \mid-85$ & 317 & 41,4 \\
\hline $85|-| 99$ & 35 & 4,6 \\
\hline TOTAL & 766 & 100,0 \\
\hline \multicolumn{3}{|l|}{ Idade (anos) } \\
\hline Média (dp) & & (56,7 (17,7) \\
\hline Mediana & & 58 \\
\hline Mínimo - Máximo & & $17-99$ \\
\hline \multicolumn{3}{|l|}{ Tipo de Internação } \\
\hline Clínica & 505 & 65,9 \\
\hline Cirúrgica Eletiva & 120 & 15,7 \\
\hline Cirúrgica Emergência & 141 & 18,4 \\
\hline TOTAL & 766 & 100,0 \\
\hline \multicolumn{3}{|l|}{ Comorbidades (ICC) } \\
\hline Média (dp) & & $1,9(2)$ \\
\hline Mediana & & 1 \\
\hline Mínimo - Máximo & & $0-13$ \\
\hline \multicolumn{3}{|l|}{ Tempo de Internação (dias) } \\
\hline Média (dp) & & $7,8(10,3)$ \\
\hline Mediana & & 4 \\
\hline Mínimo - Máximo & & $2-160$ \\
\hline \multicolumn{3}{|l|}{ SAPS II } \\
\hline Média (dp) & & $21,3(21,3)$ \\
\hline Mediana & & 12,8 \\
\hline Mínimo - Máximo & & $0,5-95,4$ \\
\hline \multicolumn{3}{|l|}{ LODS } \\
\hline Média (dp) & & $2,3(3,8)$ \\
\hline Mediana & & 0,3 \\
\hline Mínimo - Máximo & & $0,0-14,7$ \\
\hline \multicolumn{3}{|l|}{ NAS } \\
\hline Média (dp) & & 63,5(17,5) \\
\hline Mediana & & 71,6 \\
\hline Mínimo - Máximo & & $26,9-173,1$ \\
\hline
\end{tabular}

Com relação às características demográficas da amostra, na Tabela 1 observa-se que a maioria dos pacientes $(58,2 \% / 446)$ era do sexo masculino, com idade média de 56,7 anos $(\mathrm{dp}=17,7)$ e mediana de 58 anos; grande parte dos pacientes encontrava-se na faixa etária entre 60 e 84 anos (41,4\%/ 317), seguido de 30,3\% (232) com idade entre 45 e 59 anos. 
As internações clínicas (505/ 65,9\%) predominaram sobre as cirúrgicas, sendo de 7,8 dias $(\mathrm{dp}=10,3)$ a média de duração das internações, com variação de 2 a 160 dias.

Quanto à avaliação de gravidade nas primeiras 24h, a probabilidade de morte foi, em média, de 21,3\% ( $\mathrm{dp}=21,3)$, segundo o SAPS II; enquanto a probabilidade de morte ao longo do tempo foi de $0,23 \%(d p=3,7)$ em média, segundo o LODS.

Segundo o NAS, a carga de trabalho de enfermagem média foi 63,5\% $(\mathrm{dp}=17,5)$, mediana de $71,6 \%$, mínima de $26,9 \%$ e máxima de $173,1 \%$.

\subsection{INCIDÊNCIA E CARACTERIZAÇÃO DAS ÚLCERAS POR PRESSÃO}

Dentre os 766 pacientes, 143 desenvolveram UP, perfazendo incidência de 18,7\%.

A Tabela 2 apresenta a distribuição das UP segundo sua classificação e localização anatômica.

Tabela 2 - Distribuição das úlceras por pressão segundo classificação e localização anatômica. São Paulo, 2012.

\begin{tabular}{|c|c|c|c|c|c|c|c|c|c|c|}
\hline \multirow{3}{*}{ Localização } & \multicolumn{8}{|c|}{ "Classificação } & \multirow{2}{*}{\multicolumn{2}{|c|}{ TOTAL }} \\
\hline & \multicolumn{2}{|c|}{ I } & \multicolumn{2}{|c|}{ II } & \multicolumn{2}{|c|}{ III } & \multicolumn{2}{|c|}{ UPNC } & & \\
\hline & $\mathbf{n}$ & $\%$ & $\mathbf{n}$ & $\%$ & $\mathbf{N}$ & $\%$ & $\bar{n}$ & $\%$ & $\mathbf{n}$ & $\%$ \\
\hline Sacro & 61 & $\overline{42,6}$ & 445 & 31,5 & $\overline{11}$ & 0,7 & 7 & 44,9 & 114 & 799,7 \\
\hline Calcâneo & 7 & 4,9 & 7 & 4,9 & - & - & - & - & 14 & 9,8 \\
\hline Glúteo & 1 & 0,7 & 3 & 2,1 & - & - & - & - & 4 & 2,8 \\
\hline Trocânter & 2 & 1,4 & 2 & 1,4 & - & - & - & - & 4 & 2,8 \\
\hline Orelha & 1 & 0,7 & 2 & 1,4 & - & - & - & - & 3 & 2,1 \\
\hline Cotovelo & - & - & 1 & 0,7 & - & - & - & - & 1 & 0,7 \\
\hline Escápula & - & - & 1 & 0,7 & - & - & - & - & 1 & 0,7 \\
\hline Occipício & - & - & - & - & - & - & 1 & 0,7 & 1 & 0,7 \\
\hline Nariz & - & - & 1 & 0,7 & - & - & - & - & 1 & 0,7 \\
\hline TOTAL & 72 & 50,3 & 62 & 43,3 & 1 & 0,7 & 8 & 5,6 & 143 & 100,0 \\
\hline
\end{tabular}

Do total de 143 UP, 50,3\% (72) foram classificadas na Categoria I e 43,3\% (62), na Categoria II. Não foram diagnosticadas UP nas Categorias IV e SLTP.

A localização anatômica mais frequente foi a sacral $(79,7 \% / 114)$, das quais $42,6 \%$ (61) classificaram-se como Categoria I e 31,5\% (45) como Categoria II. 
A gravidade do dano foi considerada fraca para 51,0\% (73) das UP, moderada para $42,7 \%(61)$ e grave para $6,3 \%(9)$.

Em média, as UP desenvolveram-se em 6,9 dias $(\mathrm{dp}=5,9)$, com mediana de 4 dias, mínimo de 2 e máximo de 30 dias.

\subsection{FATORES DE RISCO PARA O DESENVOLVIMENTO DE ÚLCERAS POR PRESSÃO}

A Tabela 3 apresenta as associações entre as variáveis demográficas (sexo e idade) e UP.

Tabela 3 - Associações entre as variáveis demográficas sexo e idade e úlcera por pressão. São Paulo, 2012.

\begin{tabular}{|c|c|c|c|c|c|c|c|}
\hline \multirow{3}{*}{$\begin{array}{c}\text { Variáveis } \\
\text { Demográficas }\end{array}$} & \multicolumn{4}{|c|}{ Úlcera por Pressão } & \multirow{2}{*}{\multicolumn{2}{|c|}{ TOTAL }} & \multirow{3}{*}{ valor-p } \\
\hline & \multicolumn{2}{|c|}{ Ausente } & \multicolumn{2}{|c|}{ Presente } & & & \\
\hline & 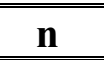 & $\%$ & $\bar{n}$ & $\%$ & $\mathbf{n}$ & $\%$ & \\
\hline \multicolumn{8}{|l|}{ Sexo } \\
\hline Masculino & 355 & 79,6 & 91 & 20,4 & 446 & 100,0 & \multirow{3}{*}{$0,146^{1}$} \\
\hline Feminino & 268 & 83,8 & 52 & $16,2 \%$ & 320 & 100,0 & \\
\hline TOTAL & 623 & 81,3 & 143 & 18,7 & 766 & 100,0 & \\
\hline \multicolumn{8}{|c|}{ Idade (faixa etária) } \\
\hline$<45$ & 158 & 86,8 & 24 & 13,2 & 182 & 100,0 & \multirow{5}{*}{$0,058^{1}$} \\
\hline $45 \mid-60$ & 192 & 82,8 & 40 & 17,2 & 232 & 100,0 & \\
\hline $60 \mid-85$ & 247 & 77,9 & 70 & 22,1 & 317 & 100,0 & \\
\hline $85 \mid-100$ & 26 & 74,3 & 9 & 25,7 & 35 & 100,0 & \\
\hline TOTAL & 623 & 81,3 & 143 & 18,7 & 766 & 100,0 & \\
\hline \multicolumn{8}{|l|}{ Idade (anos) } \\
\hline Média (dp) & \multicolumn{2}{|c|}{$55,8(17,8)$} & \multicolumn{2}{|c|}{$60,4(17,2)$} & \multicolumn{2}{|c|}{$56,7(17,7)$} & \\
\hline Mediana & \multicolumn{2}{|c|}{57,0} & \multicolumn{2}{|c|}{61,0} & \multicolumn{2}{|c|}{58,0} & $0,005^{2}$ \\
\hline Mínimo-Máximo & \multicolumn{2}{|c|}{$17-99$} & \multicolumn{2}{|c|}{$19-93$} & \multicolumn{2}{|c|}{$17-99$} & \\
\hline
\end{tabular}

1. Qui-quadrado de Pearson $\quad$ 2. Teste de Mann-Whitney

Pacientes com maior idade apresentaram maiores incidências de UP $(\mathrm{p}=0,005$, para a média, e $\mathrm{p}=0,058$, limítrofe para as faixas etárias) com maiores coeficientes a partir dos 60 anos. Ao reunirem-se as faixas etárias 60 a 84 anos e 85 ou mais, verifica-se incidência de $47,8 \%$. 
A Tabela 4 apresenta as associações entre as variáveis clínicas e UP.

Tabela 4 - Associações entre as variáveis clínicas e úlcera por pressão. São Paulo, 2012.

\begin{tabular}{|c|c|c|c|c|c|c|c|}
\hline \multirow{3}{*}{ Variáveis Clínicas } & \multicolumn{4}{|c|}{ Úlcera por Pressão } & \multirow{2}{*}{\multicolumn{2}{|c|}{ TOTAL }} & \multirow{3}{*}{ valor-p } \\
\hline & \multicolumn{2}{|c|}{ Ausente } & \multicolumn{2}{|c|}{ Presente } & & & \\
\hline & n & $\%$ & $\bar{n}$ & $\%$ & $\bar{n}$ & $\%$ & \\
\hline \multicolumn{8}{|c|}{ Diagnóstico de Admissão } \\
\hline Digestório & 96 & 15,4 & 15 & 10,5 & 144 & 14,5 & \multirow{10}{*}{$0,189^{1}$} \\
\hline Neurológico & 92 & 14,8 & 28 & 19,6 & 120 & 15,7 & \\
\hline Circulatório & 93 & 14,9 & 15 & 10,5 & 108 & 14,1 & \\
\hline Traumatológico & 85 & 13,6 & 22 & 15,4 & 107 & 14,0 & \\
\hline Infeccioso & 66 & 10,6 & 20 & 14,0 & 86 & 11,2 & \\
\hline Respiratório & 65 & 10,4 & 18 & 12,6 & 83 & 10,8 & \\
\hline Neoplásico & 58 & 9,3 & 14 & 9,8 & 72 & 9,4 & \\
\hline Outros & 50 & 8,0 & 5 & 3,5 & 55 & 7,2 & \\
\hline Urológico & 18 & 2,9 & 6 & 4,2 & 24 & 3,1 & \\
\hline TOTAL & 623 & 100,0 & 143 & 100,0 & 766 & 100,0 & \\
\hline \multicolumn{8}{|l|}{ Tipo de Internação } \\
\hline Clínica & 404 & 80,0 & 101 & 20,0 & 505 & 100,0 & \multirow{4}{*}{$0,056^{1}$} \\
\hline Cirúrgica Eletiva & 107 & 89,2 & 13 & 10,8 & 120 & 100,0 & \\
\hline Cirúrgica Emergência & 112 & 79,4 & 29 & 20,6 & 141 & 100,0 & \\
\hline TOTAL & 623 & 81,3 & 143 & 18,7 & 766 & 100,0 & \\
\hline \multicolumn{8}{|l|}{ Cuidados Paliativos } \\
\hline Não & 620 & 82,8 & 129 & 17,2 & 749 & 100,0 & \multirow{3}{*}{$<0,001^{1}$} \\
\hline Sim & 3 & 17,6 & 14 & 82,4 & 17 & 100,0 & \\
\hline TOTAL & 623 & 81,3 & 143 & 18,7 & 766 & 100,0 & \\
\hline \multicolumn{8}{|l|}{ Condição de Saída } \\
\hline Não sobrevivente & 78 & 60,9 & 50 & 39,1 & 128 & 100,0 & \multirow{3}{*}{$<0,001^{1}$} \\
\hline Sobrevivente & 545 & 85,4 & 93 & 14,6 & 638 & 100,0 & \\
\hline TOTAL & 623 & 81,3 & 143 & 18,7 & 766 & 100,0 & \\
\hline \multicolumn{8}{|l|}{ Colchão } \\
\hline Piramidal & 3 & 37,5 & 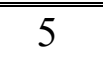 & 62,5 & 8 & 100,0 & \multirow{4}{*}{$0,017^{1}$} \\
\hline Pneumático & 80 & 81,6 & 18 & 18,4 & 98 & 100,0 & \\
\hline Convencional & 534 & 81,7 & 120 & 18,3 & 654 & 100,0 & \\
\hline TOTAL & 617 & 81,2 & 143 & 18,8 & 760 & 100,0 & \\
\hline \multicolumn{8}{|l|}{ ICC } \\
\hline Média (dp) & \multicolumn{2}{|c|}{$1,9(2)$} & \multicolumn{2}{|c|}{$2(1,9)$} & \multicolumn{2}{|c|}{$1,9(2)$} & \\
\hline Mediana & \multicolumn{2}{|c|}{1} & \multicolumn{2}{|c|}{1} & \multicolumn{2}{|c|}{1} & $0,299^{2}$ \\
\hline Mínimo-Máximo & & & & & & -13 & \\
\hline Tempo de Internação & n dias & & & & & & \\
\hline Média $(\mathrm{dp})$ & 5,9 & & & $7,4)$ & 7,8 & $(10,3)$ & \\
\hline Mediana & & & & & & 4 & $<0,001^{2}$ \\
\hline Mínimo-Máximo & & & & & & 160 & \\
\hline SAPS II & & & & & & & \\
\hline Média (dp) & 20,8 & $0,8)$ & 23, & $23,5)$ & 21,3 & $(21,3)$ & \\
\hline Mediana & & & & & & 2,8 & $0,205^{2}$ \\
\hline Mínimo-Máximo & 0,5 & & 0, & 95,4 & 0,5 & $-95,4$ & \\
\hline
\end{tabular}




\section{LODS}

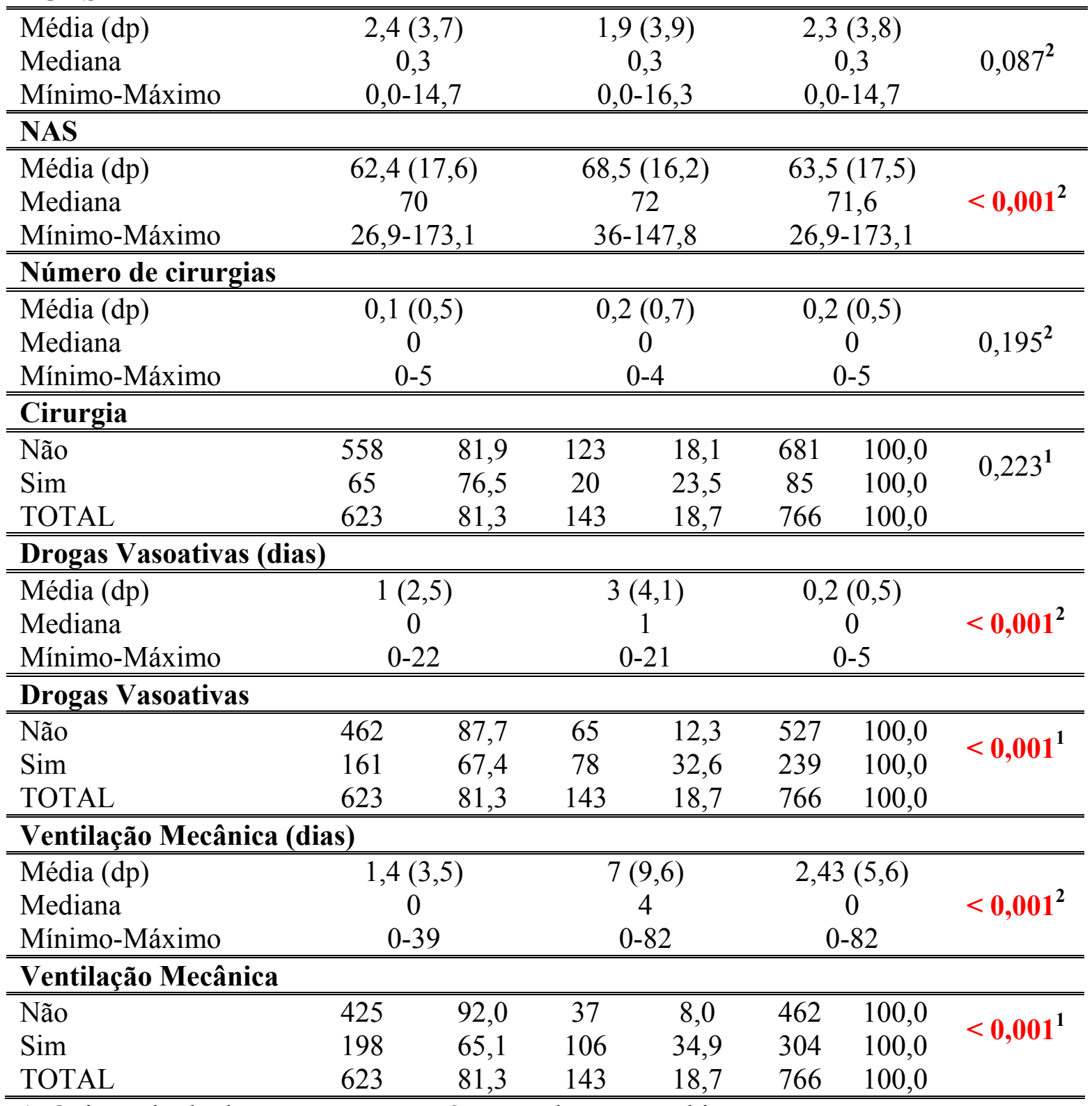

1. Qui-quadrado de Pearson 2. Teste de Mann-Whitney

De acordo com a Tabela 4, observa-se que a incidência de UP foi maior entre os pacientes que estavam em cuidados paliativos $(\mathrm{p}<0,001)$, assim como entre aqueles que foram $a$ óbito $(\mathrm{p}<0,001)$.

Com relação ao tipo de colchão, houve diferença estatisticamente significativa $(p=0,017)$ entre os grupos. A incidência de UP $(62,5 \%)$ foi maior entre aqueles que permaneceram em colchonete piramidal. 
Comparando-se a média do tempo de internação entre os grupos com e sem UP, constata-se que houve diferença estatisticamente significativa $(p<0,001)$, ou seja, os pacientes que desenvolveram UP permaneceram, em média, internados por mais dias.

Houve ainda diferença estatisticamente significativa $(\mathrm{p}<0,001)$ quanto à média do NAS. Para os pacientes que desenvolveram UP, a média foi de $68,5 \%(\mathrm{DP}=16,2)$, mediana de $72 \%$, com variação de $36 \%$ a $147,8 \%$; já para aqueles que não desenvolveram UP, foi de $62,4 \%$ (DP=17,6), mediana de 70\%, mínima de 26,9\% e máxima de $173,1 \%$. Ao converterem-se esses resultados em horas de assistência, os pacientes que desenvolveram UP demandaram 16,4 horas, enquanto os que não as desenvolveram, demandaram 15 horas de assistência de enfermagem.

A incidência de UP $(32,6 \%)$ foi superior entre aqueles que fizeram uso de drogas vasoativas $(\mathrm{p}<0,001)$. Comparando-se as médias do número de dias em uso de drogas vasoativas, observa-se que a diferença também foi estatisticamente significativa $(p<0,001)$ entre os grupos, superior para aqueles que desenvolveram UP ( 3 dias/ $\mathrm{DP}=4,1$ e $1 \mathrm{dia} / \mathrm{DP}=2,5$ respectivamente).

Pacientes que permaneceram em ventilação mecânica apresentaram incidência maior de UP $(p<0,001)$. Houve diferença estatisticamente significativa $(p<0,001)$ também com relação à média do número de dias em ventilação mecânica. Dentre os pacientes que desenvolveram UP, a média foi de 7 dias $(\mathrm{DP}=9,6)$, sendo de 1,4 dias $(\mathrm{DP}=3,5)$ para aqueles sem UP.

A Tabela 5 apresenta a regressão logística das variáveis de interesse para a incidência de UP. Tabela 5 - Regressão logística* das variáveis de interesse para a incidência de úlcera por pressão (n=760). São Paulo, 2012.

\begin{tabular}{lccc}
\hline \multicolumn{1}{c}{ Variáveis } & Odds ratio & IC 95\% & valor-p \\
\hline \hline $\begin{array}{l}\text { Ventilação } \\
\text { Mecânica }\end{array}$ & 3,479 & $2,190-5,528$ & $<\mathbf{0 , 0 0 1}$ \\
$\begin{array}{l}\text { Cuidados } \\
\begin{array}{l}\text { Paliativos } \\
\text { Tempo }\end{array}\end{array}$ & 7,829 & $1,927-31,817$ & $\mathbf{0 , 0 0 4}$ \\
$\begin{array}{l}\text { Internação } \\
\text { NAS }\end{array}$ & 1,101 & $1,071-1,132$ & $<\mathbf{0 , 0 0 1}$ \\
Faixa Etária & 1,015 & $1,003-1,027$ & $\mathbf{0 , 0 1 6}$ \\
$\quad \mathbf{4 5 - 5 9}$ & 1,627 & $0,858-3,087$ & 0,136 \\
$\quad \mathbf{6 0 - 8 4}$ & 2,331 & $1,283-4,236$ & $\mathbf{0 , 0 0 5}$ \\
$\quad \mathbf{8 5 +}$ & 2,695 & $0,945-7,683$ & 0,064 \\
\hline \hline
\end{tabular}

*Método Stepwise Forward 
Os dados da Tabela 5 mostram que pacientes em ventilação mecânica apresentam três vezes e meia maior chance de desenvolver UP; estar em cuidados paliativos aumenta a chance de UP em 7,8 vezes; cada dia a mais de internação aumenta em 10,1\% a chance de UP; cada ponto do NAS aumenta a chance de UP em 1,5\%; entre 60 e 84 anos a chance é 2,3 vezes maior de UP do que quem tem menos de 45 anos e a partir dos 85 anos, a chance é 2,7 vezes maior de UP do que quem tem menos de 45 anos. 


\section{DISCUSSÃO}

A discussão é composta dos seguintes tópicos:

- incidência de UP;

- fatores de risco para o desenvolvimento de UP; e

- carga de trabalho de enfermagem e UP.

\subsection{INCIDÊNCIA DE ÚLCERA POR PRESSÃO}

A incidência de UP é considerada importante indicador da qualidade da assistência prestada, além de ser utilizada como parâmetro na avaliação das estratégias e protocolos para a sua prevenção.

Neste estudo, a incidência de UP foi de 18,7\%. No Brasil, Ventura e colaboradores, 2014 acompanhando 64 pacientes internados em uma UTI pública, encontraram incidência de UP de 18,8\%; enquanto que na Bélgica, Nijs e colaboradores, ${ }^{2009}$ em 520 pacientes de uma UTI cirúrgica de longa permanência em um hospital universitário, obtiveram incidência de $20,1 \%$.

Nos últimos 10 anos, a incidência de UP em UTI no Brasil variou de 10,8\% ${ }^{\text {Campanili et }}$ al., 2015 a 50,0\% Fernandes e Torres, 2008 (Quadro 1) e de 3,0\% Frankel et al., 2007 a 33,3\% Suriadi et al., 2007 (Quadro 2) ao redor do mundo. Diferenças na população do estudo, qualidade da assistência prestada, presença de protocolos de prevenção e, principalmente, na metodologia e na condução dos estudos são alguns dos fatores que podem contribuir para a variabilidade dos resultados, dificultanto as comparações. No entanto, admitindo-se que a maioria das UP é evitável, a incidência encontrada na grande maioria desses estudos pode ser considerada alta. Levando-se em conta que a UP é um evento adverso e que sua incidência, um indicador de qualidade da assistência, muito ainda precisa ser feito no âmbito da prevenção, no intuito de alcançar índices mais aceitáveis. 


\subsection{FATORES DE RISCO PARA O DESENVOLVIMENTO DE ÚLCERA POR PRESSÃO}

As alterações fisiológicas e a susceptibilidade às doenças, inerentes ao envelhecimento, comprometem a capacidade dos tecidos em tolerar a pressão e expõem os idosos às UP mais do que qualquer outro grupo de risco. Bergstrom e Braden, 1992; Bergstrom et al., 1996; Bours et al., 2001; Burd et al., 1992; Campanili et al., 2015Cox, 2011; Eachempati et al., 2001; Frankel et al., 2007; Gosnell et al., 1992; Hoshowsky e Schramm, 1994; Lindgren et al., 2004; Nixon et al., 2006; Ooi et al., 1999; Perneger et al., 2002; Schultz et al., 1999; Shahin et al., 2008; Slowikowski e Funk, 2010; Theaker et al., 2000; Williams et al., 2001

O aumento da idade vem sendo apontado como um importante preditor no desenvolvimento de UP em variados cenários. Bergstrom e Braden, 1992; Bergstrom et al., 1996; Bours et al., 2001; Burd et al., 1992; Campanili et al., 2015Cox, 2011; Eachempati et al., 2001; Frankel et al., 2007; Gosnell et al., 1992; Hoshowsky e Schramm, 1994; Lindgren et al., 2004; Nixon et al., 2006; Ooi et al., 1999; Perneger et al., 2002; Schultz et al., 1999; Shahin et al., 2008; Slowikowski e Funk, 2010; Theaker et al., 2000; Williams et al., 2001 Alguns estudos Burd et al., 1992; Gosnell et al., 1992, Lindgren et al., 2004; Williams et al., 2001 apontam que o risco para UP é maior em pacientes acima dos 65 anos de idade.

Especificamente em pacientes críticos, vários são os estudos Bours et al., 2001;Campanili et al., 2015; Cox, 2011; Eachempati et al., 2001; Frankel et al., 2007; Shahin et al., 2008; Slowikowski e Funk, 2010; Theaker et al., 2000 que identificaram relação entre idade avançada e desenvolvimento de UP.

Neste estudo, dentre aqueles com 60 a 84 anos, a chance de desenvolver UP foi 2,3 vezes maior do que entre aqueles com menos de 45 anos e, a partir dos 85 anos, essa chance foi ainda um pouco superior (2,7 vezes) comparativamente àqueles com idade inferior a 45 anos.

Frankel e colaboradores, ${ }^{2007}$ que avaliaram os registros relacionados às UP em prontuários de 820 pacientes internados em uma UTI cirúrgica de um hospital universitário, corroboram os achados deste estudo ao apontarem idade acima de 60 anos como fator de risco para UP.

Cox, ${ }^{2011}$ que também avaliou registros de pacientes $(n=347)$ admitidos em uma UTI médico-cirúrgica, buscou correlacionar quais fatores de risco eram mais preditivos para os pacientes críticos. Idade avançada foi considerada importante fator preditor, sendo de 73 anos, a média etária daqueles que desenvolveram UP. 
Maior predisposição ao desenvolvimento de UP relacionado à idade também foi encontrada por Campanili e colaboradores. ${ }^{2015}$ Em coorte que acompanhou 370 pacientes internados em uma UTI cardiopneumológica de um hospital universitário, 6,48\% dos pacientes com idade igual ou superior a 60 anos desenvolveram UP. De acordo com a análise Classification And Regression Tree (CART), para esse fator de risco, idade igual ou superior a 42,5 anos discriminou mais adequadamente o grupo que desenvolveu UP.

Além do envelhecimento, outro fator é determinante para a fragilidade da pele: o fim da vida. Langemo e Brown, 2006; Santos, 2009; Sibbald et al., 2010; Worley, 2007 A pele, como qualquer outro órgão, também pode entrar em falência. Quando o processo de morrer compromete os mecanismos homeostáticos do corpo, os órgãos começam a sofrer e o corpo pode reagir desviando sangue da pele para órgãos vitais, resultando na diminuição da perfusão da pele e das partes moles e, consequentemente, no comprometimento dos processos metabólicos cutâneos. Pequenos traumas são capazes de ocasionar complicações maiores como hemorragia, gangrena, infecção, lesão por fricção e UP. A tolerância à pressão e à fricção diminui de tal maneira que pode se tornar quase impossível prevenir a quebra da integridade da pele e consequentes infecções oportunistas. Olshansky, 2010; Santos, 2009; Sibbald et al., 2010; Yastrub, 2010

O comprometimento da resposta imunológica também tem um papel fundamental, especialmente nos pacientes com câncer em estágio avançado e aqueles em tratamento com corticóides e agentes imunossupressores. Com as mudanças da pele ao final da vida, é muito difícil protegê-la das agressões do meio, a despeito de qualquer tipo de cuidado preventivo. Langemo et al., 2007; Santos, 2009; Sibbald et al., 2010; Worley, 2007

Fatores de risco, sintomas e sinais associados às mudanças da pele ao final da vida não estão muito bem elucidados e são frequentemente relacionados a outros fatores como idade, doenças preexistentes e reações adversas a medicamentos. Entre os mais frequentes estão fraqueza e limitação progressiva da mobilidade, perda de apetite, de peso, caquexia, debilidade, baixo nível sérico de albumina, pré-albumina e hemoglobina, desidratação, redução de perfusão tissular e da temperatura da pele, deficiência de oxigenação, descoramento, necrose e perda da integridade da pele, este último devido a incontinência, irritantes químicos, exposição crônica a fluidos corporais, pressão, fricção, cisalhamento e infecções, além de função imunológica deficiente. Langemo et al., 2007; Santos, 2009; Sibbald et al., 2010; Yastrub, 2010

Dado que as mudanças fisiológicas que acontecem como resultado do processo de morrer afetam substancialmente a pele e as partes moles, indivíduos em cuidados paliativos, 
em fase final de vida, são considerados de alto risco para o desenvolvimento de UP. Langemo e Brown, 2006; Langemo et al., 2007; Olshansky, 2010; Santos, 2009; Sibbald et al., 2010; Worley, 2007; Yastrub, 2010

Neste estudo, segundo a análise de regressão logística, estar em cuidados paliativos aumentou a chance de UP em 7,8 vezes.

O tempo de internação tem se constituído em importante fator de risco para o desenvolvimento de UP e outras lesões em pacientes críticos. Cada dia a mais de internação aumentou em 10,1\% a chance de desenvolver UP, para os pacientes que participaram deste estudo. Tempo de internação na UTI também esteve relacionado ao desenvolvimento de UP em vários outros estudos, corroborando os achados desta investigação. Campanili et al., 2015; Cox, 2011; Fernandes e Torres, 2008; Sayar et al., 2008; Terekeci et al., 2009

Em estudo prospectivo, Sayar e colaboradores, ${ }^{2008}$ acompanhando 140 pacientes internados em três UTI (médica, cirúrgica e de reanimação) de um hospital universitário, referiram que cada dia a mais de internação aumentou em $20 \%$ a chance de desenvolver UP, aproximadamente o dobro da porcentagem aqui obtida. Fernandes e Torres ${ }^{2008}$ identificaram associação entre tempo de permanência na UTI superior a 7 dias e a ocorrência de duas UP em 40 pacientes internados em duas UTI, uma geral e outra cardiológica, de um hospital privado. Outros autores como Terekeci e colaboradores ${ }^{2009}$ e Cox ${ }^{2011}$ também encontraram esse tipo de associação significativa entre o tempo de permanência em UTI e o desenvolvimento de UP. No último estudo, a média de permanência na UTI para pacientes que desenvolveram UP foi de 11,7 dias comparativamente a 3,3 dias para aqueles que não a desenvolveram. Para Campanili e colaboradores, ${ }^{2015}$ em estudo já citado anteriormente, a análise CART mostrou que tempo de permanência na UTI maior ou igual a 9,5 dias também classificou os pacientes com UP. Todos esses achados confirmam o maior tempo de internação em UTI como um dos preditores para a ocorrência de UP.

Além dos fatores de risco já descritos, o suporte ventilatório destacou-se como um dos fatores determinantes de maiores chances para o desenvolvimento de UP em pacientes críticos $(\mathrm{OR}=3,479)$. Intervenção comum nesse tipo de paciente, a ventilação mecânica pode levar à diminuição do retorno venoso ao coração, do volume final diastólico do ventrículo esquerdo, do débito cardíaco e à hipotensão, ocasionando diminuição da perfusão tissular. A diminuição da oxigenação pode levar à morte celular e necrose dos tecidos. Quando a pressão nas proeminências ósseas associa-se à diminuição da perfusão tissular, a isquemia leva à formação da UP. Apostolopoulou et al., 2014; Manzano et al., 2010; Pender e Frazier, 2005

Juntamente aos problemas de oxigenação, a ventilação mecânica também torna os pacientes mais vulneráveis às UP, uma vez que limita as possibilidades de movimentação no 
leito. Além do próprio aparato tecnológico dificultar as mudanças no posicionamento, a instabilidade hemodinâmica, normalmente presente nos pacientes que necessitam desse tipo de suporte, pode restringir e até mesmo impedir as mudanças de decúbito periódicas. Apostolopoulou et al., 2014; Manzano et al., 2010; Pender e Frazier, 2005 Deve-se considerar ainda diminuição da capacidade sensorial devida a sedação e analgesia a que, não raro, os pacientes em ventilação mecânica são submetidos, dificultando sobremaneira as mudanças efetivas em seu posicionamento. Apostolopoulou et al., 2014; Manzano et al., 2010; Pender e Frazier, 2005

Pender e Frazier, ${ }^{2005}$ único estudo transversal acerca da influência da ventilação mecânica no desenvolvimento de UP, encontraram prevalência de $20 \%$ em 40 pacientes submetidos a suporte ventilatório. Apenas dois estudos Apostolopoulou et al., 2014; Manzano et al., 2010 avaliaram a incidência de UP, especificamente em pacientes em ventilação mecânica.

Em um estudo de coorte prospectivo em nove UTI médico-cirúrgicas da Espanha, Manzano e colaboradores, ${ }^{2010}$ apontam incidência de UP de $16 \%$ em pacientes mecanicamente ventilados e incidência por densidade de 13,5 UP por 1000 pacientes-dias de permanência em UTI. No outro estudo prospectivo em duas UTI médico-cirúrgicas gregas, Apostolopoulou e colaboradores ${ }^{2014}$ constataram incidência de 29,6\% de UP também em pacientes sob ventilação mecânica, e coeficientes de incidência por densidade de 14 UP por 1000 ventilações mecânicas-dia e de 13,9 UP por 1000 pacientes-dias de permanência em UTI.

Segundo os achados do presente estudo, pacientes em ventilação mecânica tem três vezes e meia maior chance de desenvolver UP. Nijs e colaboradores, ${ }^{2009}$ obtiveram maior OR, de cerca de cinco vezes maior chance de UP em pacientes submetidos à ventilação mecânica em uma UTI cirúrgica de longa permanência de um hospital universitário.

Tempo de internação prolongado e aumento da carga de trabalho requerida são apontados como os principais fatores de oneração dos custos associados ao tratamento das UP. Aproximadamente $6 \%$ dos pacientes que adquirem UP acabam permanecendo mais tempo internados, Allman e Laprade, 1986; Kuhn e Coulter, 1992 enquanto que a demanda de cuidados para a equipe de enfermagem chega a aumentar em $50 \%$. Barratt, ${ }^{1987}$ No que se refere ao custo adicional, essa ocorrência representou 8,5 bilhões de dólares anuais para os EUA nas décadas de 80 Allman e Laprade, 1986 e 90. Kuhn e Coulter, 1992 


\subsection{CARGA DE TRABALHO DE ENFERMAGEM E ÚLCERA POR PRESSÃO}

Para este estudo, a carga média de trabalho de enfermagem, segundo o NAS, foi de $63,5 \%$; o que equivale a dizer que, em média, foram gastas 15,2 horas de assistência de enfermagem por paciente-dia. Estudos nacionais, Altafin et al., 2014; Conishi e Gaidzinski, 2007; Dias, 2008; Ducci e Padilha, 2008; Ducci et al., 2008; Feitosa et al., 2012; Gonçalves et al., 2006; 2012; Inoue et al., 2011; Leite et al., 2012; Nogueira et al., 2007; 2013; Queijo e Padilha, 2009; Padilha et al., 2010; Silva, 2008 que também utilizaram o NAS para aferição da carga de trabalho de enfermagem em UTI, encontraram valores médios que variaram de $51,5 \%{ }^{\text {Nogueira et al., } 2007}$ a 104\%. Inoue et al., $2011 \mathrm{Na}$ literatura internacional Adell et al., 2005; 2006; CarmonaMonge et al., 2013; Lucchini et al., 2014; Stafseth et al., 2011 as médias variaram de 41\% Adell et al., 2006 a 96,2\%. Stafseth et al., 2011

As diferentes pontuações do NAS, encontradas nesses estudos, poderiam ser explicadas pelas características dos pacientes internados nessas UTI, pela própria natureza dos hospitais, além de diferenças técnicas e operacionais na aplicação do instrumento.

Especificamente para aqueles que desenvolveram UP, a média do NAS aqui verificada foi de $68,5 \%$, sendo de $62,4 \%$ para aqueles que não a desenvolveram. Em tempo gasto nas intervenções realizadas pela equipe de enfermagem, esses percentuais representam 16,4 e 15 horas de assistência de enfermagem por paciente-dia para os pacientes com e sem UP, respectivamente. Segundo a análise de regressão logística, cada ponto do NAS aumentou a chance de UP em 1,5\%. Maior demanda de trabalho aumenta as chances de ocorrerem falhas na execução dos protocolos assistenciais de prevenção de UP e, portanto, eleva o risco para a ocorrência desse evento adverso. Oliveira, 2012

Há evidências de que a carga de trabalho é um dos mais importantes estressores entre os enfermeiros de UTI, interferindo nos resultados da assistência prestada. Blegen et al., 1998; Carayon e Gurses, 2005; Inoue e Matsuda, 2010; Laschinger e Leiter, 2006; Robert et al., 2000 Há ainda evidências de que a excessiva carga de trabalho de enfermagem resulta em aumento da incidência de UP nessas unidades. Al-Kandari e Thomas, 2009; Blegen et al., 1998; Oliveira, 2012; Stone et al., 2007

Estudo transversal realizado nas clínicas médicas e cirúrgicas de cinco hospitais gerais

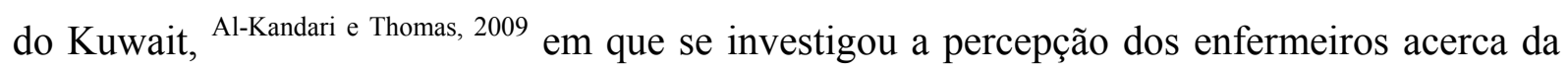
ocorrência de eventos adversos relacionados à carga de trabalho de enfermagem, também mostrou correlação entre o aumento da carga de trabalho e o desenvolvimento de UP. No Brasil, Oliveira ${ }^{2012}$ investigou as associações entre os escores NAS e Braden, na ocorrência 
de UP, em pacientes internados em UTI geral de um hospital de grande porte de Belo Horizonte. Para aqueles que desenvolveram UP, a média do NAS foi de 66,1\% e, para cada 10 pontos acrescidos no NAS, a chance de ocorrência de UP elevou-se 1,1 vezes.

Diferentemente desses estudos, Cremasco e colaboradores, ${ }^{2009}$ não constataram associação entre carga de trabalho de enfermagem e risco para o desenvolvimento de UP. Os autores investigaram as associações entre os escores NAS e Braden, na ocorrência de UP, em pacientes internados em três UTI de um hospital universitário, de nível terciário, localizado em São Paulo. Para eles, uma elevada carga de trabalho significaria que o paciente estaria suficientemente assistido e, por conseguinte, isso reduziria a ocorrência de UP. Registros analisados por Stone e colaboradores. ${ }^{2007}$ também mostraram que o maior número de horas de assistência de enfermagem por paciente-dia associou-se significativamente à baixa incidência de UP em 15.846 pacientes idosos, internados em 51 UTI de 31 hospitais norte-americanos. 
CONCLUSÃO 


\section{CONCLUSÃO}

O estudo sobre a incidência de UP e os fatores de risco para seu desenvolvimento em UTI possibilitou concluir que:

- a incidência de UP foi de 18,7\%;

- maior idade mostrou chances maiores de desenvolvimento de UP. Entre 60 e 84 anos a chance foi 2,3 vezes maior do que quem tinha menos de 45 anos e, a partir dos 85 anos, a chance foi 2,7 vezes maior;

- estar em cuidados paliativos aumentou a chance de desenvolver UP em 7,8 vezes;

- cada dia a mais de internação aumentou em 10,1\% a chance de desenvolver UP;

- pacientes em ventilação mecânica tiveram três vezes e meia maior chance de desenvolver UP; e

- cada ponto do NAS aumentou a chance de desenvolver UP em 1,5\%. 
CONSIDERAÇÕES FINAIS 


\section{CONSIDERAÇÕES FINAIS}

Estudos da incidência de UP e dos fatores associados ao seu desenvolvimento oferecem a oportunidade de conhecer e, sobretudo, de refletir sobre uma ocorrência frequente na prática clínica.

Certamente, este estudo permite ampliar as evidências científicas acerca do desenvolvimento das UP, assim como dos fatores de risco associados ao seu desenvolvimento. Além disso, espera-se que também possa contribuir para o estabelecimento de estratégias voltadas à melhoria dos coeficientes aqui apresentados e na implementação de programas de prevenção dessas lesões, visando à melhoria na qualidade da assistência prestada e conferindo maior segurança aos pacientes.

Apesar da importância dos resultados obtidos, algumas limitações devem ser mencionadas.

A principal refere-se às limitações próprias do desenho retrospectivo do estudo. A revisão de prontuários pode incorrer no viés retrospectivo, ou seja, na tendência de imputar causa quando o resultado é previamente conhecido.

Como o estudo foi baseado na análise de prontuários e não no exame direto dos pacientes envolvidos, a incidência real de UP pode estar subestimada. Isso se deve à falta de uniformidade nos critérios diagnósticos, bem como na classificação das UP, entre as diversas unidades de internação; especialmente no HCFMUSP, onde a avaliação pela Escala de Braden havia sido recentemente introduzida, não havendo ainda protocolo assistencial de prevenção de UP. Assim, têm-se diagnósticos e classificação de UP realizados por profissionais que não contaram com uma capacitação prévia dentro de um protocolo único, podendo comprometer a qualidade dos registros.

Por fim, apesar do presente estudo ter sido realizado em duas instituições de diferentes complexidades, ele não pode ser considerado multicêntrico e, portanto, generalizações devem ser consideradas com cautela. 
REFERÊNCIAS 


\section{REFERÊNCIAS}

Adell AB, Campos RA, Bou MY, Bellmunt JQ, Garcia CG, Canuto MS, et al. Care workload in critical patients: comparative study NEMS versus NAS. Enferm Intensiva. 2006; 17(2):6777.

Adell AB, Campos RA, Cubedo RM, Quintana BJ, Sanahuja RE, Sanchís MJ, et al. Nursing Activity Score (NAS): our experience with a nursing load calculation system based on times. Enferm Intensiva. 2005; 16(4):164-73.

Al-Kandari F, Thomas D. Perceived adverse patient outcomes correlated to nurses' workload in medical and surgical wards of selected hospitals in Kuwait. J Clin Nurs. 2009; 18:581-90.

Allegranzi B, Storr J, Dziekan G, Leotsakos A, Donaldson L, Pittet D. The first global patient safety challenge "Clean Care is Safer Care": from launch to current progress and achievements. J Hosp Infect. 2007; 65(Supp12):115-23.

Allman R, Laprade C. Pressure sores amount hospitalized patients. Int Med. 1986; 105(3):337-42.

Altafin JAM, Grion CMC, Tanita MT, Festti J, Cardoso LTQ, Veiga CFF et al. Nursing Activities Score e carga de trabalho em unidade de terapia intensiva de hospital universitário. Rev Bras Ter Intensiva. 2014; 26(3):292-8.

Apostolopoulou E, Tselebis Athanasios, Terzis K, Kamarinou E, Lambropoulos I, Kalliakmanis A. Pressure ulcer incidence and risk factors in ventilated intensive care patients. Health Sci J. 2014; 8(3):333-42.

Aranaz-Andrés JM, Aibar-Remón C, Limón-Ramírez R, Amarilla A, Restrepo FR, Urroz O et al. Diseño del estudio IBEAS: prevalencia de efectos adversos en hospitales de Latinoamérica. Rev Calid Asist. 2011; 26(3):194-200.

Ayello EA, Braden B. How and why to do pressure ulcer risk assessment. Adv Skin Wound Care. 2002; 15(3):125-33.

Baharestani MM, Black JM, Carville K, Clark M, Cuddigan JE, Dealey C et al. Dilemmas in measuring and using pressure ulcer prevalence and incidence: an international consensus. Int Wound J. 2009; 6:97-104.

Barratt E. Pressure sores: putting risk calculators in their place. Nurs Times. 1987; 83:65-70.

Benoit R, Mion L. Risk factors for pressure ulcer development in critically ill patients: a conceptual model to guide research. Res Nurs Health. 2012; 35(4):340-62.

Bergstrom N, Braden B. A prospective study of pressure sore risk among institutionalized elderly. J Am Geriatr Soc. 1992; 40(8):747-58.

Bergstrom N, Braden B, Kemp M, Champagne M, Ruby E. Multisite study of incidence of pressure ulcers and the relationship between risk level, demographic characteristics, 
diagnoses, and prescription of preventive interventions. J Am Geriatr Soc. 1996; 41(1):22-30.

Bergstrom N, Braden BJ, Laguzza A, Holman V. The Braden Scale for predicting pressure sore risk. Nurs Res. 1987; 36(4):205-10.

Black JM, Edsberg LE, Baharestani MM, Langemo D, Goldberg M, McNichol L et al. Pressure ulcers: avoidable or unavoidable? Results of the National Pressure Ulcer Advisory Panel Consensus Conference. Ostomy Wound Manage. 2011; 57(2):24-37.

Blegen MA, Goode C, Reed L. Nurse staffing and patient outcomes. Nurs Res. 1998; 47:4350 .

Bours GJ, De Laat E, Halfens RJ, Lubbers M. Prevalence, risk factors and prevention of pressure ulcers in Dutch intensive care units results of a cross-sectional survey. Int Care Med. 2001; 27:1599-605.

Braden B, Bergstrom N. A conceptual schema for the study of the etiology of pressure sores. Rehabil Nurs. 1987; 12(1):8-12.

Brasil. Ministério da Saúde. Anexo 2 - protocolo para prevenção de úlcera por pressão. Brasília: MS; 2013. Disponível em http://www.anvisa. gov.br/hotsite/segurancadopaciente/documentos/julho/PROTOCOLO\%20ULCERA\%20POR \%20PRESS\%C3\%83O.pdf. Acesso em: 14 de junho de 2015.

Bucknall TK. Medical error and decision making: learning from the past and present in intensive care. Austral Crit Care. 2010; 32:150-6.

Burd C, Langemo DK, Olson B, Hanson D, Hunter S, Savage T. Epidemiology of pressure ulcers in a skilled care facility. J Geront Nurs. 1992; 18:29-39.

Burnes Bolton L, Aydin CE, Donaldson N, Storer Brown N, Sandhu M, Fridman M, et al. Mandated nurse staffing ratios in California: a comparison of staffing and nursing-sensitive outcomes pre- and postregulation. Policy Polit Nurs Pract. 2007; 8(4):238-50.

Campanili TCGF, Santos VLCG, Thomaz PBM, Nogueira PC, Strazzieri-Pulido KC. Incidência de úlceras por pressão em pacientes de unidade de terapia intensiva cardiopneumológica. Rev Esc Enferm. 2015; 49(n esp):(no prelo).

Carayon P, Gurses AP. A human factors engineering conceptual framework of nursing workload and patient safety in intensive care units. Intens Crit Care Nurs. 2005; 21:284-301.

Carmona-Monge FJ, Jara-Perez A, Quiros-Herranz C, Rollan-Rodriguez G, Cerrillo-Gonzalez I, Garcia-Gomez S, et al. Assessment of nursing workload in three groups of patients in a Spain ICU using the Nursing Activities Score Scale. Rev Esc Enferm USP. 2013; 47(2):33540 .

Charlson ME, Pompei P, Ales KL, Mackenzie CR. A new method of classifying prognostic comorbidity in longitudinal studies: development and validation. J Chronic Dis. 1987; 40(5):373-83. 
Cho SH, Ketefian S, Barkauskas VH, Smith DG. The effects of nurse staffing on adverse events, morbidity, mortality and medical costs. Nurs Res. 2003; 52(2):71-9.

Coleman S, Gorecki C, Nelson EA, Close SJ, Defloor T, Halfens R, et al. Patient risk factors for pressure ulcer development: systematic review. Int J Nurs Stud. 2013; 50:974-1003.

Coleman S, Nixon J, Keen J, Wilson L, McGinnis E, Dealey C, et al. A new pressure ulcer conceptual framework. J Adv Nurs. 2014; doi:10.1111/jan.12405.

Conishi RMY, Gaidzinski RR. Evaluation of the Nursing Activities Score (NAS) as a nursing workload measurement tool in an adult ICU. Rev Esc Enf USP. 2007; 41(3):346-54.

Cox J. Predictors of pressure ulcers in adult critical care patients. Am J Crit Care. 2011; 20(5):364-74.

Cremasco MF, Wenzel F, Sardinha FM, Zanei SSV, Whitaker IY. Úlcera por pressão: risco e gravidade do paciente e carga de trabalho de enfermagem. Acta Paul Enferm. 2009; 22(Especial - 70 Anos):897-902.

Defloor T. The risk of pressure sores: a conceptual scheme. J Clin Nurs. 1999; 8(2):206-16.

Department of Health. Pressure sores: a key quality indicator. Department of Health, London; 1993.

Dias MCCB. Application of the Nursing Activities Score (NAS) as a nursing workload measurement tool in a Cardiac Surgery Intensive Care Unit. MS Dissertation. University of São Paulo, School of Nursing; 2008. Accessed May 15, 2015. http://www.teses.usp.br/teses/disponiveis/7/7131/tde-17102006-131800/.

Diridollou S, Vabre V, Berson M, Vaillant L, et al. Skin ageing: changes of physical properties of human skin in vivo. Int J Cosmet Sci. 2001; 23:353-62.

Ducci AJ, Padilha KG. Nursing activities score: a comparative study between retrospective and prospective applications in intensive care unit. Acta Paul Enf. 2008; 21(4):380-4.

Ducci AJ, Zanei SSV, Whitaker IY. Nursing workload to verify nurse/ patient ratio in a cardiology ICU. Rev Esc Enf USP. 2008; 42(4):673-80.

Eachempati SR, Hydo LJ, Barie PS. Factors influencing the development of decubitus ulcers in critically ill surgical patients. Crit Care Med. 2001; 29:1678-82.

Efteli EU, Günes ÜY. A prospective, descriptive study of risk factors related to pressure ulcer development among patients in intensive care units. Ostomy Wound Manage. 2013; 59(7):227.

Feitosa MC, Leite IRL, Silva GRF. Demanda de intervenções de enfermagem a pacientes sob cuidados intensivos: NAS - Nursing Activities Score. Esc Anna Nery. 2012: 16(4):682-8.

Fernandes NCS, Torres GV. Incidência e fatores de risco de úlceras de pressão em pacientes de unidade de terapia intensiva. Cienc Cuid Saude. 2008; 7(3):304-10. 
Frankel H, Sperry J, Kaplan L. Risk factors for pressure ulcer development in a best practice surgical intensive care unit. Am Surg. 2007; 73:1215-7.

Gonçalves LA, Andolhe R, Oliveira EM, Barbosa RL, Faro ACM, Gallotti RMD, et al. Alocação da equipe de enfermagem e ocorrência de eventos adversos/ incidentes em unidade de terapia intensiva. Rev Esc Enferm USP. 2012; 46(Esp):71-7.

Gonçalves LA, Padilha KG. Fatores associados à carga de trabalho de enfermagem em Unidade de Terapia Intensiva. Rev Esc Enferm USP. 2007; 41(4):645-52.

Gosnell DJ, Johannsen J, Ayres M. Pressure ulcer incidence and severity in a community hospital. Decubitus. 1992; 5:56-62.

Hanson D, Langemo DK, Anderson J, Thompson P, Hunter S. Friction and shear considerations in pressure ulcer development. Adv Skin Wound Care. 2010; 23(1):21-4.

Harris CL, Fraser C. Malnutrition in the institutionalized elderly: the effects on wound healing. Ostomy Wound Manage. 2004; 50(10):54-63. Erratum in: Ostomy Wound Manage. 2004; 50(11):10.

Hoshowsky VM, Schramm CA. Intraoperative pressurecprevention: an analysis of bedding materials. Res Nurs Health. 1994; 17:333-9.

Hussain SH, Limthongkul B, Humphreys TR. The biomechanical properties of the skin. Dermatol Surgery. 2013; 39:2.

Inoue KC, Kuroda CM, Matsuda LM. Nursing Activities Scores (NAS): carga de trabalho de enfermagem em UTI e fatores associados. Cienc Cuid Saude. 2011: 10(1):134-40.

Inoue KC, Matsuda LM. Sizing the nursing staff in an intensive care unit for adults. Acta Paul Enferm. 2010: 23(3):379-84.

Jackson C. The revised Jackson/Cubbin pressure area risk calculator. Int Crit Care Nurs. 1999; 15(3):169-75.

Kaiser Family Foundation. National Survey on Consumers' Experiences with Patient Safety and Quality Information. 2004. Available at:

http://www.kff.org/kaiserpolls/pomr111704pkg.cfm. Accessed 8 jun 2015.

Kaitani T, Tokunaga K, Matsui N, Sanada H. Risk factors related to the development of pressure ulcers in the critical care setting. J Clin Nurs. 2010; 19:414-21.

Kuhn B, Coulter S. Balancing the pressure ulcer cost and quality equation. Nurs Econ. 1992; 10(5):352-9.

Landis EM. Micro-injection studies of capillary blood pressure in human skin. Heart. 1930; 15:209-28.

Langemo D, Anderson J, Hanson D, Thompson P, Hunter S. Understanding palliative wound 
care. Nursing. 2007; 37(1):65-6.

Langemo D, Brown G. Skin fails too: acute, chronic and end-stage skin failure. Adv Skin Wound Care. 2006; 9(4):206-11.

Laschinger HK, Leiter MP. The impact of nursing work environments on patient safety outcomes: the mediating role of burnout/ engagement. J Nurs Adm. 2006; 36(5):259-67.

Le Gall JR, Klar J, Lemeshow S, Saulnier F, Alberti C, Artigas A, Teres D. The logistic organ dysfunction system. A new way to assess organ dysfunction in the intensive care unit. JAMA. 1996; 276:802-10.

Le Gall JR, Lemeshow S, Saulnier F. A new Simplified Acute Physiology Score (SAPS II) based on a European/ North American multicenter study. JAMA. 1993; 270(24):2957-63.

Leite IRL, Silva GRF, Padilha KG. Nursing Activities Score e demanda de trabalho de enfermagem em terapia intensiva. Acta Paul Enferm. 2012; 25(6):837-43.

Linder-Ganz E, Gefen A. The effects of pressure and shear on capillary closure in the microstructure of skeletal muscles. Ann Biomed Eng. 2007; 35(12):2095-2107.

Lindgren M, Unosson M, Fredrikson M, Ek AC. Immobility - a major risk factor for development of pressure ulcers among adult hospitalized patients: a prospective study. Scand J Caring Sc. 2004; 18:57-64.

Lucchini A, De Felippis C, Elli S, Schifano L, Rolla F, Pegoraro F et al. Nursing Activities Score (NAS): 5 years of experience in the intensive care units of an Italian University hospital. Intensive Crit Care Nurs. 2014; 30:152-8.

Mainz J. Defining and classifying clinical indicators for quality improvement. Int J Qual Health Care. 2003; 15:523-30.

Maklebust J. Pressure ulcers: etiology and prevention. Nurs Clin North Am. 1987; 22(2):35977.

Manzano F, Navaro M, Roldan D, Moral M, Leyva I, Guerrero C. Pressure ulcer incidence and risk factors in ventilated intensive care patents. J Crit Care. 2010; 25(3):469-76.

Matos LS, Duarte NLV, Minetto RC. Incidência e prevalência de úlcera por pressão no CTI de um hospital público do DF. Rev Eletr Enf [Internet]. 2010; 12(4):719-26. Available from: http://www.fen.ufg.br/revista/v12/n4/v12n4a18.htm. doi: 10.5216/ree.v12i4.8481. Acesso em 15 de abril de 2015.

McGahan M, Kucharski G, Coyer F. Nurse staffing levels and the incidence of mortality and morbidity in the adult intensive care unit: a literature review. Aust Crit Care. 2012; 25:64-77.

Miranda DR, Raoul N, Rijk A, Schaufeli W, Iapichino G. Nursing activities score. Crit Care Med. 2003; 31(2):374-82.

National Panel Ulcer Advisory Panel. Terms and definitions related to support surfaces. 2007. 
Disponível em http://www.npuap.org em 03 de março de 2015.

National Pressure Ulcer Advisory Panel, European Pressure Ulcer Advisory Panel and Pan Pacific Pressure Injury Alliance. Prevention and Treatment of Pressure Ulcers: Quick Reference Guide. Emily Haesler (Ed.). Cambridge Media: Osborne Park, Western Australia; 2014.

Nijs N, Toppets A, Defloor T, Bernaerts K, Milisen K, Van Den Berghe G. Incidence and risk factors for pressure ulcers in the intensive care unit. J Clinical Nurs. 18:1258-66.

Nixon J, Cranny G, Iglesias C, Nelson EA, Hawkins K, Phillips A, et al. Randomised, controlled trial of alternating pressure mattresses compared with alternating pressure overlays for the prevention of pressure ulcers: PRESSURE (pressure relieving support surfaces) trial. Br Med J. 2006; 332(7555):1413-6.

Nogueira LS, Koike KM, Sardinha DS, Padilha KG, Sousa RMC. Carga de trabalho de enfermagem em unidades de terapia intensiva públicas e privadas. Rev Bras Ter Intensiva. $2013 ; 25(3): 225-32$.

Nogueira LS, Santos MR, Mataloun SE, Moock M. Nursing Activities Score: comparação com o Índice APACHE II e a mortalidade em pacientes admitidos em unidade de terapia intensiva. Rev Bras Ter Intensiva. 2007; 19(3):327-30.

Norton D, McLaren R, Exton-Smith AN. An Investigation of Geriatric Nursing Problems in Hospital, (C) National Corporation for the Care of Old People (now Centre for Policy on Ageing), London, 1962.

Numata Y, Schulzer M, van der Wal R, Globerman J, Semenuik P, Balka E, et al. Nurse staffing levels and hospital mortality in critical care settings: literature review and metaanalysis. J Adv Nurs. 2006; 55(4):435-48.

Oliveira CR. Associações entre carga de trabalho de enfermagem e ocorrência de úlcera por pressão em pacientes internados em unidade de terapia intensiva. [dissertação]. Belo Horizonte (MG): Escola de Enfermagem, Universidade Federal de Minas Gerais; 2012.

Olshansky K. "Kennedy terminal ulcer" and "skin failure," where are the data? J Wound Ostomy Continence Nurs. 2010; 37(5):466-7.

Ooi WL, Morris JN, Brandeis GH, Hossain M, Lipsitz LA. Nursing home characteristics and the development of pressure sores and disruptive behaviour. Age Ageing. 1999; 28(1):45-52.

Ousey K. Pressure area care. Oxford: John Wiley \& Sons; 2009.

Padilha KG, Sousa RM, Garcia PC, Bento ST, Finardi EM, Hatarashi RH. Nursing workload and staff allocation in an intensive care unit: a pilot study according to Nursing Activities Score (NAS). Intensive Crit Care Nus. 2010; 26(2):108-13.

Paiva MCMS, Paiva SAR, Berti HW. Adverse events: analysis of a notification instrument used in nursing management. Rev Esc Enferm. 2010; 44(2):286-93. 
Pancorbo-Hidalgo PL, Garcia-Fernandez FP, Lopez-Medina IM, Alvarez-Nieto C. Risk assessment scales for pressure ulcer prevention: a systematic review. J Adv Nurs. 2006; 54(1):94-110.

Paranhos WY, Santos VLCG. Avaliação de risco para úlcera de pressão por meio da Escala de Braden na língua portuguesa. Rev Esc Enf USP. 1999; 33(n. esp.):191-206.

Pender LR, Frazier SK. The relationship between dermal pressure ulcers, oxygenation and perfusion in mechanically ventilated patients. Intensive Crit Care Nurs. 2005; 21:29-38.

Pereira LC, Luz MHBA, Santana WS, Bezerra SMG, Figueiredo MLF. Incidence of pressure ulcers in an intensive care unit of a public hospital. Rev Enferm UFPI. 2013; 2(4):21-7.

Perneger TV, Rae AC, Gaspoz JM, Borst F, Vitek O, Heliot C. Screening for pressure ulcer risk in an acute care hospital: development of a brief bedside scale. J Clinical Epidemiol. 2002; 55(5):498-504.

Queijo AF, Padilha KG. Nursing Activities Score (NAS): cross-cultural adaptation and validation to Portuguese language. Rev Esc Enf USP. 2009; 43(Suppl.):1001-8.

Robert J, Fridkin S, Blumberg HM, Anderson B, White N, Ray SM, et al. The influence of the composition of the nursing staff on primary bloodstream infection rates in a surgical intensive care unit. Infect Control Hosp Epidemiol. 2000; 21:12-7.

Rocha ABL. Tradução para a língua portuguesa, adaptação transcultural e aplicação clínica da escala de Waterlow para a avaliação de risco de desenvolvimento de úlcera de decúbito. [dissertação] São Paulo (SP): Universidade Federal de São Paulo, 2003.

Russell L. Malnutrition and pressure ulcers: nutritional assessment tools. Br J Nurs. 2000; 9(4):194-6, 198, 200 passim.

Santos VLCG (tradução). SCALE - modificações da pele no final da vida. Rev Estima. 2009; $7(3): 42-4$.

Santos VLCG, Caliri MHL. Conceito e classificação de úlcera por pressão: atualização do NPUAP. Rev Estima. 2007; 5(3):43-4.

Sayar S, Turgut S, Dogan H, Ekici A, Yurtsever S, Demirkan F, et al. Incidence of pressure ulcers in intensive care unit patients at risk according to the Waterlow scale and factors influencing the development of pressure ulcers. J Clinical Nursing. 18:765-74.

Schoonhoven L, Haalboom JRE, Bousema MT, Algra A, Grobbee DE, Grypdonck MH, et al. Prospective cohort study of routine use of risk assessment scales for prediction of pressure ulcers. Br Med J 2002; 325:797-9.

Schultz AA, Bien M, Dumond K, Brown K, Myers A. Etiology and incidence of pressure ulcers in surgical patients. AORN J. 1999; 70(3):434,37-40,43-4,46-9.

Seongsook J, Ihnsook J, Younghee L. Validity of pressure ulcer risk assessment scales: Cubbin Jackson, Braden and Douglas scale. Int J Nurs Stud. 2004; 41(2):199-204. 
Serpa LF; Santos VLCG. Validity of the Braden Nutrition Subscale in Predicting Pressure Ulcer Development. J Wound Ostomy Continence Nurs. 2014; 41:436-43.

Serpa LF, Santos VLCG, Oliveira AO, Caetano VC, Donadon SR. Incidência de úlcera por pressão em pacientes críticos. Rev Estima. 2011; 9(3):21-6.

Shahin ES, Dassen T, Halfens RJ. Pressure ulcer prevalence in intensive care patients: a cross-sectional study. J Eval Clin Prac. 2008; 14:563-8.

Shuldham C, Parkin C, Firouzi A, Roughton M, Lau-Walker M. The relationship between nurse staffing and patient outcomes: a case study. Int J Nurs Stud. 2009; 46:986-92.

Sibbald RG, Krasner DL, Lutz J. SCALE: skin changes at life's end: final consensus statement. Adv Skin Wound Care. 2010; 23(5):225-36.

Silva MCM. Factors regarding discharge, death and readmission into the intensive care unit. $\mathrm{PhD}$ Thesis. University of São Paulo, School of Nursing. 2008. Accessed Jun 22, 2015. http://www.teses.usp.br/teses/disponiveis/7/7139/tde-20042007-092510/.

Silva MLN, Caminha RTÓ, Oliveira SHS, Diniz ERS, Oliveira JL, Neves VSN. Úlcera por pressão em unidade de terapia intensiva: análise da incidência e lesões instaladas. Rev Rene. 2013; 14(5):938-44.

Silva SC. Ocorrências iatrogênicas em unidade de terapia intensiva: impacto na gravidade e na carga de trabalho de enfermagem. [tese]. São Paulo (SP): Escola de Enfermagem, Universidade de São Paulo; 2003.

Slowikowski GC, Funk M. Factors associated with pressure ulcers in patients in a surgical intensive care unit. J Wound Ostomy Continence Nurs. 2010; 37(6):619-26.

Sousa B. Translation, adaptation, and validation of the Sunderland Scale and the Cubbin \& Jackson Revised Scale in Portuguese. Rev Bras Ter Intensiva. 2013; 25(2):106-14.

Souza DMST, Santos VLCG. Úlceras por pressão e envelhecimento. Rev Estima. 2006; $4(1): 36-44$.

Stafsetha SK, Solmsa D, Bredalb IS. The characterisation of workloads and nursing staff allocation in intensive care units: a descriptive study using the Nursing Activities Score for the first time in Norway. Intensive Crit Care Nurs. 2011; 27:290-4.

Stone PW, Mooney-Kane C, Larson EL, Horan T, Glance LG, Zwanziger J, et al. Nurse working conditions and patient safety outcomes. Med Care. 2007; 45(6):571-8.

Strazzieri-Pulido KC, Santos VLCG. Superfícies de suporte: parte I. Rev Estima. 2010; 8(1):40-2.

Suriadi SH, Sugama J, Kitagawa A, Thigpen B, Kinosita S, Murayama S. Risk factors in the development of pressure ulcers in an intensive care unit in Pontianak, Indonesia. Int Wound J. 2007; 4(3):208-15. 
Terekeci H, Kucukardali Y, Top C, Onem Y, Celik S, Öktenli Ç. Risk assessment study of the pressure ulcers in intensive care unit patients. Eur J Intern Med. 2009; 20:394-7.

Theaker C, Mannan M, Ives N, Soni N. Risk factors for pressure sores in the critically ill. Anaesthesia. 2000; 55:221-4.

Unrah L. Licensed nurse staffing and adverse events in hospitals. Med Care. 2003; 41(1):14252.

Ventura JA, Moura LTR, Carvalho MFAA. Braden scale and incidence of pressure ulcers in an intensive care unit. Rev Enferm UFPE Online. 2014; 8(7):2047-53.

Weissman JS, Rothschild JM, Bendavi E, Sprivulis P, Fachi F, Cook EF et al. Hospital workload and adverse events. Medical Care. 2007; 45(5):448-55.

West E, Mays N, Rafferty AM, Rowan K, Sanderson C. Nursing resources and patient outcomes in intensive care: a systematic review of the literature. Int J Nurs Stud. 2009; 46:993-1011.

Whitman GR, Kim Y, Davidson LJ, Wolf GA, Wang SL. The impact of staffing on patient outcomes across specialty units. J Nurs Adm. 2002; 32(12):633-9.

Williams DF, Stotts NA, Nelson K. Patients with existing pressure ulcers admitted to acute care. J Wound Ostomy Continence Nurs. 2001; 28:36.

World Health Organization. The conceptual framework for the international classification for patient safety. Version 1.1. Technical Report January 2009. Accessed Jun 22, 2015. http://www.who.int/patientsafety/implementation/taxonomy/icps technical_report_en.pdf

Worley CA. Skin failure: the permissible pressure ulcer? Dermatol Nurs. 2007; 19(4):384-5.

Wound Ostomy and Continence Nurses Society (WOCN). Guideline for prevention and management of pressure ulcers. Mount Laurel: J Wound Ostomy Continence Nurs. 2010.

Yang KP. Relationship between nurse staffing and patient outcomes. J Nurs Res. 2003; 11:149-58.

Yastrub DJ. Pressure or pathology: distinguishing pressure ulcers from the Kennedy terminal ulcer. J Wound Ostomy Continence Nurs. 2010: 37(3):249-50. 
APÊNDICE 
APÊNDICE A - Instrumento para a coleta de dados
A. Ficha:
B. Código do paciente:
C. Nome:
D. Sexo: $\quad 0 . M \quad 1 . F$

E. Idade (anos):

F. Idade (faixas etárias): $<45 / 45-59 / 60-84 / 85+$

G. Tipo de Internação: 1 . Clínica

2. Cirúrgica Eletiva 3. Cirúrgica Emergência

H. Tempo de Internação (dias):

I. Condição de alta da UTI: 0 . Não sobrevivente 1 . Sobrevivente

J. Índice de Comorbidade de Charlson
K. SAPS II
L. LODS
M. NAS

N. Diagnóstico de admissão:

O. Cirurgias: 0. Não 1. Sim $\quad$ P. Número de Cirurgias:

Q. Drogas Vasoativas: 0.Não 1.Sim R. Número de Drogas Vasoativas:

S. Ventilação Mecânica: 0.Não 1.Sim T. Número de Dias em VM:

U. Tipo de Colchão: 1. Piramidal 2. Pneumático $\quad$ 3. Convencional

V. Cuidados Paliativos: 0.Não 1.Sim

W. Braden Mínimo: 0. Fora de Risco 1 . Risco Baixo $\quad$ 2. Risco Moderado 3 . Risco Alto

4. Risco Muito Alto

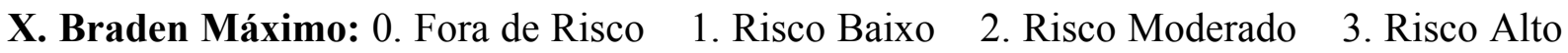

4. Risco Muito Alto

Y. Úlcera por Pressão: 0 . Ausente 1 . Presente

Z. Classificação: $1.1 \quad 2.2 \quad 3.3 \quad 4.4 \quad$ 5. SLTP $\quad$ 6. UPNPC

AA. Localização da UP: 1. Sacro $\quad$ 2. Trocânter $\quad$ 3. Glúteo $\quad$ 4. Calcâneo $\quad$ 5. Orelha 6. Cotovelo 7. Escápula 8. Occipício 9. Nariz
AB. Gravidade do Dano: 0. Dano Ausente 1 . Fraca 2. Moderada 3. Grave 4. Morte AC. Tempo para o Aparecimento da UP (dias): 
ANEXOS 


\section{ANEXO 1 - Aprovação do Comitê de Ética em Pesquisa do Instituto Central do Hospital das Clínicas da Faculdade de Medicina da Universidade de São Paulo (CAPPesq ICHC-FMUSP)}

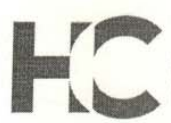

A Comissão de Ética para Análise de Projetos de Pesquisa CAPPesq da Diretoria Clínica do Hospital das Clínicas da Faculdade de Medicina da Universidade de São Paulo, em sessão de 22/06/2011, APROVOU o Protocolo de Pesquisa $n^{\circ}$ 0196/11, intitulado: "SEGURANÇA DO PACIENTE EM UNIDADES DE TERAPIA INTENSIVA:INFLUENNCIA DOS FATORES HUMANOS DE ENFERMAGEM NA OCORRENCIA DE EVENTOS ADVERSOS" apresentado pelo Departamento de DIVISĀO DE ENFERMAGEM, inclusive o Termo de Consentimento Livre e Esclarecido.

Cabe ao pesquisador elaborar e apresentar à CAPPesq, os - relatórios parciais e final sobre a pesquisa (Resolução do Conselho Nacional de Saúde n० 196, de 10/10/1996, inciso (X.2, letra "c").

Pesquisador (a) Responsável: Floracy Gomes Ribeiro

Pesquisador (a) Executante: Kátia Grillo Padilha

CAPPesq, 27 de Junho de 2011

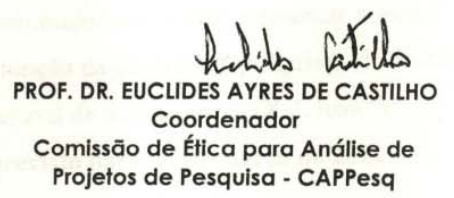

Comissáo de Ética para Análise de Projetos de Pesquisa do HCFMUSP da Diretoria Clinica do Hospital das Clinicas da Faculdade de Medicina da Universidade de Sáo Paulo Rua Ovidio Pires de Campos, 225, $5^{\circ}$ andar - CEP 05403010 - São Paulo - SP Fone: 01130696442 Fax: 01130696492 


\section{ANEXO 2 - Aprovação do Comitê de Ética em Pesquisa do Hospital Universitário da Universidade de São Paulo (CEP HU-USP)}

São Paulo, 05 de março de 2011.

$I^{m o(a)} \cdot S^{r(a)}$.

Karina Sichieri

Departamento de Enfermagem do Hospital Universitário

UNIVERSIDADE DE SÃO PAULO

REFERENTE: Projeto de Pesquisa "Segurança do paciente em unidades de terapia intensiva e semi-intensiva: influência dos fatores humanos de enfermagem na ocorrência de eventos adversos" - Pesquisador(a) responsável: Karina Sichieri - CoInvestigador(es): Katia Grillo Padilha, Silvia Regina Secoli, Flavia de Oliveira Motta Maia - Registro CEP-HU/USP: 1086/10 - SISNEP CAAE: 0002.0.198.000-11.

Prezado(a) Senhor(a)

O Comitê de Ética em Pesquisa do Hospital Universitário da Universidade de Sãn Paulo, em reunião ordinária realizada no dia 04 de março de 2011, analisou o Projeto de Pesquisa acima citado, considerando-o como APROVADO, bem como o seu Termo de Consentimento Livre e Esclarecido.

Lembramos que cabe ao pesquisador elaborar e apresentar a este Comitê, relatórios anuais (parciais ou final, em função da duração da pesquisa), de acordo com a Resolução no 196/96 do Conselho Nacional de Saúde, inciso IX.2, letra "c".

O primeiro relatórin está previsto para 04 de março de 2012.

Atenciosamente,

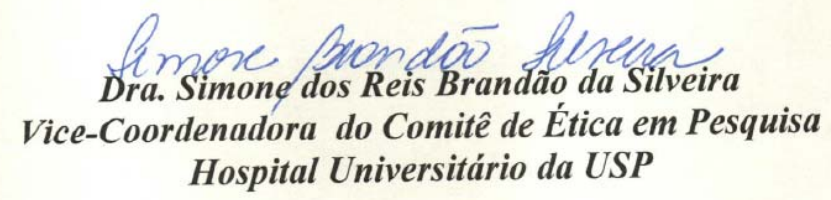




\section{ANEXO 3 - Classificação dos Eventos Adversos/ Incidentes}

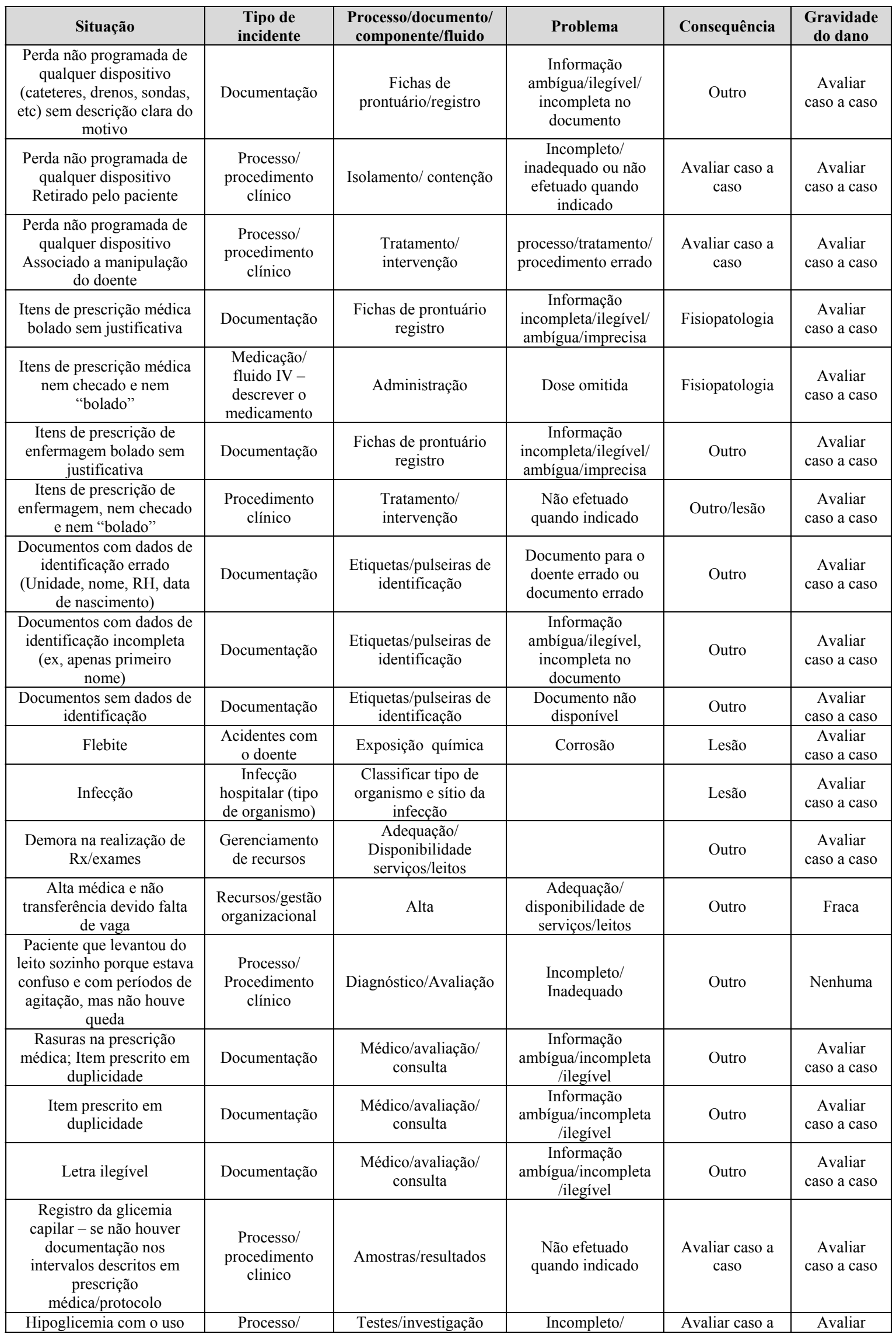




\begin{tabular}{|c|c|c|c|c|c|}
\hline $\begin{array}{c}\text { de insulinoterapia } \\
\text { contínua, sem o controle } \\
\text { da glicemia }\end{array}$ & $\begin{array}{l}\text { Procedimento } \\
\quad \text { clínico }\end{array}$ & & Inadequado & caso & caso a caso \\
\hline $\begin{array}{l}\text { Hipoglicemia com o uso } \\
\text { de insulinoterapia } \\
\text { contínua, com o controle } \\
\text { adequado da glicemia }\end{array}$ & $\begin{array}{c}\text { Não considerar } \\
\text { EA, se inicio } \\
\text { da terapêutica } \\
\text { OU } \\
\text { Processo/ } \\
\text { Procedimento } \\
\text { clínico } \\
\end{array}$ & Diagnóstico/Avaliação & $\begin{array}{l}\text { Incompleto/ } \\
\text { Inadequado }\end{array}$ & $\begin{array}{l}\text { Avaliar caso a } \\
\text { caso }\end{array}$ & $\begin{array}{c}\text { Avaliar } \\
\text { caso a caso }\end{array}$ \\
\hline $\begin{array}{l}\text { Hipotensão com o uso de } \\
\text { nipride com o controle } \\
\text { adequado da glicemia }\end{array}$ & $\begin{array}{c}\text { Não considerar } \\
\text { EA, se inicio } \\
\text { da terapêutica } \\
\text { OU } \\
\text { Processo/Proced } \\
\text { imento clínico }\end{array}$ & Diagnóstico/Avaliação & $\begin{array}{l}\text { Incompleto/ } \\
\text { Inadequado }\end{array}$ & $\begin{array}{l}\text { Avaliar caso a } \\
\text { caso }\end{array}$ & $\begin{array}{c}\text { Avaliar } \\
\text { caso a caso }\end{array}$ \\
\hline $\begin{array}{c}\text { Atraso na administração da } \\
\text { medicação }\end{array}$ & $\begin{array}{c}\text { Medicação/ } \\
\text { fluido EV }\end{array}$ & Administração & Frequência errada & $\begin{array}{c}\text { Avaliar caso a } \\
\text { caso }\end{array}$ & $\begin{array}{c}\text { Avaliar } \\
\text { caso a caso }\end{array}$ \\
\hline Lesão fúngica inguinal & Infecção & $\begin{array}{c}\text { Tipo de organismo: } \\
\text { Fungo }\end{array}$ & $\begin{array}{l}\text { Sitio da infecção: } \\
\text { Outros (descrever) }\end{array}$ & $\begin{array}{c}\text { Avaliar caso a } \\
\text { caso }\end{array}$ & $\begin{array}{c}\text { Avaliar } \\
\text { caso a caso }\end{array}$ \\
\hline
\end{tabular}




\section{ANEXO 4 - Manual para análise de eventos adversos e incidentes}

1. Perda não programada de cateter (periférico ou central), assim como extubação acidental - Além de classificar como perda não planejada no campo "artefatos terapêuticos", também deve estar registrada em incidentes.

2. Medicamentos prescritos, suspensos e prescritos novamente com modificação apenas de dose ou frequência - considerar apenas um item prescrito (o primeiro)

3. Medicamentos prescritos, suspensos e substituídos por outro (ex: troca de antibiótico) considerar dois itens.

4. Infusão de droga vasoativa - inserir $\mathrm{Mcg} / \mathrm{Kg} / \mathrm{min}$. Em relação à vasopressina, inserir em $\mathrm{UI} / \mathrm{Kg} / \mathrm{min}$

5. Gravidade do dano:

a. Nenhuma - A consequência no doente é assintomática ou sem sintomas detectados e não necessita tratamento.

b. Fraca - A consequência no doente é sintomática, com sintomas ligeiros, perda de funções ou danos mínimos ou intermédios de curta duração, sem intervenção ou com uma intervenção mínima requerida (por exemplo: observação extra, inquérito, análise ou pequeno tratamento).

c. Moderada - A consequência no doente é sintomática, requerendo intervenção (por exemplo: procedimento suplementar, terapêutica adicional) um aumento na estadia, ou causou danos permanentes ou a longo prazo, ou perda de funções.

d. Severa/Grave - A consequência no doente é sintomática, requerendo intervenção para salvar a vida ou grande intervenção médico/cirúrgica, encurta a esperança de vida ou causa grandes danos permanentes ou a longo prazo, ou perda de funções.

e. Morte - No balanço das probabilidades, a morte foi causada ou antecipada a curto prazo, pelo incidente.

6. - Apache / LODS - digitar apenas os parâmetros diários (NÃO PRECISA CALCULAR O INDICE DE GRAVIDADE):

- Glasgow -um único valor para cada dia internado na UTI (pior valor das 24h). Nos casos em que o paciente é sedado e intubado, considerar o valor da ECGl registrado antes do procedimento e manter este valor até a retirada da sedação e extubação.

- Temperatura - o valor máximo e mínimo diário

- PAM - valor máximo e mínimo diário

- PA sistólica -valor máximo e mínimo diário

- PA diastólica - valor máximo e mínimo diário

- FC - valor máximo e mínimo diário

- F Respiratória - valor máximo e mínimo diário

- Débito urinário das 24 horas (litros). $\mathrm{Na}$ ausência desta informação (Ex: registrado no $\mathrm{BH}$ "perdas" ou "++++"), considerar débito urinário de 1,2 litros/24 horas

- Relação $\mathrm{PaO} 2 / \mathrm{FiO} 2$ diária (em mmHg) . Nos casos em que não existem dados da gasometria arterial, considerar o valor da $\mathrm{PaO}_{2}$ de $100 \mathrm{mmHg}$ e dividi-lo pelo maior valor da $\mathrm{FiO}_{2}$ registrado nas 24 horas. Atentar para o horário da realização do exame de gasometria arterial para fazer a relação (considerar sempre a $\mathrm{FiO}_{2}$ que corresponde ao mesmo horário da gasometria) e registrar sempre o pior valor desta relação. 
7. Cateter de oxigênio: considerar os seguintes valores de $\mathrm{FiO}_{2}$

a) Cateter nasal:

$\begin{array}{lc}\text { FluxoO2 } & \text { FiO2 } \\ 1 \mathrm{~L} / \mathrm{min} & 21-24 \% \\ 2 \mathrm{~L} / \mathrm{min} & 25-28 \% \\ 3 \mathrm{~L} / \mathrm{min} & 29-32 \% \\ 4 \mathrm{~L} / \mathrm{min} & 33-36 \% \\ 5 \mathrm{~L} / \mathrm{min} & 37-40 \%\end{array}$

Máscara simples

$\begin{array}{ll}\text { Fluxo O2 } & \text { FiO2 } \\ 5-6 \mathrm{~L} / \mathrm{min} & 40 \% \\ 6-7 \mathrm{~L} / \mathrm{min} & 50 \% \\ 7-8 \mathrm{~L} / \mathrm{min} & 60 \%\end{array}$

Máscara de venturi:

$\begin{array}{lcl}\text { Cor } & \text { Fluxo O2 } & \text { FiO2 } \\ & \text { Unidade } & \text { Horário do } \\ \text { azul } & 4 \mathrm{~L} / \mathrm{min} & 24 \% \\ \text { amarelo } & 4 \mathrm{~L} / \mathrm{min} & 28 \% \\ \text { branco } & 6 \mathrm{~L} / \mathrm{min} & 32 \% \\ \text { verde } & 8 \mathrm{~L} / \mathrm{min} & 36 \% \\ \text { rosa } & 8 \mathrm{~L} / \mathrm{min} & 40 \% \\ \text { Laranja } & 15 \mathrm{~L} / \mathrm{min} & 50 \%\end{array}$

8. Paciente que recusa a realização de procedimentos - como mudança de decúbito, por exemplo - - - Não considerar como incidente

9. Mudança de decúbito: Considerar apenas a checagem (não precisa ter especificado o registro da posição colocada, ou seja: DD, DLE, etc)

10. Insulinoterapia contínua: controle de glicemia a cada 2 horas

11. Peso: considerar o peso de entrada (no hospital ou na UTI, se houver). Na ausência da informação (mais comum), considerar algum peso registrado durante a internação na UTI ou o peso normal de um adulto hígido, ou seja $70 \mathrm{~kg}$, apesar de não ser o real.

12. Controle de dor: considerar obrigatoriedade do registro da escala de dor (ver no verso da folha de Balanço Hidrico ), de acordo com horário dos sinais vitais, sempre que o paciente estiver consciente)

13. Sobre o período de validade da prescrição médica para as 24 horas, no HC: observar que existem diferentes rotinas para o inicio da prescrição médica, , cujos horários são os seguintes 
Horário de

início da

Prescrição

Médica

$4^{\circ} \mathrm{GS} \quad 14 \mathrm{hs}$

$4^{\circ} \mathrm{GN} \quad 14 \mathrm{hs}$

MI 14hs

Neuro 12hs

UTI $6^{\circ}$ andar $16 \mathrm{hs}$

Nefro 7hs

Queimados 8hs

UTI $9^{\circ}$ andar $10 \mathrm{hs}$ 
ANEXO 5 - Instrumento para levantamento de eventos adversos/incidentes

I) DADOS DE IDENTIFICAÇÃO DO PACIENTE

NO. IDENTIFICAÇÃO: $\quad$ UTI:

LEITO:

IDADE --------ANOS SEXO: M( ) F( )

DATA DE NASC----/--------/--------

PROVENIÊNCIA: OS ( ) ENF( ) CC ( ) OUTRO

DATA INTERNAÇÃO NA UTI / / HORA HS

DATA DE INTERNAÇÃO NO SERVIÇO DE ORIGEM

HORA

CONDIÇÃO DE SAÍDA DA UTI

A. ALTA ( ) DATA: ___ _ _ TRANSFERÊNCIA ( )

QUAL

B) ÓBITO ( ) DATA:

HORA:

$\mathrm{H}$

II) DADOS DE ADMISSÃO

DIAGNÓSTICOS DE INTERNAÇÃO NA UTI:

III) PARÂMETROS DE GRAVIDADE

\begin{tabular}{|c|c|c|c|c|c|c|c|c|}
\hline \multicolumn{2}{|c|}{ PARÂMETROS } & $--/--$ & ----- & $--/--$ & $---/--$ & $---/--$ & $---/--$ & $--/--$ \\
\hline \multirow{2}{*}{$\begin{array}{l}\text { Pontuação } \\
\text { Glasgow }\end{array}$} & mín & & & & & & & \\
\hline & máx & & & & & & & \\
\hline \multirow{2}{*}{ Temperatura } & mín & & & & & & & \\
\hline & máx & & & & & & & \\
\hline \multirow{2}{*}{$\mathrm{FC}(\mathrm{bpm})$} & mín & & & & & & & \\
\hline & máx & & & & & & & \\
\hline \multirow{2}{*}{ PASist (mmHg) } & mín & & & & & & & \\
\hline & máx & & & & & & & \\
\hline \multirow{2}{*}{$\begin{array}{l}\mathrm{PaO} 2 \\
\mathrm{Fi} \mathrm{O} 2 \\
\end{array}$} & mín & & & & & & & \\
\hline & corresp & & & & & & & \\
\hline \multirow{2}{*}{ Plaquetas } & mín & & & & & & & \\
\hline & máx & & & & & & & \\
\hline \multirow{2}{*}{ Leucócitos } & mín & & & & & & & \\
\hline & máx & & & & & & & \\
\hline \multirow{2}{*}{ Sódio } & mín & & & & & & & \\
\hline & máx & & & & & & & \\
\hline \multirow{2}{*}{ Potássio } & mín & & & & & & & \\
\hline & máx & & & & & & & \\
\hline \multirow{2}{*}{ Bicarbonato sérico } & mín & & & & & & & \\
\hline & máx & & & & & & & \\
\hline \multirow{2}{*}{ Creatinina sérica } & mín & & & & & & & \\
\hline & máx & & & & & & & \\
\hline \multirow{2}{*}{ Uréia sérica } & mín & & & & & & & \\
\hline & máx & & & & & & & \\
\hline \multirow{2}{*}{$\begin{array}{c}\text { Bilirrubinas totais } \\
\text { (dir+ind) }\end{array}$} & mín & & & & & & & \\
\hline & máx & & & & & & & \\
\hline T Protrombina & $(\%)$ & & & & & & & \\
\hline Débito urinário & $\mathrm{ml} / 24 \mathrm{~h}$ & & & & & & & \\
\hline SAPS II & & & & & & & & \\
\hline
\end{tabular}

IV) INTERVENÇÕES HOSPITALARES

TIPO/DATA

\begin{tabular}{|c|c|c|c|c|c|c|}
\hline$--/--$ & $--/--$ & $--/--$ & $--/--$ & $--/-$ & $--/--$ & $--/--$ \\
\hline
\end{tabular}

Marcar o número de ocorrências

Número de folhas de prescrição abertas nas últimas $24 \mathrm{hs}$

Número itens prescritos nas últimas 24 hs (todos)

\begin{tabular}{|l|l|l|l|l|l|l|l|}
\hline & & & & & & \\
\hline
\end{tabular}




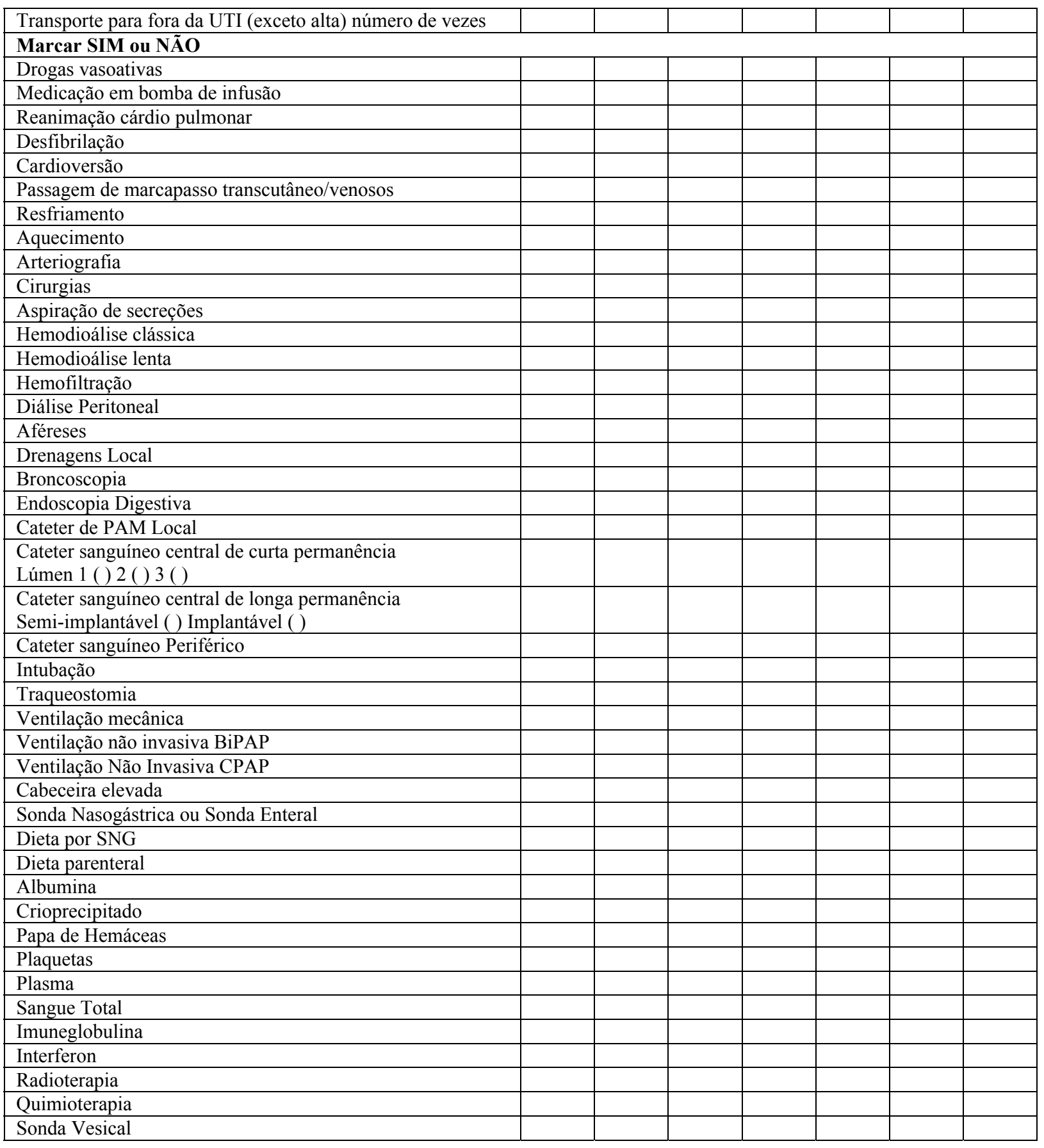

\section{V) IDENTIFICAÇÃO DE EA/I NOS PRONTUÁRIOS}

1) INCIDENTE SEM DANO: são os erros no cuidado em saúde que não envolvem lesão mensurável ou dano ao paciente.

2) INCIDENTE COM DANO: são os erros no cuidado em saúde que envolvem lesão mensurável ou dano ao paciente. Esses incidentes também são denominados de EVENTOS ADVERSOS.

Hipoglicemia - dextro $<70$ mg/dl; GLICEMIA $<60 \mathrm{mg} / \mathrm{dl}$

\begin{tabular}{|c|c|c|c|}
\hline DATA & $\begin{array}{c}\text { HORÁRIO } \\
\text { DO EA/I }\end{array}$ & DESCRIÇÃO & CLASSIFICAÇÃO \\
\hline & & & \\
\hline & & & \\
\hline
\end{tabular}




\section{ANEXO 6 - Nursing Activities Score}

\begin{tabular}{|c|c|c|c|c|c|c|c|c|c|}
\hline \multicolumn{10}{|c|}{ ATIVIDADES BÁSICAS } \\
\hline 1 & Monitorização e Controles & $\%$ & $--/--$ & $--/--$ & $--/--$ & $--/--$ & $--/--$ & $--/--$ & $--/--$ \\
\hline $1 \mathrm{a}$ & $\begin{array}{l}\text { Sinais vitais horários, cálculo e registro regular do } \\
\text { balanço hídrico }\end{array}$ & 4,5 & & & & & & & \\
\hline $1 b$ & $\begin{array}{l}\text { Presença à beira do leito e observação contínua ou ativa } \\
\text { por } 2 \text { horas ou mais em algum plantão por razões de } \\
\text { segurança, gravidade ou terapia, tais como: ventilação } \\
\text { mecânica não invasiva, desmame, agitação, confusão } \\
\text { mental, posição prona, procedimentos de doação de } \\
\text { órgãos, preparo e administração de fluidos ou medicação, } \\
\text { auxílio em procedimentos específicos. }\end{array}$ & 12,1 & & & & & & & \\
\hline $1 \mathrm{c}$ & $\begin{array}{l}\text { Presença à beira do leito e observação contínua ou ativa } 4 \\
\text { horas ou mais em algum plantão por razões de segurança, } \\
\text { gravidade ou terapia, tais como os exemplos acima. }\end{array}$ & 19,6 & & & & & & & \\
\hline 2 & $\begin{array}{l}\text { Investigações laboratoriais: bioquímicas e } \\
\text { microbiológicas. }\end{array}$ & 4,3 & & & & & & & \\
\hline 3 & Medicação, exceto drogas vasoativas. & 5,6 & & & & & & & \\
\hline 4 & \multicolumn{9}{|l|}{ Procedimentos de higiene } \\
\hline $4 a$ & $\begin{array}{l}\text { Realização de procedimentos de higiene tais como: } \\
\text { curativo de feridas e cateteres intravasculares, troca de } \\
\text { roupa de cama, higiene corporal do paciente em situações } \\
\text { especiais (incontinência, vômito, queimaduras, feridas } \\
\text { com secreção, curativos cirúrgicos complexos com } \\
\text { irrigação), procedimentos especiais (p. ex. isolamento) } \\
\text { etc. }\end{array}$ & 4,1 & & & & & & & \\
\hline $4 \mathrm{~b}$ & $\begin{array}{l}\text { Realização de procedimentos de higiene que durem mais } \\
\text { do que } 2 \text { horas em algum plantão. }\end{array}$ & 16,5 & & & & & & & \\
\hline $4 \mathrm{c}$ & $\begin{array}{l}\text { Realização de procedimentos de higiene que durem } \\
\text { mais do que } 4 \text { horas em algum plantão. }\end{array}$ & 20,0 & & & & & & & \\
\hline 5 & Cuidados com drenos. Todos (exceto sonda gástrica). & 1,8 & & & & & & & \\
\hline 6 & \multicolumn{9}{|c|}{$\begin{array}{l}\text { Mobilização e posicionamento } \\
\text { Incluindo procedimentos tais como: mudança de decúbito, mobilização do paciente; transferência da cama para a } \\
\text { cadeira; mobilização do paciente em equipe (p. ex. paciente imóvel, tração, posição prona). }\end{array}$} \\
\hline $6 a$ & $\begin{array}{l}\text { Realização do(s) procedimento (s) até } 3 \text { vezes em } 24 \\
\text { horas. }\end{array}$ & 5,5 & & & & & & & \\
\hline $6 \mathrm{~b}$ & $\begin{array}{l}\text { Realização do(s) procedimento(s) mais do que } 3 \text { vezes } \\
\text { em } 24 \text { horas ou com } 2 \text { enfermeiros em qualquer } \\
\text { frequ ência. }\end{array}$ & 12,4 & & & & & & & \\
\hline $6 c$ & $\begin{array}{l}\text { Realização do(s) procedimento(s) com } 3 \text { ou mais } \\
\text { enfermeiros em qualquer frequ ência. }\end{array}$ & 17,0 & & & & & & & \\
\hline 7 & \multicolumn{9}{|c|}{$\begin{array}{l}\text { Suporte e cuidados aos familiares e pacientes } \\
\text { Incluindo procedimentos tais como telefonemas, entrevistas, aconselhamento. Frequ entemente, o suporte e cuidado, } \\
\text { sejam aos familiares ou aos pacientes permitem `a equipe continuar com outras atividades de enfermagem (p. ex: } \\
\text { comunicação com o paciente durante procedimentos de higiene, comunicação com os familiares enquanto presente à } \\
\text { beira do leito observando o paciente). }\end{array}$} \\
\hline $7 \mathrm{a}$ & $\begin{array}{l}\text { Suporte e cuidado aos familiares e pacientes que } \\
\text { requerem dedicação exclusiva por cerca de } 1 \text { hora em } \\
\text { algum plantão tais como: explicar condições clínicas, } \\
\text { lidar com a dor e angústia, lidar com circunstâncias } \\
\text { familiares difíceis. }\end{array}$ & 4,0 & & & & & & & \\
\hline $7 \mathrm{~b}$ & $\begin{array}{l}\text { Suporte e cuidado aos familiares e pacientes que } \\
\text { requerem dedicação exclusiva por } 3 \text { horas ou mais em } \\
\text { algum plantão tais como: morte, circunstâncias especiais } \\
\text { (p. ex. grande número de familiares, problemas de } \\
\text { linguagem, familiares hostis). }\end{array}$ & 32,0 & & & & & & & \\
\hline 8 & \multicolumn{9}{|l|}{ Tarefas administrativas e gerenciais } \\
\hline $8 \mathrm{a}$ & $\begin{array}{l}\text { Realização de tarefas de rotina tais como: processamento } \\
\text { de dados clínicos, solicitação de exames, troca de } \\
\text { informações profissionais (por ex. passagem de plantão, } \\
\text { visitas clínicas). }\end{array}$ & 4,2 & & & & & & & \\
\hline $8 \mathrm{~b}$ & $\begin{array}{l}\text { Realização de tarefas administrativas e gerenciais que } \\
\text { requerem dedicação integral por cerca de } 2 \text { horas em }\end{array}$ & 23,2 & & & & & & & \\
\hline
\end{tabular}




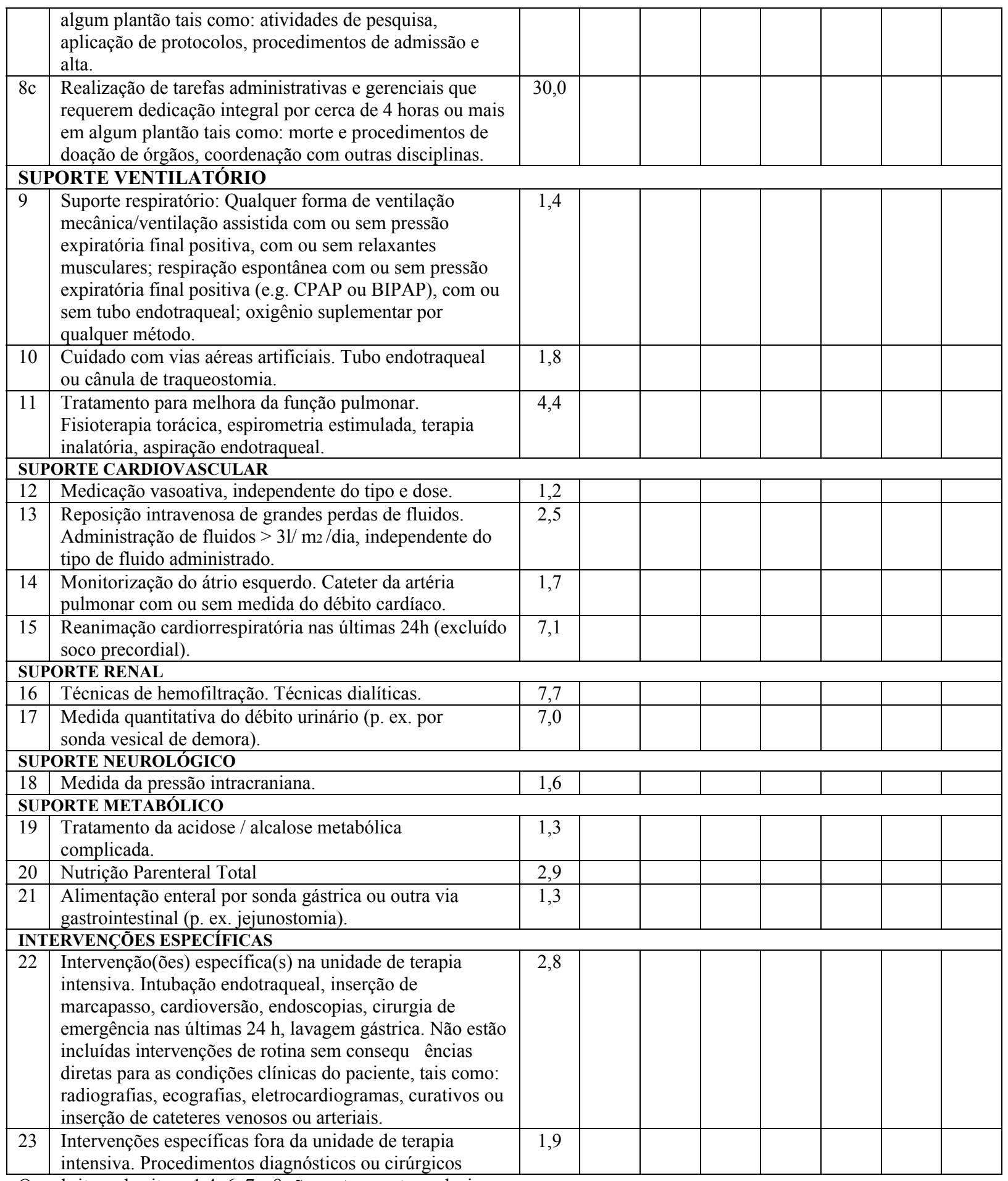

Os sub-itens dos itens 1,4, 6, 7 e 8 são mutuamente exclusivos 


\section{ANEXO 7 - Manual do Nursing Activities Score}

\section{Monitorização e controles}

1a. Sinais vitais, cálculo e registro do balanço hídrico $(4,5 \%)$

Aplica-se a pacientes que NÃ̃O necessitaram de mudanças freqüentes no tratamento e que exigiram monitorização e controles de rotina ou "normal" de acordo a rotina da unidade, nas 24 horas.

1b. Presença à beira do leito e observação contínua ou ativa por 2 horas ou mais em algum plantão por razões de segurança, gravidade ou terapia, tais como: ventilação mecânica não invasiva, desmame, agitação, confusão mental, posição prona, manta térmica, punção periférica, punção de cateter central, várias tentativas de punção, preparo e administração de fluídos ou medicação e auxílio em procedimentos específicos. $(12,1 \%)$

Aplica-se a pacientes que por razões de segurança, gravidade ou terapia, tiveram sua monitorização intensificada, para "além do normal" de acordo com a rotina da unidade, em pelo menos um plantão nas 24 horas.

1c. Presença à beira do leito e observação contínua ou ativa por 4 horas ou mais em algum plantão por razões de segurança, gravidade ou terapia. $(19,6 \%)$

Aplica-se a pacientes que por razões de segurança, gravidade ou terapia, tiveram sua monitorização intensificada, para "muito além do normal" de acordo com a rotina da unidade, em pelo menos um plantão nas 24 horas.

2. Investigações Laboratoriais: bioquímicas e microbiológicas $(4,3 \%)$

Aplica-se a pacientes submetidos a qualquer exame bioquímico ou microbiológico, independente da quantidade, realizados em laboratório ou a beira do leito, com a participação do profissional de enfermagem, inclusive glicemia capilar.

3. Medicação, exceto drogas vasoativas $(5,6 \%)$

Inclui os pacientes que receberam qualquer tipo de medicamento, independente da via ou dose. Não se aplica neste item o soro de manutenção.

\section{Procedimentos de higiene}

4a. Realização de procedimentos de higiene tais como: curativo de feridas e cateteres intravasculares, troca de roupa de cama, higiene corporal do paciente em situações especiais (incontinência, vômito, queimaduras, feridas com secreção, curativos cirúrgicos complexos com irrigação) e procedimentos especiais (p. ex. isolamento). $(4,1 \%)$

Aplica-se ao paciente que foi submetido a qualquer um dos procedimentos de higiene descritos acima, com freqüência "normal" de acordo com as horas estabelecidas na Unidade, em pelo menos um plantão nas 24 horas.

4b. Realização de procedimentos de higiene que durem mais do que 2 horas em algum plantão. $(16,5 \%)$ 
Aplica-se ao paciente que foi submetido a qualquer um dos procedimentos de higiene descritos no item 4a, com freqüência "além do normal" de acordo com as horas estabelecidas na Unidade, em pelo menos um plantão nas 24 horas.

4c. Realização de procedimentos de higiene que durem mais do que 4 horas em algum plantão. $(20,0 \%)$

Aplica-se ao paciente que foi submetido a qualquer um dos procedimentos de higiene descritos no item $4 \mathrm{a}$, com freqüência "muito além do normal" de acordo com as horas estabelecidas na Unidade, em pelo menos um plantão nas 24 horas.

5. Cuidados com drenos. Todos (exceto sonda gástrica) $(1,8 \%)$

Aplica-se a pacientes que estejam com qualquer sistema de drenagem instalado. INCLUI SONDA VESICAL DE DEMORA (SVD) e exclui sondas gástricas (nasogástricas, nasoenterais, gastrostosmias e outras).

\section{Mobilização e posicionamento}

Inclui procedimentos tais como: mudança de decúbito, mobilização do paciente, transferência da cama para a cadeira e mobilização do paciente em equipe (p. ex. paciente imóvel, tração, posição prona).

6a. Realização do (s) procedimento (s) até três vezes em 24 horas. (5,5\%)

Aplica-se ao paciente submetido aos procedimentos de mobilização e posicionamento descritos, ATÉ TRÊS VEZES em 24 horas.

6b. Realização do(s) procedimento(s) mais do que 3 vezes em 24 horas ou com 2 enfermeiros em qualquer freqüência. $(12,4 \%)$

Aplica-se ao paciente submetido aos procedimentos de mobilização e posicionamento descritos no item 6, que tenham sido realizados MAIS DO QUE 3 VEZES EM 24 HORAS Ou cOM 2 MEMBROS DA EQUIPE DE ENFERMAGEM em PELO MENOS UM PLANTÃO nas 24 horas.

6c. Realização do(s) procedimento(s) com 3 ou mais enfermeiros em qualquer freqüência. $(17,0 \%)$

Aplica-se ao paciente submetido aos procedimentos de mobilização e posicionamento descritos no item 6, que tenham sido realizados com 3 OU MAIS MEMBROS DA EQUIPE DE ENFERMAGEM em qualquer freqüência em pelo menos um plantão nas 24 horas.

\section{Suporte e cuidados aos familiares e pacientes}

Inclui procedimentos tais como telefonemas, entrevistas e aconselhamentos. Freqüentemente o suporte e cuidado, sejam aos familiares ou aos pacientes, permitem a equipe continuar com outras atividades de enfermagem (p.ex: comunicação com os pacientes durante procedimentos de higiene ou comunicação com os familiares enquanto presente à beira do leito observando o paciente).

7a. Suporte e cuidado aos familiares e pacientes que requerem dedicação exclusiva por cerca de 1 hora em algum plantão tais como: explicar condições clínicas, lidar com a dor e angústia e lidar com circunstâncias familiares difíceis. $(4,0 \%)$

Aplica-se ao paciente e família que tenham recebido suporte emocional com dedicação exclusiva, com duração "normal" de acordo com as horas estabelecidas na Unidade, em pelo menos um plantão nas 24 horas. 
7b. Suporte e cuidados aos familiares e pacientes que requerem dedicação exclusiva por 3 horas ou mais em algum plantão tais como: morte, circunstâncias especiais (p. ex. grande número de familiares, problemas de linguagem, familiares hostis ou presença de escolta policial). $(32,0 \%)$

Aplica-se ao paciente e sua família que tenham recebido suporte emocional com dedicação exclusiva, com duração "além do normal" de acordo com as horas estabelecidas na Unidade, em pelo menos um plantão nas 24 horas.

\section{Tarefas administrativas e gerenciais}

8a. Realização de tarefas de rotina tais como: processamento de dados clínicos, solicitação de exames e troca de informações profissionais (por ex. passagem de plantão e visitas clínicas). $(4,2 \%)$

Inclui qualquer tarefa administrativa e gerencial relacionada ao paciente, que teve duração "normal", de acordo com as horas estabelecidas na Unidade.

8b. Realização de tarefas administrativas e gerenciais que requerem dedicação integral por cerca de 2 horas em algum plantão tais como: atividades de pesquisa, aplicação de protocolos, procedimentos de admissão e alta. $(23,2 \%)$

Inclui qualquer tarefa administrativa e gerencial relacionada ao paciente, que teve duração "além do normal", de acordo com as horas estabelecidas na Unidade.

8c. Realização de tarefas administrativas e gerenciais que requerem dedicação integral por cerca de 4 ou mais de tempo em algum plantão tais como: morte e procedimentos de doação de órgãos, coordenação com outras disciplinas. $(30,0 \%)$

Inclui qualquer tarefa administrativa e gerencial relacionada ao paciente, que teve duração "muito além do normal", de acordo com as horas estabelecidas na Unidade.

\section{Suporte Ventilatório}

9. Suporte respiratório. Qualquer forma de ventilação mecânica/ventilação assistida com ou sem pressão expiratória final positiva, com ou sem relaxantes musculares; respiração espontânea com ou sem pressão expiratória final positiva (CPAP ou BIPAP), com ou sem tubo endotraqueal; oxigênio suplementar por qualquer método. $(\mathbf{1 , 4 \% )}$

Aplica-se ao paciente em uso de qualquer suporte ventilatório (Cateter nasal de $\mathrm{O}_{2}$, Intubação Orotraqueal, Macronebulização, Máscara de Venturi, Ventilação Mecânica não Invasiva e outros).

10. Cuidado com vias aéreas artificiais. Tubo endotraqueal ou cânula de traqueostomia. $(1,8 \%)$

Aplica-se ao paciente em uso de tubo orotraqueal, nasotraqueal ou traqueostomia.

11. Tratamento para melhora da função pulmonar. Fisioterapia torácica, espirometria estimulada, terapia inalatória e aspiração endotraqueal. $(4,4 \%)$

Aplica-se ao paciente que tenha recebido qualquer tratamento para melhora da função pulmonar, realizado em qualquer freqüência, pela equipe de enfermagem. 


\section{Suporte Cardiovascular}

12. Medicação vasoativa, independente do tipo e dose. $(1,2 \%)$

Aplica-se ao paciente que tenha recebido qualquer medicação vasoativa, independente do tipo e dose.

13. Reposição intravenosa de grandes perdas de fluídos. Administração de fluídos > 4,5L/dia, independente do tipo de fluído administrado. $(2,5 \%)$

Aplica-se ao paciente que tenha recebido quantidade maior do que 4,5 litros de solução por dia, independente do tipo de fluído administrado.

14. Monitorização do átrio esquerdo. Cateter de artéria pulmonar com ou sem medida do débito cardíaco. $(1,7 \%)$

Aplica-se ao paciente que tenha usado cateter em artéria pulmonar.

15. Reanimação cardiorespiratória nas últimas 24 horas (excluído soco precordial) $(7,1 \%)$

Aplica-se ao paciente que tenha tido PCR e recebido medidas de reanimação, excluindo soco precordial.

\section{Suporte Renal}

16. Técnicas de hemofiltração. Técnicas dialíticas. $(7,7 \%)$

Aplica-se ao paciente que tenha recebido qualquer tipo de procedimento dialítico, intermitente ou contínuo.

17. Medida quantitativa do débito urinário (p. ex. por sonda vesical de demora) $(7,0 \%)$ Aplica-se ao paciente com controle de diurese, com ou sem qualquer tipo de cateter urinário. Considerar apenas quando o registro for em "ml" (descartar dados como cruzes, perdas no leito ou em fralda, sem pesagem).

\section{Suporte Neurológico}

18. Medida da pressão intracraniana $(1,6 \%)$

Aplica-se ao paciente que foi submetido a monitorização da PIC. Não considerar se o paciente for portador apenas de DVE.

\section{Suporte Metabólico}

19. Tratamento da acidose/alcalose metabólica. (1,3\%)

Aplica-se ao paciente que recebeu droga específica para correção da acidose ou alcalose metabólica, excluindo-se a reposição volêmica para corrigir alcalose (Bicarbonato de Sódio e outros)

\section{Nutrição Parenteral Total. $(2,8 \%)$}

Aplica-se ao paciente que recebeu infusão venosa central ou periférica de substâncias com a finalidade de suprir as necessidades nutricionais. 
21. Alimentação enteral por sonda gástrica ou outra via gastrointestinal (p.ex. jejunostomia). (1,3\%)

Aplica-se ao paciente que recebeu substâncias com a finalidade de suprir as necessidades nutricionais, através de sonda, por qualquer via do trato gastrointestinal.

Intervenções específicas

22. Intervenção(ões) específica(s) na Unidade de Terapia Intensiva. $\underline{\text { NÃO }}$ estão incluídas intervenções de rotina sem conseqüências diretas para as condições clínicas do paciente tais como: radiografias, ecografias, curativos ou inserção de cateteres venosos ou arteriais. Considerar intubação endotraqueal, inserção de marcapasso, cardioversão, endoscopias, cirurgia de emergência, lavagem gástrica, eletrocardiograma e outras nas últimas 24 horas. $(2,8 \%)$

Aplica-se ao paciente submetido a qualquer intervenção diagnóstica ou terapêutica, listada acima, dentro da UTI.

23. Intervenções específicas fora da Unidade de Terapia Intensiva. (1,9\%)

Aplica-se ao paciente submetido a uma ou mais intervenções diagnósticas ou terapêuticas realizadas fora da UTI.

\section{OBSERVAÇÕES:}

Os itens 1,4,6,7 e 8 são mutuamente excludentes, assim como as categorias "normal", "além do normal" e "muito além do normal".

O cômputo do NAS total será feito considerado a maior pontuação obtida nos itens 1,4,6,7 e 8 das 24 horas . 